\title{
A STUDY OF RELATIVE COSTS OF FLEXIBLE HIGHWAY PAVEMENTS
}

DECEMBER 1970 NUMBER 29

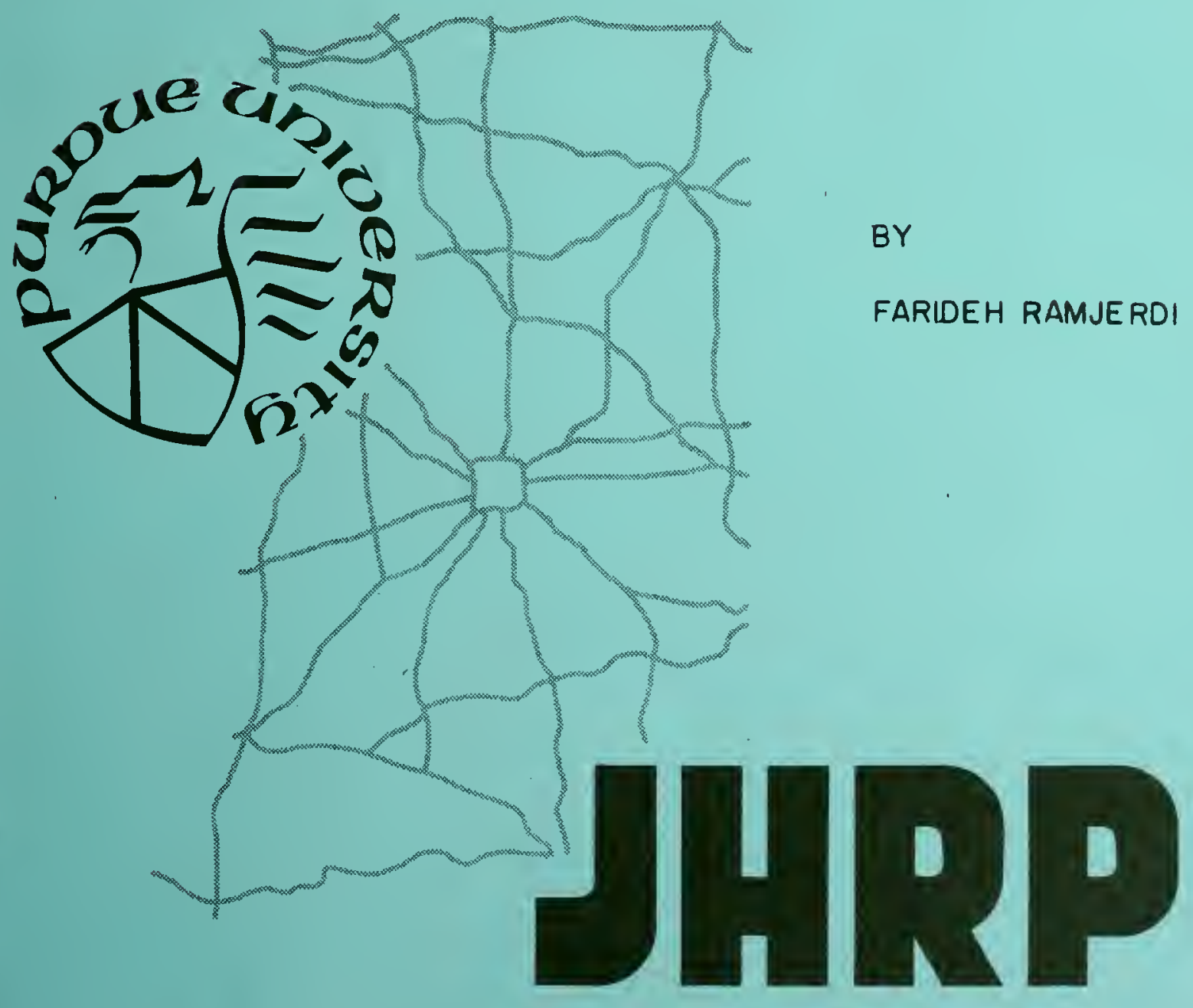

JOINT HIGHWAY RESEARCH PROJECT PURDUE UNIVERSITY AND 


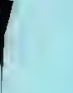

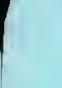

.

.

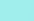
5

. 


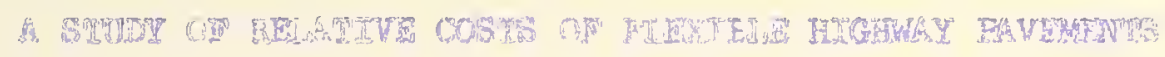

mo

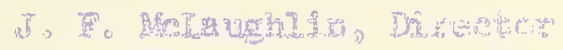

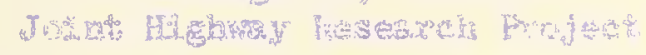

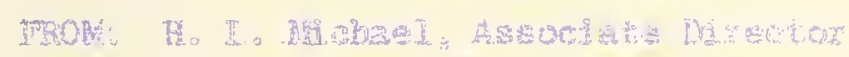

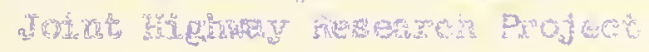

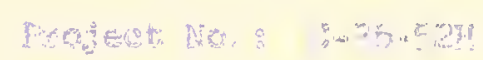

Fide: $N_{3}=30$

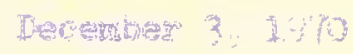

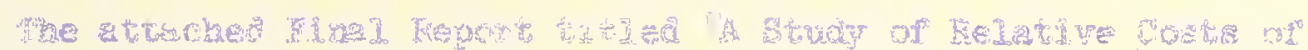

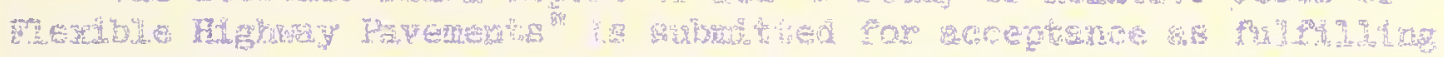

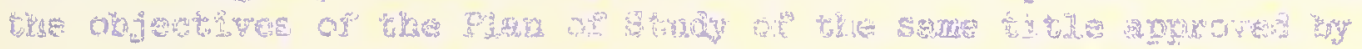
the A A

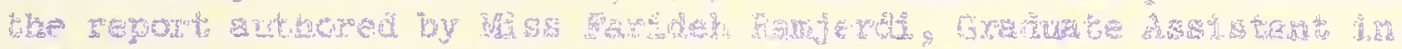

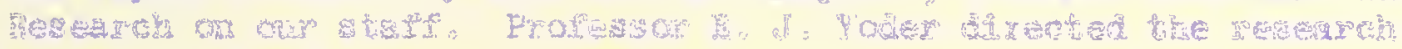

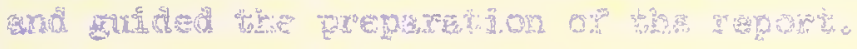

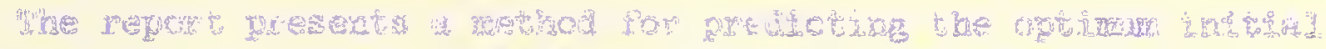

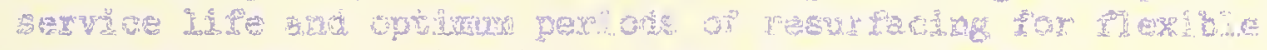

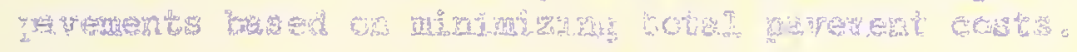

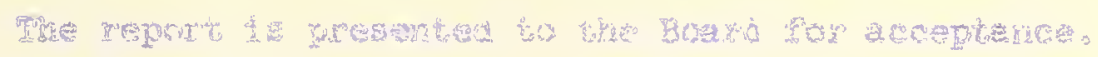

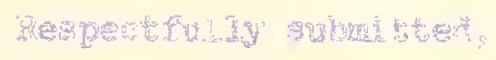

$$
\begin{aligned}
& 2 \text { pan } 3
\end{aligned}
$$

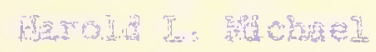

$$
\begin{aligned}
& \text { A }
\end{aligned}
$$

HUX

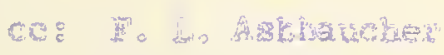

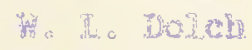

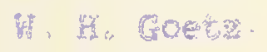

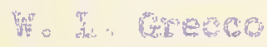

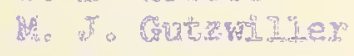

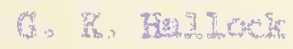

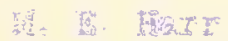

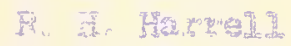

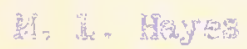

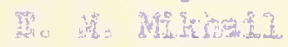

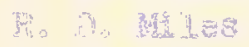

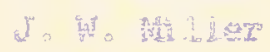

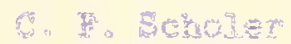

程。 B. Ecote

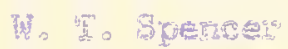

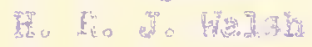

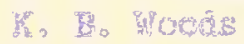

琵, Y, Yoorer 
Tysu dregort

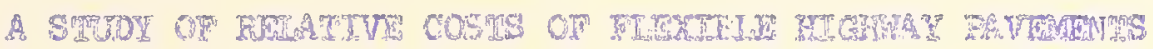

by

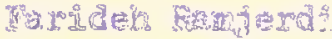

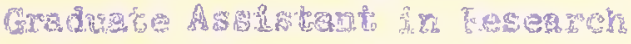

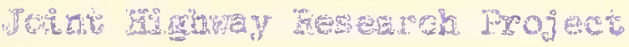

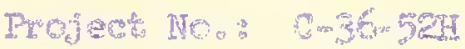

The

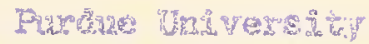

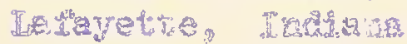

Desender 3, 5970 
Digitized by the Internet Archive in 2011 with funding from

LYRASIS members and Sloan Foundation; Indiana Department of Transportation

http://www.archive.org/details/studyofrelativec00ramj 
TABLE OF CONTENTS

Poge

LIST OF TABLES . . . . . . . . . . . . . . . V V

LIST OF FIGURES. . . . . . . . . . . . . . . . . . vi

ABSTRACT . . . . . . . . . . . . . . . . $x i$

INTRODUCTION . . . . . . . . . . . . . . . . . I

BACKGROUND AND REVIEW OF LITERATURE. . . . . . . . . 3

Initial Construction Cost............. 5

Resurfacing Cost. . . . . . . . . . . . . 5

Rout1ne Maintenance Cost. . . . . . . . . . 6

Salvage Value.................

Rate of Interest. . . . . . . . . . . . . . .

Analysis Period...................

Additional Highway User Cost Resulting fron

Mintenance.

PURPOSE AND PLAN OF RESEARCH . . . . . . . . . . . .

PROCEDURE. . . . . . . . . . . . . . . 10

Regression Technique. . . . . . . . . . . 10

Average Annual Cost of Hilghways ........... 11

Structural Design Procedure . . . . . . . . . 14

Minimum Required Thickness of Asphaltic Concrete

Surface .................. . . 18

Equivalent Axle Load Applications. . . . . . . . 18

Required Pavement Thickness as a Function of Time. . 20

Resurtacing Costs .............. . . 22

Routine Maintenance Costs . . . . . . . . . 24

Unit Cost of Paving Materials ........... . 31

Roed User Cost Due to Mintenance and Resurtacing

Operations. . . . . . . . . . . . . . 31

Relationship Between the Average Speed of

Traffic and Traffic Flow ........... 32

Relationship Between the Road User Cost and

the Average Speed of Traffic . . . . . . . . 34

Road User Costs Due to Standing Delays and

Reduction of Speed . . . . . . . . . 38

Correction Factor for the Extra Turning

Mneuver Due to the Lane Closure ....... . 46 
TABLE OF CONTENTS (Continued)

Page

ANALYSIS . . . . . . . . . . . . . 51

RESULTS AND FINDINGS ................ . . . 57

RECOMMENDATIONS FOR ADDITIONAL RESEARCH. . . . . . . 77

BIBLIOGRAPHY . . . . . . . . . . . . . 78

APPENDIX A, FIGURES REIATING TO COST TRENDS. . . . . . . 80

APPENDIX B, FIGURES FOR DETERMINING ROAD USER COSTS. . . 35 
LIST OF TABLES

Table

Page

1. List of Estimated Values of Coefficient e from Figure I, and Residuals for Different CBR Values... . . . . . . . . . . . 17

2. Equations for the Road User Cost as a Function of the Average Traffic Speed for 2-lane Highwgys . . . . . . . . . . . . . 39

3. Equations for the Rod User Cost as a Function of the Average Traffic Speed for 4-lane Divided Highwrys . . . . . . . . . . . 4 40 


\section{LIST OF FIGURES}

Figure

Page

1. CBR Design Curve for $18 \mathrm{kip}$, Single-Axle,

Dual Wheel Load, Thickness Versus Application . . . 15

2. Minimum Required Thickness of Asphaltic Concrete

Surface as a Function of Total $18 \mathrm{Kip}$ Single-

Axle Load . . . . . . . . . . . . . . 19

3. An Example of Required Total Pavement Thickness

and Minimum Required Surface Thickness as a

Function of Time for an Initial ADT of 1000

Vehicles, Rate of Increase in Traffic of

10 Percent, and CBR of Subgrade of 5 Percent. . . . . 21

4. General Relationship Between Age and Required

Thickness . . . . . . . . . . . . . 23

5. Maintenance Effort Index as a Function of

Surface Thickness . . . . . . . . . . 25

6. Maintenance Effort Index as a Function of

Base and Subbase Thickness. . . . . . . . . 26

7. Maintenance Effort Index as a Function of

Subgrade CBR. . . . . . . . . . . . . 27

8. Mintenance Cost as a Function of Surface and

Base Thickness, Subgrade CBR, and Traffic Volume. . 28

9. Construction Cost Trends. . . . . . . . . 29

10. Average Speed as a Function of Traffic Flow for a

Two Lane Highway. . . . . . . . . . . . . 35

11. Average Speed as a Function of Traffic Flow for a

4-Lane Divided Highway. . . . . . . . . . 36

12. A General Example of Relating Road User Cost to the Average Speed of Traffic, When the Relations

for Free, Normal, and Restricted Operations are

known .................. 41 


\section{LIST OF FIGURES (Continued)}

Figure

Page

13. Raad User Cost for Passenger Cars on Tangents of a Two Lane Highway as a Function of Average Speed Under Normal Conditions for Several Gradient Classes .............. 42

14. Road User Cost for Passenger Cars on Tangents of a Two Lane Highway as a Function of Average Speed and Gradient Class When One Lane is Closed................ . . . 43

15. Raad User Cost for Passenger Cars on Tangents of a 4-Lane Divided Highway as a Function of Average Speed Under Normal Condtions for Several Gradient Classes . . . . . . . . . 44

16. Road User Cost for Passenger Cars on Tangents of a 4-Lane Divided Highway as a Function of Average Speed and Gradient Class when One Lane is closed... . . . . . . . . . . 45

17. Cost Per Vehicle Stop Versus Time of Standing Delay. ............... . . 47

18. Relationship Between Operating Costs on Curves and Operating Costs on Tangents........ 49

19. Correction Factor for Operating Cost as a Function of Average Speed for Closure Lengths of 1 and $1 / 2$ Miles............ . . 50

20. A Typical Plot Produced by the Calcomp Plotter . . 55

21. Optimum Initial Design Service Life of Pavement Surface as a Function of Initial Yearly Equivalent 18-Kip, Single-Axle Load Applications, Anmal Rate of Traffic Growth 2 Percent. Analysis Period of 40 Years, and for a 2-Iane Highway . . . 61

22. Optimum Initial Design Service Life of Pavement Surface as a Function of Initial Yearly Equivalent 18-Kip, Single-Axle Load Applicetions, Annual Rate of Traffic Growth 6 Percent, Analysis Period of 40 Years, and for a 2-Lane Highway . . . 62 
LIST OF FIGURES (Continued)

Figure

Page

23. Optimum Initial Design Service Life of Pavement

Surface as a Function of Initial Yearly

Equivalent 18-Kip, Single-Axle Load Applications,

Annual Rate of Traffic Growth 10 Percent, Analysis

Period of 40 Years, and for a 2-Lane Highway . . . 63

24. Optimu Initial Design Service Iffe of Pavement

Surface as a function of Initial Yearly

Equivalent 18-Kip, Single-Axle Load Applications,

Annual Rate of Traffic Growth 14 Percent, Analysis

Period of 40 Years, and for a 2-Lane Highway ... .

25. Optimm Initial Design Service Life of Pavement

Surface as a Function of Initial Yearly

Equivalent 18 -Kip Single-Axle Load Applications,

Annual Rate of Traffic Growth 2 Percent, Analysis

Period of 20 Years, and for a 2-Iane Highway . . . 65

26. Optimum Initial Design Service Life of Pavement

Surface as a Function of Initial Yearly Equivalent

18-Kip Single-Axle Load Applications, Annual

Rate of Traffic Growth 6 Percent, Analysis Period

of 20 Years, and for a 2-Lane Highway. . . . . 66

27. Optimum Initial Design Service Life of Pavement

Surface as a Function of Initial Yearly

Equivalent 18-Kip single-Axle Load Applications,

Annual Rate of Traffic Growth 10 Percent, Analysis

Period of 20 years, and for a 2-Lane highway . . . 67

28. O timu Initial Design Service Life of Pavement

Surface as a Function of Initial Yearly

Equivalent 18-Kip Single-Axle Load Applications,

Annuel Rate of Traffic Growth 14 Percent, Analysis

Period of 20 Years, and for a 2-Lane Highway . . . 68

29. Optimum Init1al Design Service Life of Favement

Surface as a Function of Initial Yearly

Equivalent 18-Kip, Single-Axle Load Applications,

Annual Rate of Traffic Growth 2 Percent, Analysis

Period of 40 Years, and for a 4-Lane Highway ... . . 69

30. Optimun Init1al Design Service Life of Favement

Surface as a Function of Initial Yearly

Equivalent 18-Kip, Single-Axle Load Applications,

Anmal Rate of Traffic Growth 6 Percent, Analysis

Period of 40 Years, and for a 4-Lane Highway . . . 70 
LIST OF FIGURES (Continued)

Figure

Page

31. Optimum Initial Design Service life of Pavement Surface as a Function of Initial Yearly Equivalent 18-Kip, Single-Axle Load Applications, Anmal Rate of Traffic Growth 10 Percent, Analysis Period of 40 Years, and for a 4-Lane Highway . . . 71

32. Optimum Initial Design Service Life of Pavement Surface as \& Function of Initial Yearly Equivalent 18-Kip, Single-Axle Load Applications, Annual Rate of Traffic Growth 14 Percent, Analys is Period of 40 Years, and for a 4-Iane Highway . . . 72

33. Optimum Initial Design Service Life of Pavement Surface as a Function of Initial Yearly Equivalent I8-Kip, Single-Axle Load Applications, Annual Rate of Traffic Growth 2 Percent, Analysis Period of 20 Years, and for a 4-Iane Highway. . . 73

34. Optimm Initial Design Service Life of Pavement Surface as a Function of Initial Yearly Equivalent 18-Kip, Single-Axle Load Applicatiors, Anmal Rate of Traffic Growth 6 Percent, Analysis Period of 20 Years, and for a 4-Lane Highway . . . 74

35. Optimum Initial Design Service Life of Pavement Surface as a Function of Initial Yearly Equivalent 18-Kip, Single-Axle Lad Applications, Annual Rate of Traffic Growth 10 Percent, Anslysis Period of 20 Years, and for 34 -Lane Highway . . . 75

36. Optimm Initial Design Service Life of Frvement Surface as a Function of Initial Yearly Equivalent 18 -Kip, Single-Axle Lod Applications, Annual Rate of Traffic Growth 14 Percent, Analysis Period of 20 Years, and for a 4-iane Highway . . . 76

Appendix A

Figure

A-1. Cost Trends - Petroleum and Products........ 80

A-2. Cost Trends - Tire ............. 81

A-3. Cost Trends - Motor Vehicle and Equipment. . . . . 82

A-4. Trends in Personal Consumption Expenditure Services. 83

A-5. Trends in Personal Income and Gross National Product. 84 


\section{LIST OF FIGURES (Continued)}

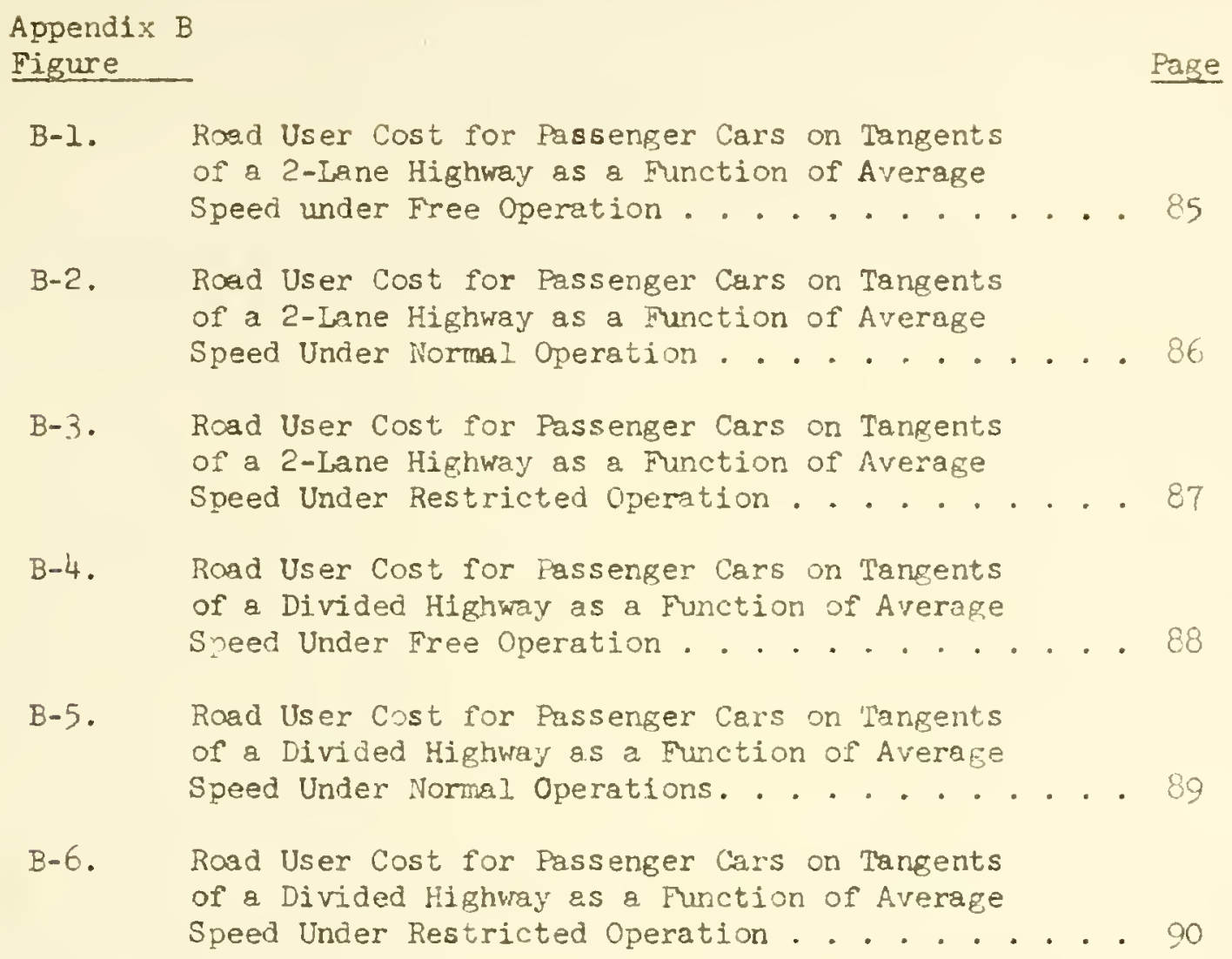

B-1. Rad User Cost for Passenger Cars on Tangents of a 2-Iane Highway as a Function of Average

B-2. Road User Cost for Passenger Cars on Tangents of a 2-Lane Highway as a Function of Average Speed Under NormaI Operation . . . . . . . . . 86

B-3. Road User Cost for Passenger Cars on Tangents of a 2-Lane Highway as a Function of Average Speed Under Restricted Operation . . . . . . . . 87

B-4. Road User Cost for Passenger Cars on Tangents of a Divided Highway as a Function of Average Speed Under Free Operation . . . . . . . . . . 88

B-5. Road User Cost for Passenger Cars on Tangents of a Divided Highway as a Function of Average Speed Under Normal Operations. . . . . . . . . 89

B-6. Road User Cost for Passenger Cars on Tangents of a Divided Highway as a Function of Average Speed Under Restricted Operation . . . . . . . . 90 


\section{A BSTRACT}

Ranjerdi, Farideh, M.S., Furdue University, January 1971, A Study of Relative Costs of Flexible Highway Fsvements. Major Professor: E. J. Yoder.

This thesis presents a method for predicting the optimum initial service life and optimum periods of resurfacing for flexible pavements. The method is based on consideration of total pavemert costs including the cost of initial construction, routine maintenance and major maintenance and increased road user costs resulting from the maintenance operations.

Standard economic analyses techniques were used for determining the average annual cost of alternate designs. The model developed by Radzikowsil for estimating routine maintenance cost of flexible highwry pavements was modified and used in the analysis. The pavement design method developed by the Corps of Engineers was utilized in estimating initial design as well as required major maintenance (resurfacing). A method was developed which presented an estimation of road user cost due to maintenance and resurfacing operations.

Variables evaluated in this research included (1) subgrade type, (2) Initial traffic volume, (3) rate of traffic growth, and (4) rate of interest on the investment. Solutions are presented for both 2-lane and 4-lane divided highways.

The results of the study are presented in the form of graphs which indicate the initial design period which results in least cost for all combinations of the variables given above. 


\section{INTRODUCTION}

The function of a highwy pavement is to provide a riding surface that adequately serves the demands of the road user with an acceptable level of performance. A great amount of research has been conducted into principles for the stmuctural design of highway pavements. Wany methods, based on an estimation of the strergth of the pevemert components coupled with an estimation of the amount of traffic which will use the parement, are available to the engineer which enables him to determine the thickness requirements for flexible pavements.

Thickness requirements for t'lexible pavements are dictated in part by the accumlated effect of traffic that wiIl use the pavement structure during its life. Design principles set forth in the AASHO Interim Guide, for example, are based upon an estimation of the total equivalent 18,000 pound single axle loads which will use the pavenent during its service life. In general, a finite service life is assumed and then resurfacing of the pavement is plarned for the end of the analysis perior. Economics of the design generally dictate that the service life for a road which will carry a high volume of traffic should be greater than the service life for a road which will carry less traficic.

The ultimate aim of the highway engineer responsible for the planning and design of pavements is to provide a pevement which will mintain specifled serviceability throughout the pavement's life, and 
to provide the highway user with the best possible service at the lowest cost. There are two primary elements of cost whjch must be considered, (1) the average annual cost of the highway facility, including both initial and maintenance costs and (2) the average annual cost of operating motor venicles on the pavement stmucture.

During the past ten to twenty years, extensive studias have been carried out for the purpose of development of mathematical models for predicting the routine maintenance cost of pavements. Usually variables such as traffic lokd, type of subgrade soll, environmental condition. and thickness of different layers of pavement have been found to be significant factors in these nodels.

Very little research has been conducted into methods of estimatinf costs resulting from accidents associated with mantenance operations. In cases where there have been need for considering these costs it has been the practice to assume a percentage of the total mainterance cost. These, however, are rough estimates at bost.

A major decision that the desian engineer must take is that regarding service life, and intervals at which ma,ior mintenance should be planned. Concelvably, for county roads and other low traffic hifhways, the most economic approach would be to plan for major maintenance at frequent intervals whereas for high traffic roads inconvenience to the rad user generally dictates that service life should be done at greater intervals. There are little factual data in the literature which can provide the design engineer with a method for making decisions relative to the inftial service life, and the optimm interval that should be considered for major maintenance. 


\section{BACKGROUND AND REVIEW OF LITERATURE}

Road life studies are concerned with finding the life expectancy of the various elements that make up a highway. It is essentially a fiscal tool designed to determine the amount and cost of replacements required each year in the future on the determination of the life of roadway elements.

Many studies hove been made to determine the useful lives of the various elements of a highway. There are many variables that needs to be considered including: soil, climate, topography, and traffic volume, each of these has an effect on the life of a type of pavement. Data have been compiled by various investigators which correlate surface type with average service life, average age, retirement rates, construction costs, and structural deterioration. (II)

In general there are three types of probable lives to consider: First, the actual physical Iife, which is ended because of physical deterioration of the materials making up the pavement; second, the service life which is the length of the time that the facility is used in caxrying out its original function without major rebuildings . Service life is ended when the facility is abandoned or rebuilt; third, the economic life, is determined by the time when the service rendered by that facility can be produced at a lower cost by a new facility. End of the economic life might result from rebuilding the old road, substitution of a different service, or by abandonment. Obviously economic life may not necessarily be the same length of time as

\footnotetext{
* Numbers in parentheses refer to references listed in the Bibliography.
} 
physical Iffe or service life. All of these probable lives depend on traffic, subsoil conditions, environmental conditions, routine maintenance and the structural qualities of the pavement.

A report on the service lives of highways published by $U$. S. Bureau of Public Roads in 1956 presented data which showed that 89\% of both flexible and rigid pavements reached the end of their service lives by reason of resurfacing and reconstmaction (8). This indicntes that resurfacing and reconstruction is a mater that should he planned for in advance.

J. W. Work (2I) developed a mathemstical model for oredictins when pavement should be resurfaced. The service life dictated by this replacement model was based primarily on ecoumics rather than enginecring considerations. He proposed that reulacemert should be done When average cost is equal to mreinal cost and marginal benefit.

E. P. Ulbricht (IE) compring alternate paverent designs, assumed that the service life of a surface is ended when its present service abllity reaches a minimum acceptable value.

In planning, any transportation facility, not only the cost of the pronosed racility but also the cost of various alternates must be considered. Normally, costs are separated into three categories (1) capital investments, including planning, desigr, and construction cost, (2) vehicle cost, including both operation and matrtenance cost of the vehicle, and (3) cost of mintaining the facility. The important characteristic of these costs is that they are highly interrelated. Anv change in design afrecting constmation costs also directly affects future maintenance and operating cost. Thus, the decision should be 
based on probable overall cost rather than initial cost alore.

To compare alternate designs, the average annual costs of the alternates generally are compared. Methods for the determination of annual highway cost have been the subfect of studies by several investigators and various methods have been developed for obtaining the average annual cost of a highway.

Mjor factors that affect the analysis of average annul cost are: Initial construction costs, resurfacing costs, routine maintenance costs, salvage value, interest rate, and analysis period. Road user costs due to delay and accident during mainterance and resurfacing operations have been considered in some studies $(10,15)$. These items are described below to the extent that are related to the purpose of this study.

\section{Initial Construction Cost}

Initial construction cost car be computed on the basis of the thickness and composition of the desifned pavement saction and the unit price for each item of povement including cost of the navement surface, base, and subbase. This cost depenas on variables such as service life, subsoil conditions, traffic to he handled during the service life of the pavement, environmental conditions, as well as the cost of materiel and labor.

\section{Resurfacing Cost}

This cost item can be computed on the basis of the thickness of resurfacing required at each stage and its unit price. Variables such as: resurfacing period, traffic to be handled prior to resurfacing, subsoil conditions, environmental conditions, rate of interest, will affect the resurfacing cost. 


\section{Routine Maintenance Cost}

Highway maintenance can be defined as follows (20). "The preserving and keepling of each roadway, structure, and facility as nearly as possible in 1ts original condition as constructed or as subsequently improved and such additional work as is necessary to keep traffic moving safely." Maintenance is a continuous operation, starting, soon after initial construction is completed. An analysis of highway maintenance expenditures based on data gathered from wide geopraphical areas have show great variation. A total of 34 different items have been identified that might influence mintenance cost (12).

To date, many stufies have been conducted to develor models for predicting maintenance cost. In ali these studies historical data have been used and, therefore, all predictions merely indicate what mainterance did cost, not what maintenance actually will cost. Usually varlables such as: subsoll condition, traffic volume, thickness of different layers of povement, psvement width, right-of-way widths, and environmertal condition were found to be significant variables (2, 4, 14). Maintenance expenditure and subdivided into different categories of which surface maintenance expenditures is of interest in this study.

\section{Salvage value}

Oglesby has suggested a zero salvage value to be considered in ecunomical studies of highways (11) whereas Winfrey (20) has suggested that the salvage value should be assumed to be low, especially for a pavement that will be difficult to be used in the future. 
In the formila recomended by Baldock (3) for determining the annual costs to compare different alternative a salvage value is applied only to the last resurfacing.

\section{Rate of Interest}

A suitable rate of interest is a measure of the likelihood that. the proposed alternative will be used for a number of years and will produce benefits estimated to prevail for the period of years used in the analysis.

\section{Anelysis Perion}

Winfrey ( $\hat{c} O)$ defines analys is period as follows: "A period of time usually mch less than the estimated probable life of the property, which is chosen for purpose of economic analysis. Pnysically, highway property may have 50 to 100 years service life expected, but an analysis of the economic wisdom of constructing a highway facility based upon such extended period is unreasonable. Comparatively short periods should be used such as 30 years".

Baldock (3) states "Puture technolog changes (in the next 40 years) may Jake present day $r$ uds obsolete and render more bttractive a different type of transportation investment. There is no indication that such changes will jeoperdize the billion of dollars now invested in roads. However, discretion requires that present and future beneficiaries carm the requisite costs to retire the investment within a reasonable period of time. This period of time my be temed the analysis period." Baldock recommended an analysis perion of 40 years. 
8

Analysis periods adopted in studies of different alternates of highway pavement have ranged from 20 to 40 years.

Additional Highway User Cost Resulting from Maintenance

Time is a valuable commodity to the highway user. Due to the reduction of highway capacity by lane closure for the purpose of resurfacing or maintenance, there is some time lost to road users and also the chance of accidents increases.

Very little research has been conducted to evaluate traffic delay and accident costs resulting from resurfacing and maintenance operations. Generally, a fixed percentage of the manterance cost is considered to be due to highway user cost (10). 
ELRPOSE AND PLAII OF RESEARCH

The purpose of this research was to develop a method for preaicting the optimum initial service life and the optimum periods of resurfacine for flexible pavents.

The formula recommended by Baldock (3) was used in this study for determining the anrual costs and comparison of alternate designs. The pavement design method developed by The Corps of Engineers and presented by Turnbull, Foster, and Ahivin (17) formed the basis for this analysis. The developed equatton by Ulbric it (18) was used to arrive at the total cumlative rumber of equivalent 18-kip single axle applications in terms of average daily traffic.

Variables included in this research include: (1) subcrade type, (2) Initial traffic volume, (3) rate of traffic grouth and (4) rate of interest. Solutions were made for: 2-lane highwy and 4-lane divided highway, and for analysis periods of 20 and 40 years. The effect of highway user cost resulting from mintenance and resurfacing operations was studied. 


\section{PROCEDURE}

\section{Regression Techrique}

Regression techrique was used quite often in this study. Following is a brief explanation of it.

Regression technique is a tool by means of which an equation that relates a dependent variable to a number of independent variables, car be obtained $(\epsilon, 13)$. The resulting equation that relates a dependent variable to a number of independent variables is usually called a regression equation. A Iinear regression equation is one which is Inear in parameters of the equation, while a non-linear regression equation is non-linear in parameters of the eqution.

Several procedures have been developed for the selection of the best repression equation. Methods used in this study were the stepwise regression and the non-linear weighted regression procedures.

The stepwise regression analysis utilized was BMDRR. In this program the most highly correlated independent variable enters into the regression first. The rext variable to enter is the one whose partial correlation with the dependent variable is the highest. At every stage variables incorporated into the regression in previous stages are reexamined, by means of comparing the partial $\mathrm{k}$-value of each variable in the regression with a preselected percentage point of the appropriate F distribution. This provides means for evaluation of the contribution made by each variable. after the other variables in the equation account for as mach variation in the $y$ (dependent varlable) as they can. 
contribution is removed from the regresion. This process is continued until no other variable will be added to the regression nor removed. The non-linear regression analysis utilized was NoNLIN, a revised version of SHARE propram no. 3094. This prouram provides the least squares estimates of the parameters in any eluation, or the parameters of any equation are such estimated to result into the minimum sums of squares of the deviations. An inftial estinate of the paraneters of the regression equation gre required, and through 1teretive procedure the values of the parameter that result in the minimum of squares of the deviations are evaluated.

\section{Avergge Anmul Cost of Hifhingys}

Baldock (3) proposed the folluwing equation to compute average anmal cost:

$$
\begin{aligned}
C= & C R F_{n}\left[1+E_{1}\left(W W E_{n 2}\right)+E_{2}\left(E \sqrt{E}_{n 2}\right)\right. \\
& \left.-\left(1-\frac{X}{X}\right)\left(E_{1} \text { or } E_{2}\right)\left(P W E_{n_{2}}\right)\right]+M
\end{aligned}
$$

where

$$
\begin{aligned}
C= & \text { average amual cost per mile of highwa; } \\
\text { CRF } & \text { capital recovery factor for an analysis period of } n \text { years } \\
& \text { and for a fiven rate of interest; } \\
A= & \text { initial construction cost per mile of pavemert; } \\
E_{1}= & \text { first resurfacing cost per mile; } \\
n_{1}= & \text { years of service life of initial pavement surface; } \\
\text { PWF }= & \text { present worth factor for } n_{1} \text { or } n_{2} \text { years for a given interest } \\
& \text { rate; }
\end{aligned}
$$




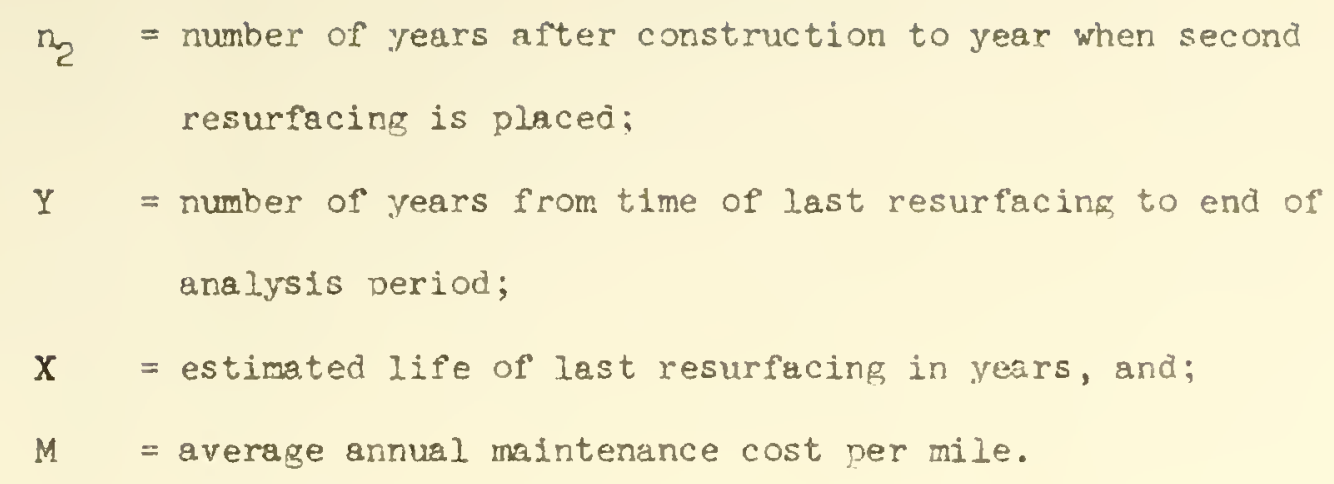

For this study the above equation was modified by placing the malntenance cost tern $(M)$ inside the bracket. This cost item w evaluated for each year from the time of infial constmuction to the end of analysis period since traffic loads on a pavement, and deterioration of the pavement due to weathering are subject to change during the analysis period. Malntenance cost depends or both of these factors. Also, highway user costs resulting from mintenance and resurfacing operations are considered. The modfied equation used is as follows:

where

$$
\begin{aligned}
& C=C R F_{n}\left[A+E_{I}\left(P N F_{n \perp}\right)+P E_{1}\left(P N F_{n I}\right)\right. \\
& +E_{2}\left(P W E_{n ?}\right)+R E_{2}\left(P W E_{n 2}\right)+\ldots . \\
& +E_{m}\left(P W F_{n m}\right)+R E_{m}(P \cdot F n) \\
& -\left(?-\frac{Y}{X}\right)\left(E_{m}\right)\left(\text { FNF }_{n \pi s}\right) \\
& \left.+\sum_{i=1}^{n} M_{1}\left(W W F_{1}\right)+\sum_{i=1}^{n} N M_{i}\left(W F_{i}\right)\right]
\end{aligned}
$$

$$
\begin{aligned}
C= & \text { average annul cost per mile of hiphway; } \\
\mathrm{CRF}_{\mathrm{n}}= & \text { capital recovery factor for an analysis of n years and for } \\
& \text { a given interest rate; } \\
\mathrm{A}= & \text { initial construction cost per mile of navement; } \\
\mathrm{E}_{1}= & \text { first resurfacing cost per mile; }
\end{aligned}
$$




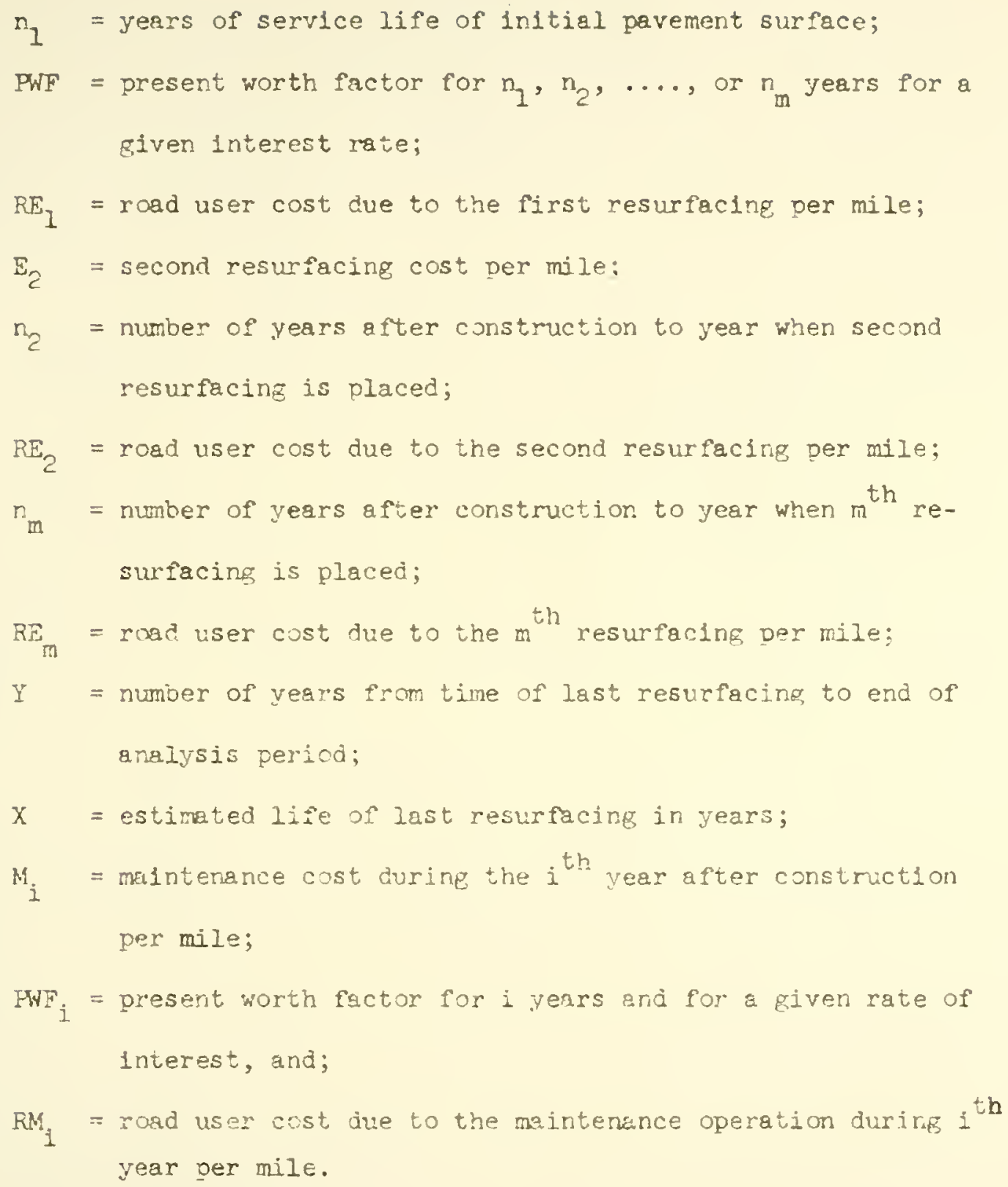

Pasic components of Equation 2 are (a) initial construction cost, (b) resurfacing costs, (c) maintenance costs, (d) road user costs due to maintenance and resurfacing operations, (e) interest rate, (f) analysis period, and $(g)$ service life of initial pavement surface, and service lives of the resurfacings. 
The major purpose of this study was to solve equation 2 for $\theta$ variety of conditions to determine the service life of the initial pavement surface and the service lives of the resurfacings, that result in the lowest average annual cost.

\section{Structural Destgn Procedure}

The structural. design orocedure used in this study was the revised pavement design method developed by the Corps of Engineers and presented by Turnbull, Foster, and Ahlvin (17). Thls procedure evaluates required thickness as a function of equivalent $18,000-1 b$ single axle loads and California Rearing Ratio of the suhgrade. Figure 1 shows the design curves of the Corps of Englneers for flexible highway pavements.

It was assuned in this study that the required thickness of pavement for one $18,000-1 \mathrm{~b}$ single axle load application is equal to zero. Therefore, the general form of design curves takes the following form:

$$
D=C \log W
$$

where

$$
\begin{aligned}
D= & \text { pavement thickness in inches; } \\
W \quad= & \text { total number of EAi applications during the design life, and; } \\
\mathrm{C}= & \text { coefficient of the equation which is a function of the CBR } \\
& \text { of subgrade. }
\end{aligned}
$$

\footnotetext{
*For simplicity, the term "equivalent 18,000-1b single axle laads" will. be abbreviated FAL.
} 


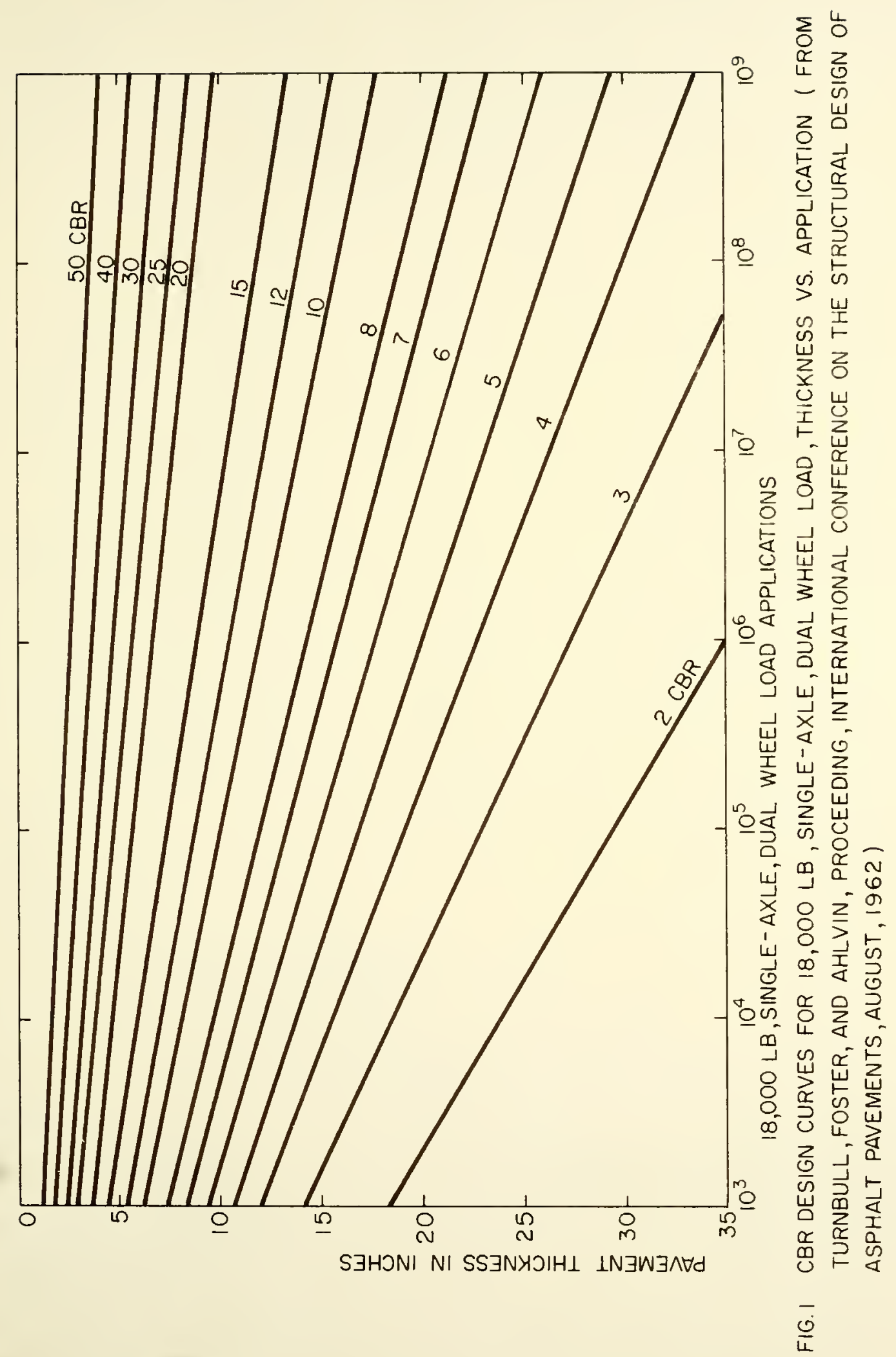


The coefficient $C$, (the slope of curves) can be estimated from Figure 1 for different values of CBR. From utilizing stepwise regression technique this coefficient was found to be:

$$
C=7.8844-8.07189 \log C B R+2.20335 \log ^{2} C B P
$$

The $\mathrm{R}^{2}$ value, the multiple correlation coefficient, for this anaIysis was as high as 0.9996 . Values of the coefilicient $C$ as estlmated from Figure 1 and the residuals (the predicted value of $C$ by regression subtracted from the estimated value of C from Figure 1) are show in Table 1 for different CBR values. The highest value or resichal was 0.04773 . This value would result in a difference in the design thickness of 0.4773 inches for $10^{10}$ applications of EAI. The value of 0.4773 is less than the error that wolld result if the desifn thickness was to be read from the design curve. The low restdual and high $R^{2}$ values indicates that the assumptions made were quite reasonabie, and hence, Fquation 3 takes the following forn:

$$
D=\left(7.8844-8.0718110 \mathrm{G}, \mathrm{CBR}-2.20335 \mathrm{log}^{2} \mathrm{CBR}\right) \log \mathrm{W}
$$

where

$$
\begin{aligned}
& D \quad=\text { pavement thickness, inches: } \\
& \mathrm{CBR}=\text { subgrade } C B R \text { value in percent, and; } \\
& W \quad=\text { the cumlative number of EAL applications. }
\end{aligned}
$$

In this study minimum thickness of base and subbase layers were assumed to be 4 and 6 inches respectively. A CBR value of 30 percent was adopted for the subbase material. 
Table 1: List of Estimated Values of Coefficient C from Figure 1, and Residuals for Different CBR Values

\begin{tabular}{|c|c|c|}
\hline $\begin{array}{l}\text { CBR } \\
\%\end{array}$ & $\begin{array}{l}\text { Coefficient as } \\
\text { estimated from } \\
\text { Figure } 1\end{array}$ & Residuals \\
\hline 2 & 5.66 & 0.00561 \\
\hline 3 & 4.56 & 0.02456 \\
\hline 4 & 3.32 & -0.00365 \\
\hline 5 & 3.30 & -0.01871 \\
\hline 6 & 2.04 & 0.00181 \\
\hline 7 & 2.62 & -0.01690 \\
\hline 8 & 2.40 & 0.00788 \\
\hline 10 & 1.89 & -0.01587 \\
\hline 12 & 1.72 & -0.02007 \\
\hline 15 & 1.47 & 0.03095 \\
\hline 20 & 1.16 & 0.04773 \\
\hline 25 & 0.32 & 0.01386 \\
\hline 30 & 0.78 & 0.01110 \\
\hline 40 & 0.60 & -0.00793 \\
\hline 50 & 0.50 & -0.03046 \\
\hline
\end{tabular}




\section{Minimum Required Thickness of Asphaltic Concrete Surface}

The Texas Highway Department has established requirements for minimum thickness of asphaltic corcrete surface, hased on expexience (16). These requisites are shown in Figlire 2. Equations 6, 7, and 8 are the results of utilizing stepwise regression analysis made on the data shown in Figure 2 for three types of base materials, Grade 1 , Grade 2, and Grade 3.

Grade 1:

$$
\text { is }=1.60649-1.78145108 w+0.71002105^{2} w
$$

Grade 2:

$$
d s=-1.91901-0.4472910 \mathrm{l} W+0.2144 \log ^{2} \mathrm{~W}
$$

Grade 3:

$$
\text { ds }=-15.51857+4.18935 \log W-0.14027 \log ^{2} w
$$

where

$$
\begin{aligned}
\mathrm{ds}= & \text { minimm required thickness of asphaltic concrete surface, } \\
& \text { inches; } \\
W= & \text { total FAl application. }
\end{aligned}
$$

The minimun thickness of surface adopted in this study was 1.9 inches.

\section{Equivalent Axle ioad Applications}

Several methads have been developed to estimate the number of equivalent axle application in tems of average daily traffic (ADT). The equation developed by Ulbricht (18) for Indiara was adopted for this study. This equation takes the folloring form: 


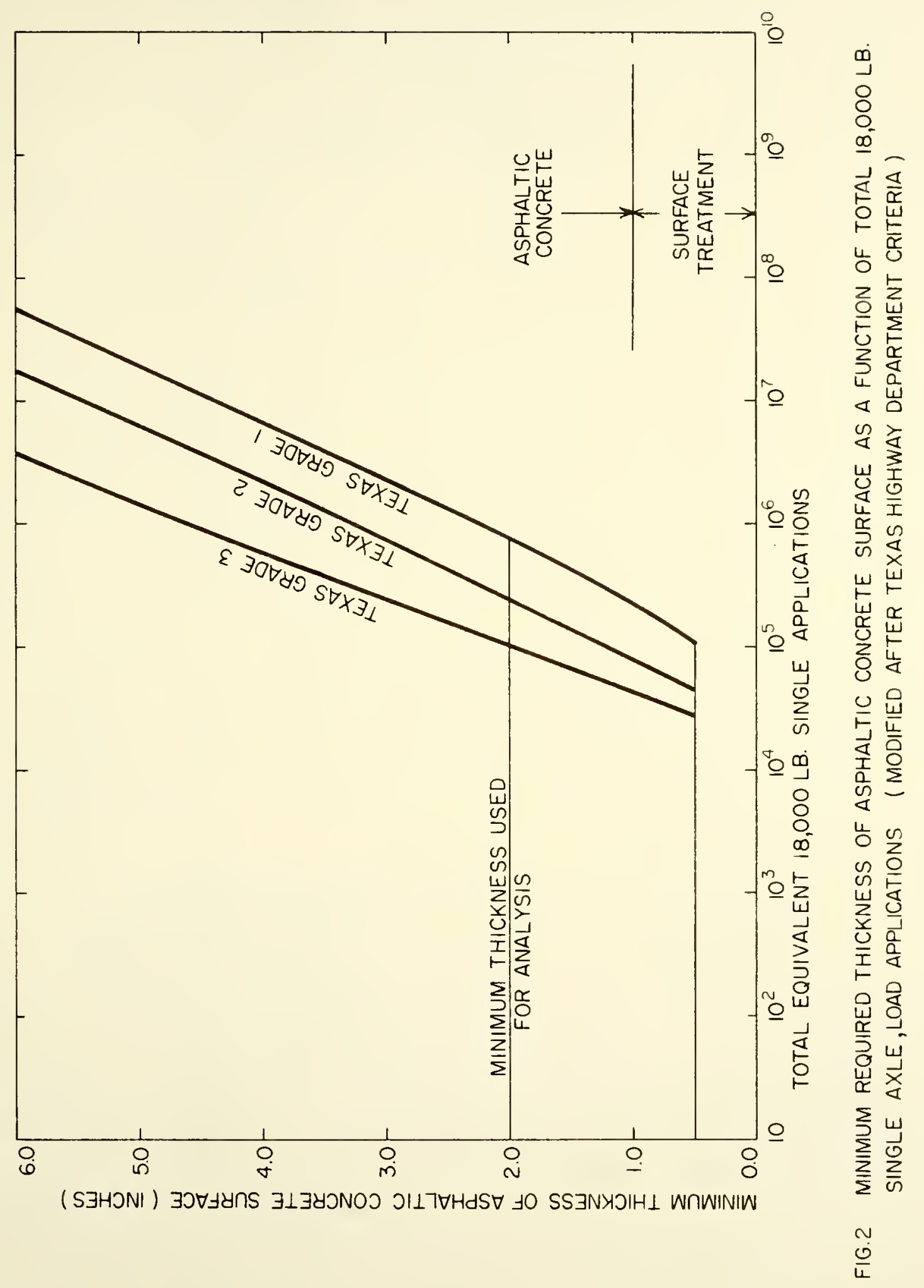




$$
\begin{aligned}
& W=(F)(V) \\
& V=365(A D T)\left[\frac{(I+J)^{Y}-I}{\ln (1+J)}\right] \\
& W=365(F)(A D I)\left[\frac{(I-J)^{Y}-1}{\ln (1+J)}\right]
\end{aligned}
$$

where

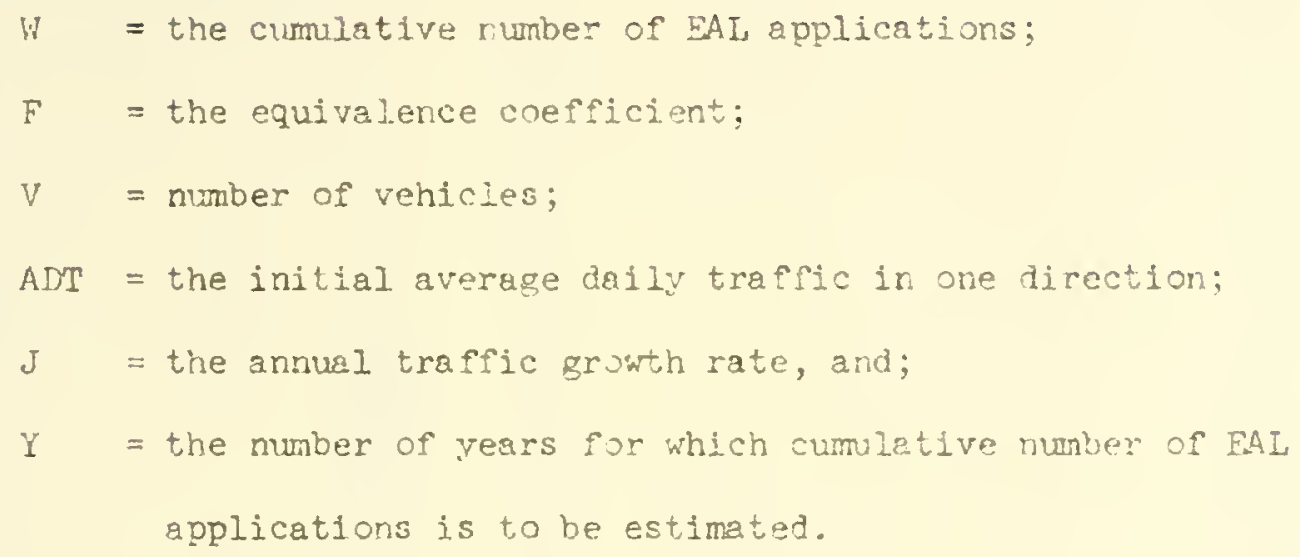

Ulbricht, in his study, classified Indiana highways into three classes by traffic weight distribution, and estimated $F$, the equivalence coefflcient for each class. An F value of 0.16 ws adopted for this study.

\section{Required Pavement Thickness as a Function of Time}

The required thickness of pavement ard the minimim required surface thickness can be ottained as a function of time by substitutirg Equation 9 for $W$ in Equatiors 5 and 6 respectiseiy. Fipure 3 shows an example of the thickness relationships with time for an initial ADT of 1000 , rate of traffic growth of 10 percent, CBR of subgrade of 5 percent and Texas Grade $I$ bese material. 


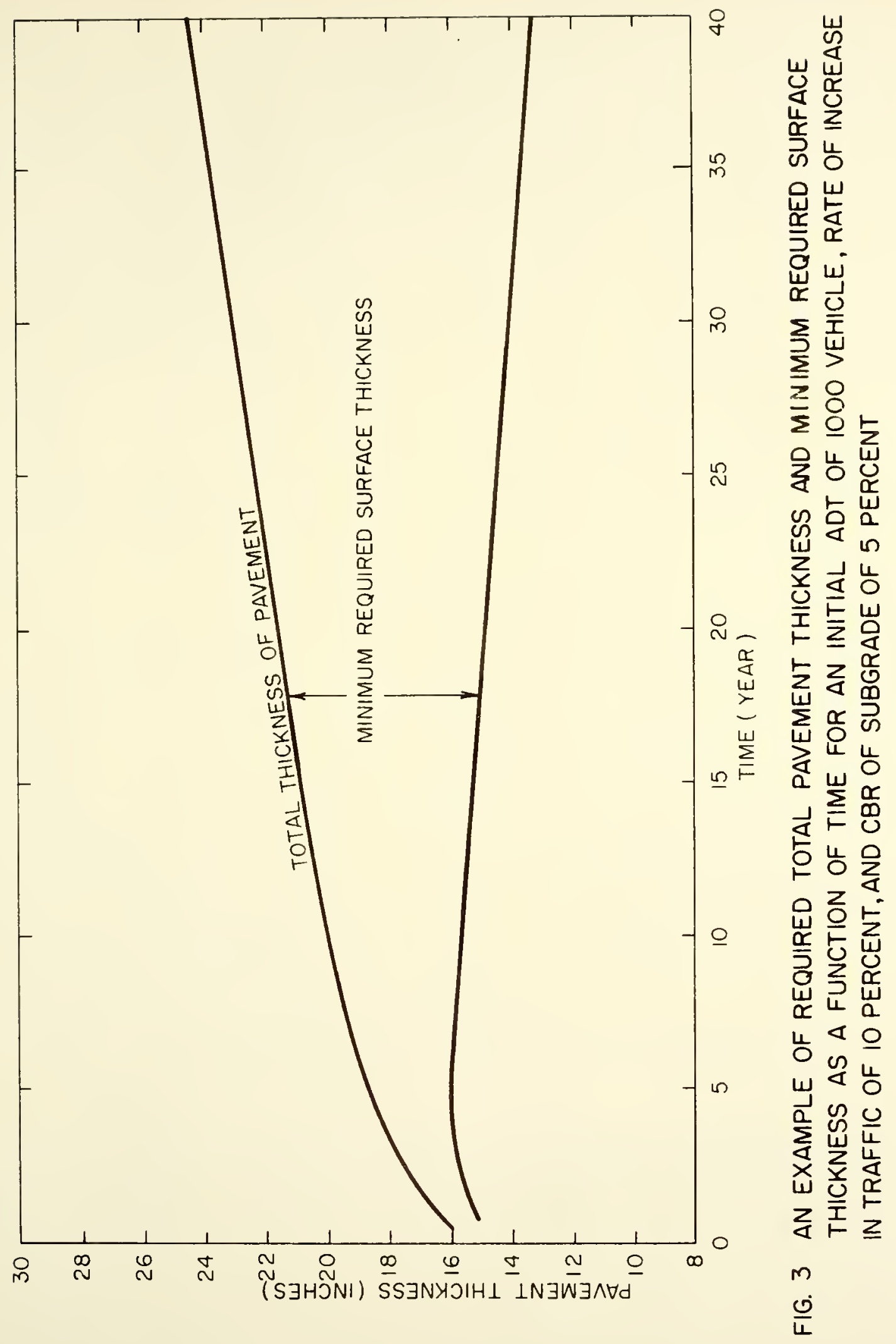




\section{Resurfacing Costs}

Resurfacing costs were computed on the basis of thickness of layers placed at each stage, and the unit price of the resurfacing material. The extra surface thickness (major resurfacing or major malntenance) required at any instant of time is equal to the difference between assumed initial design thickness and the required thickness from Figure $l$ determined on the basis of traffic up to the time of resurfacing. Figure 4 illustrates the general relationship between age and required thickness (22). In this study the period of resurfacing, had always taken the value of the inftial design service life of surface, as this was what is being done in practice.

It was assumed in this study that if a resurface was to be placed at intervals grater than 10 years, a seal coat layer was placed on the pavement at the end of 10 years in Ilen of the major resurface. Seal cont does not contribute to the structural strength of the pevement but it is applied for one or more of the following reasons (20):

1) to prevent the entrance of moisture into the base and subgrade.

2) to rejuvenate an olc, dry, or weathered surface

3) to provide a nonskid surface texture

4) to change suriace color for visibillty or for demarkation purposes

5) to supply additional asphalt on the surface for more effective sealing by trafic. 


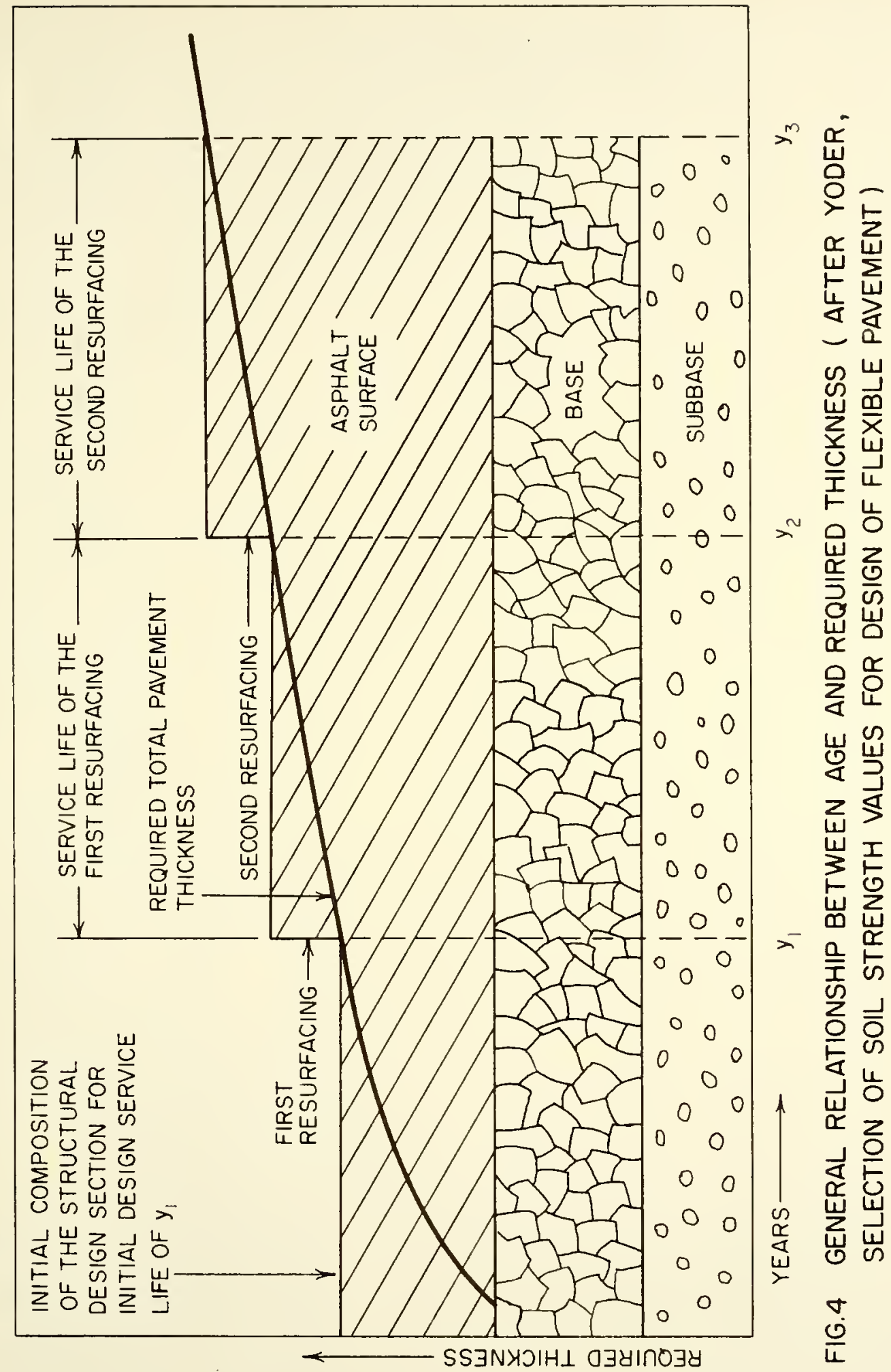




\section{Routine Mintenance Costs}

Several models have been developed to predict routine maintenance expenditures $(2,4,14)$. The model developed by Radzikowski (14) was used in this study, since surface maintenance expenditures were of major interest. Most of the other models include methods for estimating shoulder and right of way mintenance.

Four basic factors are considered in the model developed by Radzikowski for the prediction of maintenance expenditure. These factors are: (1) traffic on the section measured in vehicles per day for two lanes of pavement, (2) type of subgrade soil, (3) thickness of the surface, and ( 4 ) thickness of the vase and/or subbase. Fach of these factors are related to maintenance effort index numbers.

Maintenance effort index aumlers were estinated for each of theas four above factors and for each design. The sumation of these four irdices represents the surface maintenance effort index of each section. Mintenance expenditure was estimated from its relation with the surface mainterance effort index. Figures 5 throuch $T$ show the maintenance index numbers proposed by Radzik wski. Figure 8 shows the relationship between the summation of index numbers and routine maintenance cost.

Since the study by Radzikowski was dore in 1955, it was assumed that he used the 1955 unit-maintenance cost values. It was assumed also thet the mainterance cost trends since 1955 are the same as construction cost trends. Using data from Engineering News-Record (7) construction cost trends for the base year 1955 were obtained and the constmuction cost index for the year 1969 was used to convert the maintenance unit cost from 1955 to 1969. Figure 9 shows the constmiction cost trends for the base year 1955. 


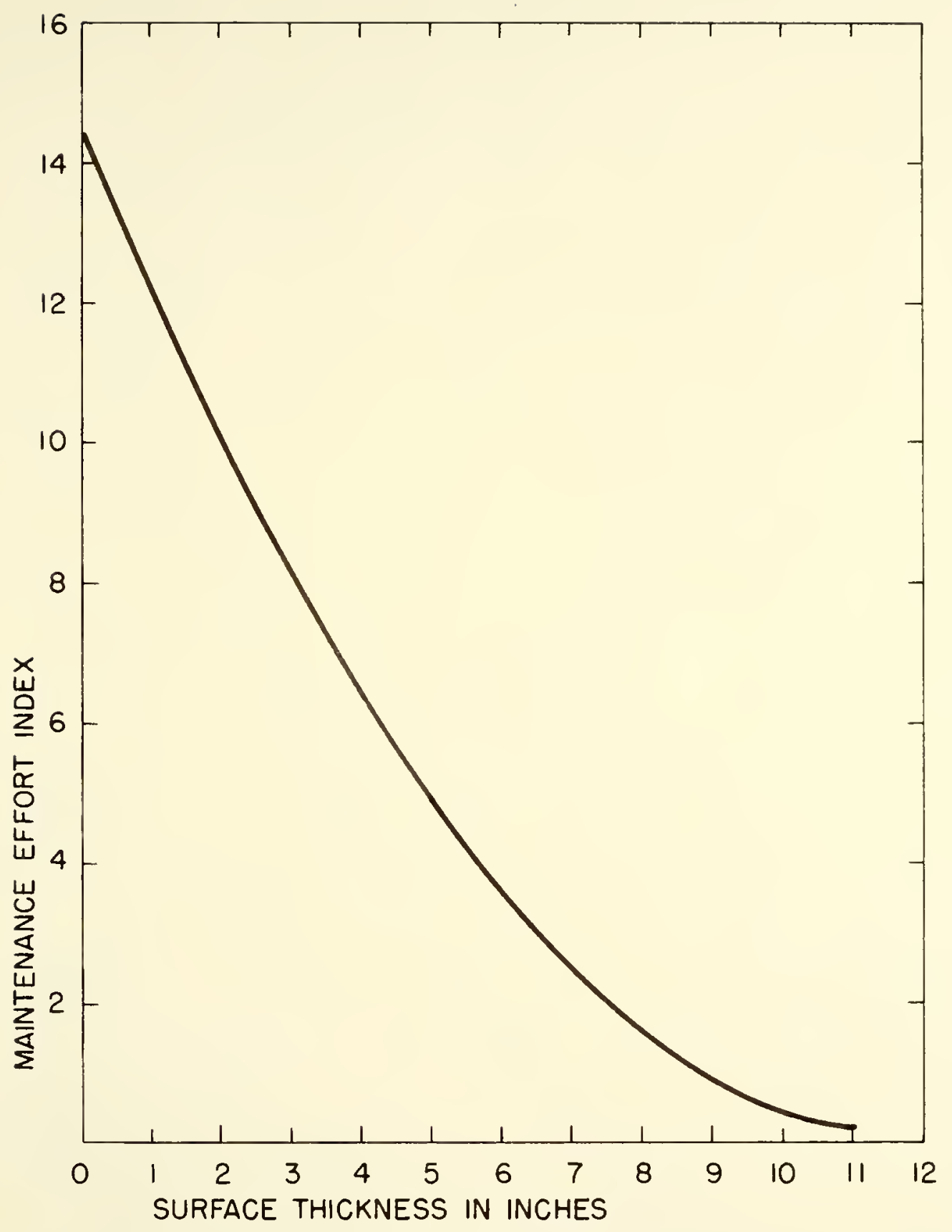

FIG.5 MAINTENANCE EFFORT INDEX AS A FUNCTION OF SURFACE THICKNESS (AFTER RADZIKOWSKI) 


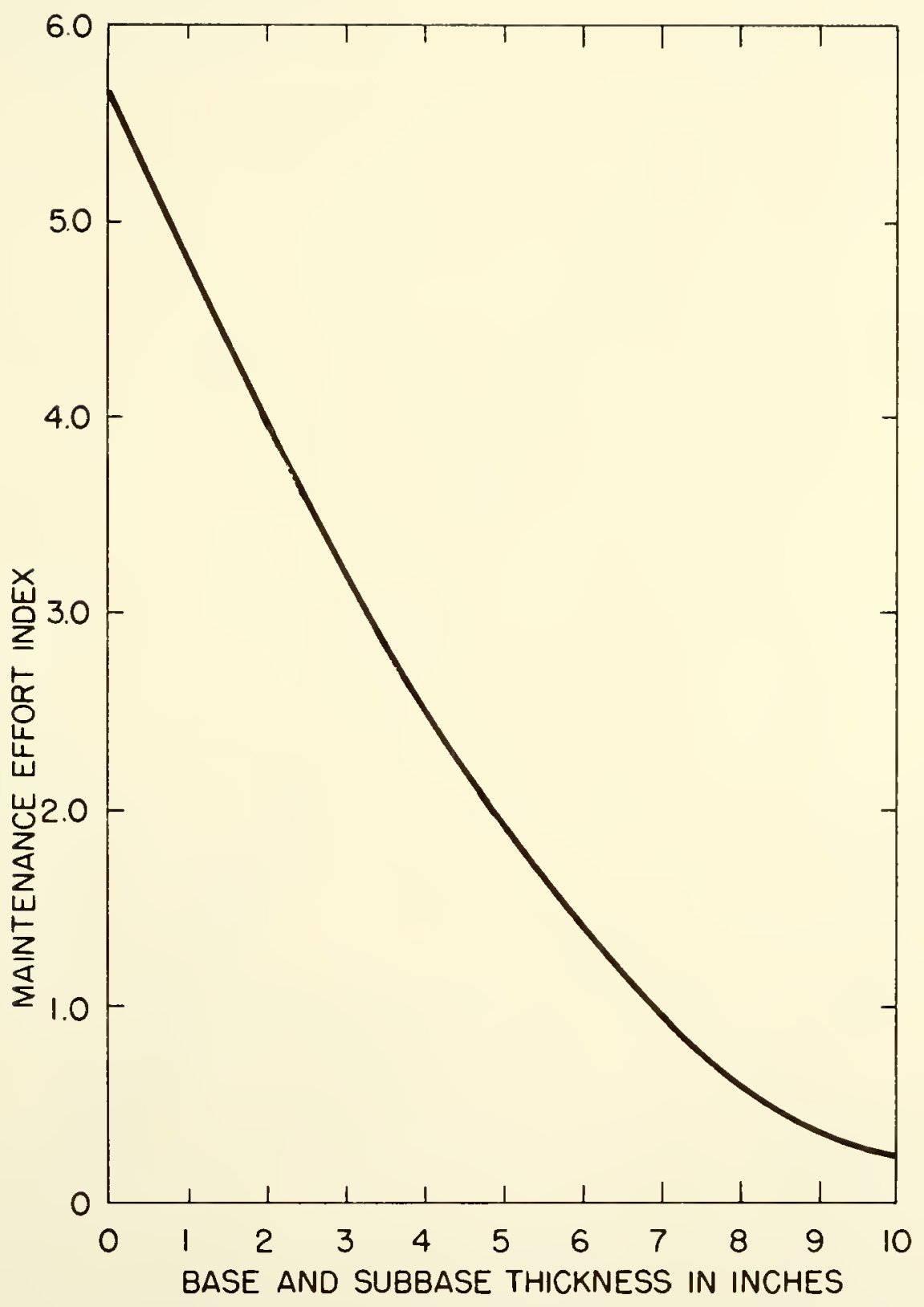

FIG.6 MAINTENANCE EFFORT INDEX AS A FUNCTION OF BASE AND SUBBASE THICKNESS (AFTER RADZIKOWSKI) 


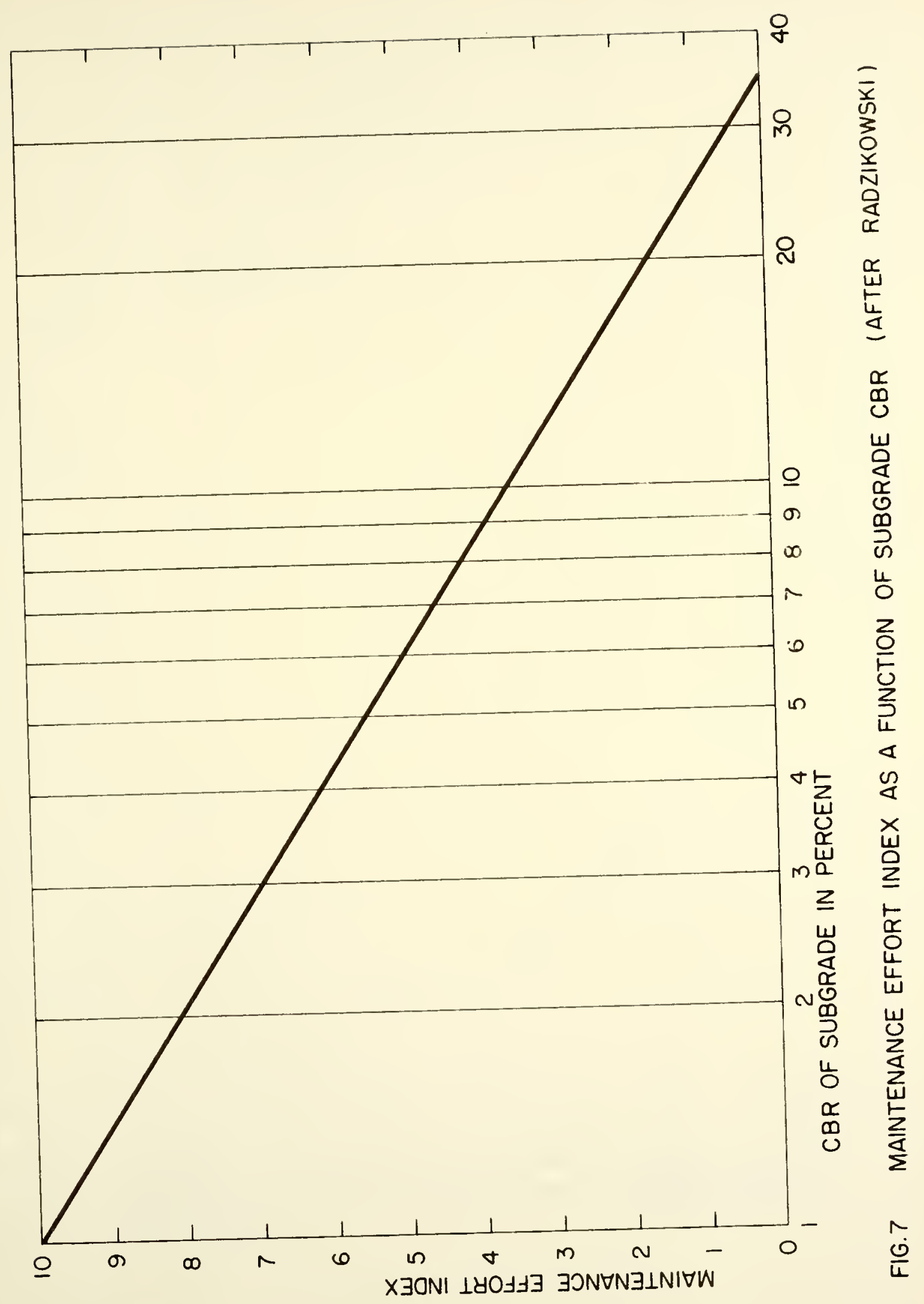




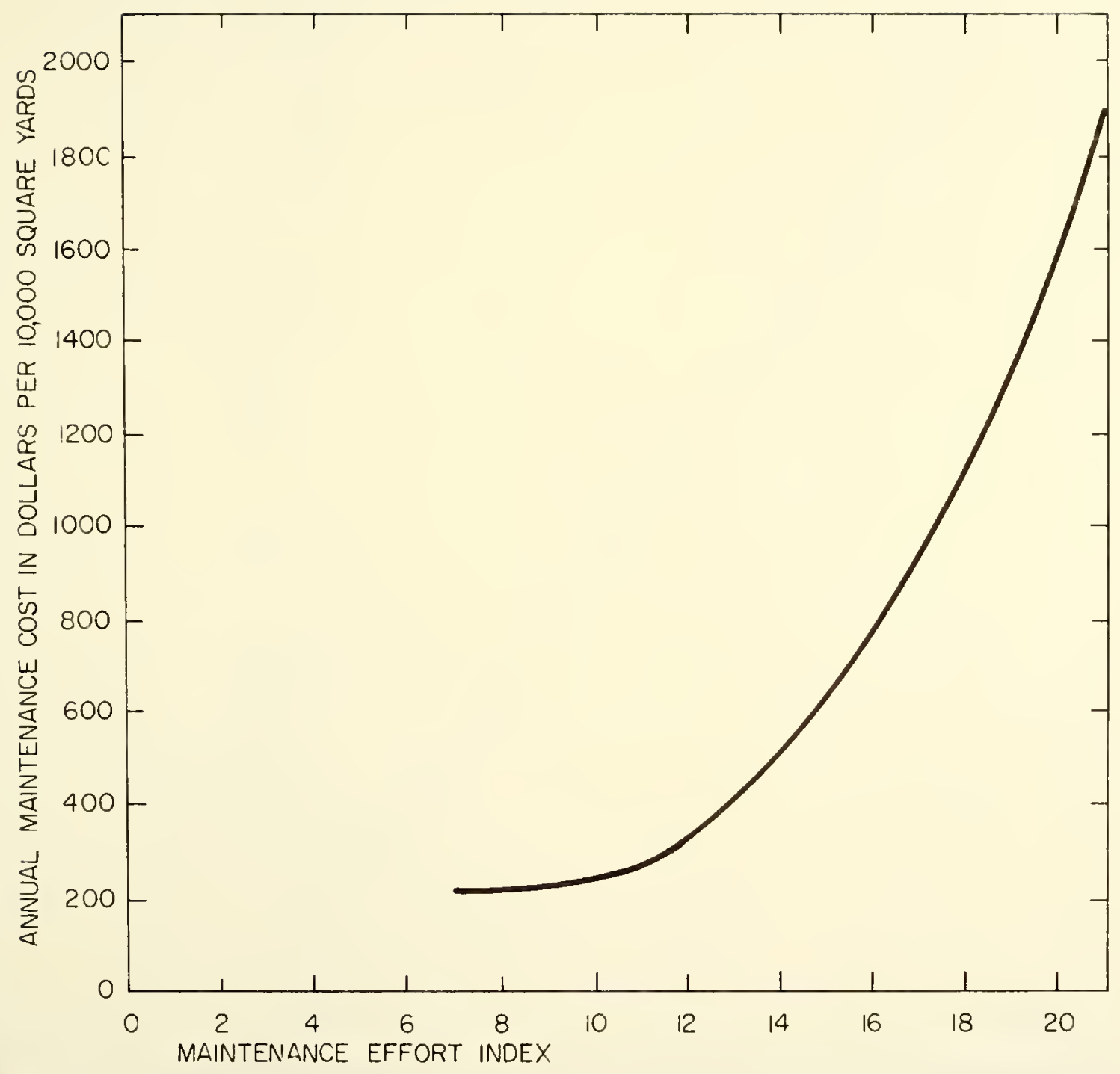

FIG.8 MAINTENANCE COST AS A FUNCTION OF SURFACE AND BASE THICKNESS, SUBGRADE CBR, AND TRAFFIC VOLUME (AFTER RADZIKOWSKI) 


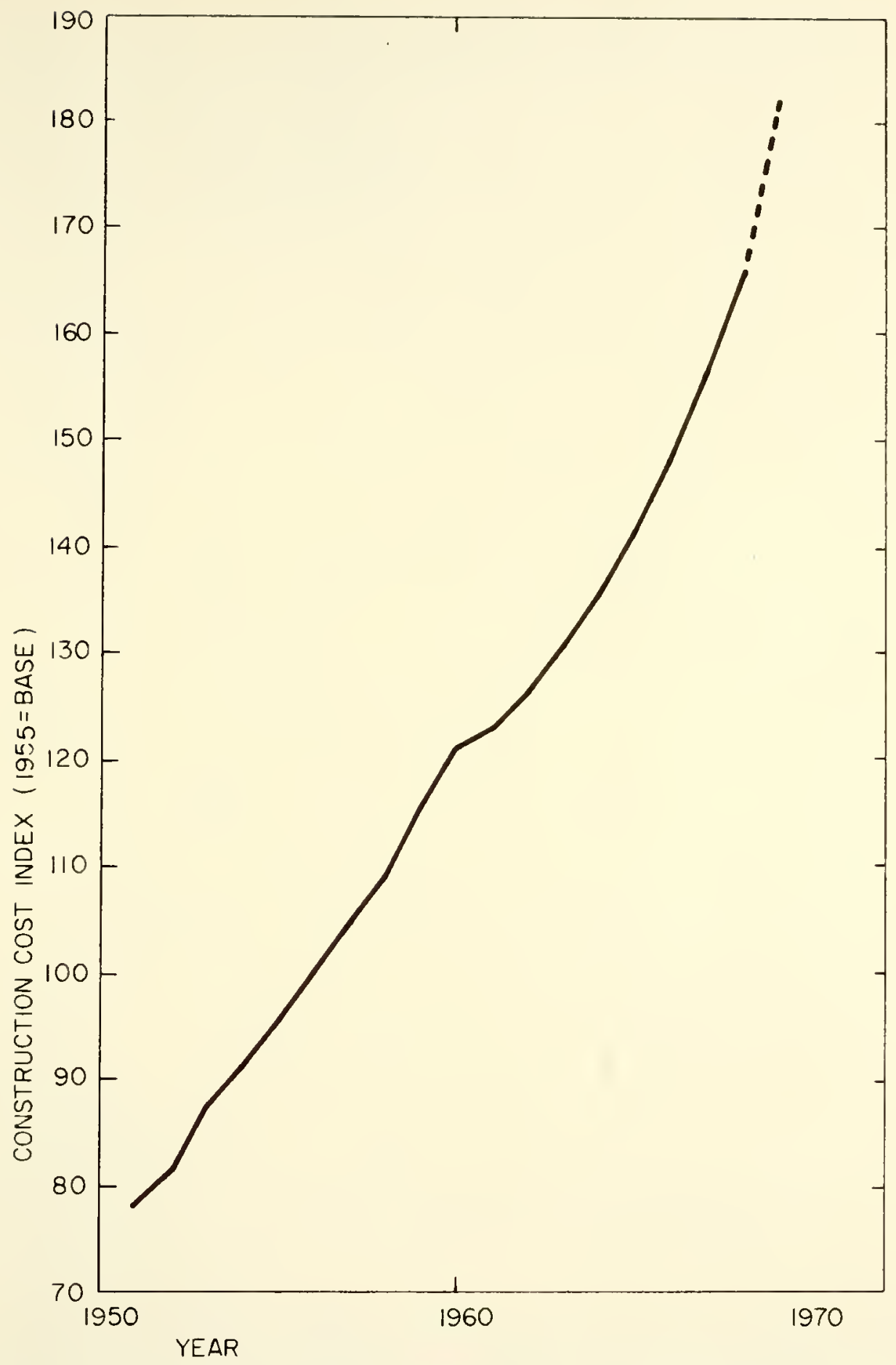

FIG. 9 CONSTRUCTION COST TRENDS (FROM ENGINEERING NEWS RECORD) 
Equations 10 through 13 relate maintenence effort index to the four basic factors described. Equations 10 and 11 were obtained utilizing stepwise regression analyses on data from Figures 5 and 6 . These equations had $R^{2}$ values of 1.0000 and .9396 , respectively. Equation 15 relates surface maintemance effort index of the section to the annual mainteriance cost per $10,000 \mathrm{sq}$. $y d^{2}$. The $R^{2}$ value for Equation 15 was .9998 .

$$
\begin{aligned}
& I_{d_{s}}=14.42857-2.41501\left(d_{s}\right)+0.10187\left(d^{2}\right) \\
& I_{d_{b s}}=5.71265-0.95354\left(a_{b}+a_{s b}\right)+0.04042 \\
& \left(a_{b}+d_{s b}\right)^{2} \\
& \left.I_{s}=9.938-6.436 \text { ( Iog, CBR } P_{S S}\right) \\
& I_{x}=\left(\frac{1}{1000}\right) x \\
& I=I_{d_{s}}+I_{q_{b}}+I_{s}+I_{x} \\
& M=279.19395-3.46509\left(I^{2}\right)+0.33537\left(I^{3}\right)
\end{aligned}
$$

where

$$
\begin{aligned}
& I_{d_{S}=} \text { maintenance effort index for surface thickness; } \\
& d_{s}=\text { surface thickness in inches; } \\
& I_{d_{U S}=} \text { maintenance effort index for the base and/or subbase } \\
& \quad \text { thickness; } \\
& d_{b}=\text { base thickness in inches; } \\
& d_{S b}=\text { subbase thickness in inches: } \\
& I_{S}=\text { maintenance effort index for the subgrade condition; } \\
& C B R=\text { subgrade cBR in percent; } \\
& I_{x}=\text { maintenance effort index for the traffic condition; }
\end{aligned}
$$




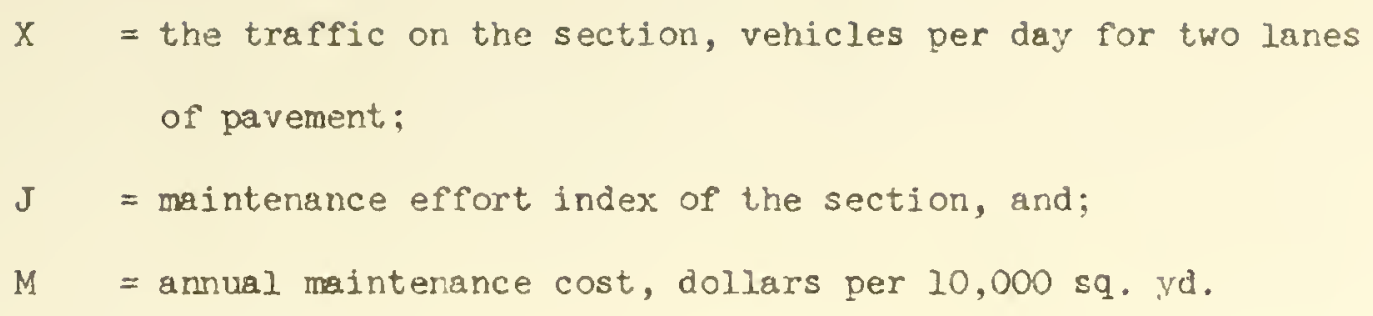

\section{Unit Cost of Paving Materials}

Unit cost of bituminous surface, hase, subbase, surface treatment, and sealing materials adopted for this study were based on the average unit bid price, obtained from the Indiana State Highway Commission, and are as follows:

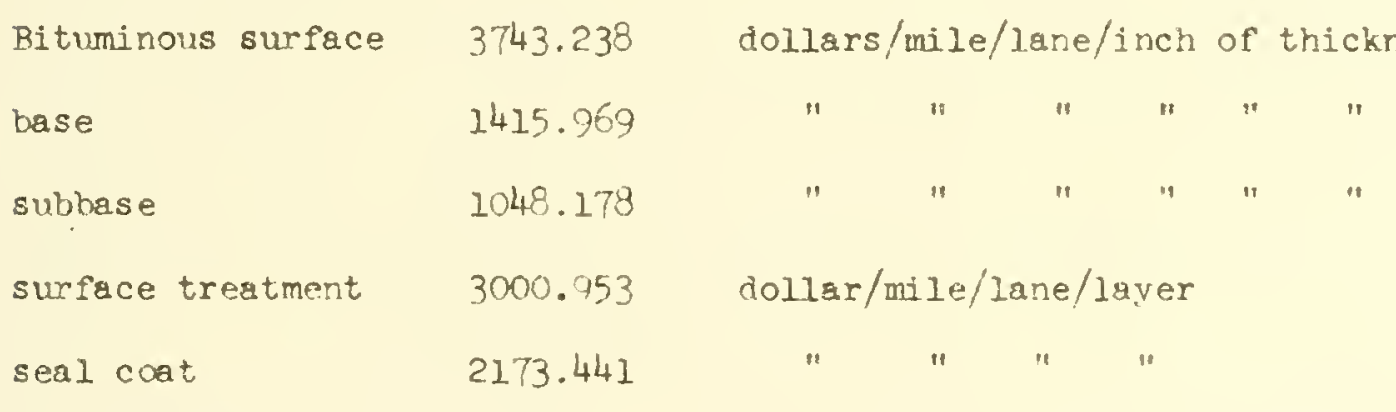

Rad User Cost Due to Maintenance and Resurfacing Operations

For the purpose of this study, road user costs due to mintenance and resurfacing operations were assumed to be extra costs to road users because of maintenance operations. These extra costs were estimated on the basis of re lationships between rod user cost and the average speed of traffic in the traffic flow. Accident costs resulting from mintenance and resurfacing operations were not considered.

In this study, it was assumed that specifications would limit the extent of lane closure for each resurfacing, operation to $1 / 2$ rile with a duration of closure of 8 hours. For sealing operations, the length of the lane closure would be 1 mile with a duration of closure of 8 hours. 
This latter amount was also used for routine maintenance operation. It was also assumed that each section was closed once a year for routine maintenance operation. The shoulder would be used as a traffic lane when one lane was closed on the 2-lane highway. No attempt was made to optimize the extent and the duration of the closure in relation to the traffic.

Rolationshio Between thr iverage Speed of Traffic and Traffic Flow.

In this study, th highwy types considered were 2-1ane and 4-lane divided highweys. Relationships between the average speed of traffic and vehicular flow in passenger car equivalevits (p.c.e.'s) during both, normal conditions and with one lane closed were estabilshed using data from the Hilghwy Canacity Manual (9). The average factor used for conversion of truck traffic to passenger car equivalerts was:

$$
1 \text { truck }=3.58 \text { p.c.e. }
$$

For both of the highway types (2 lane and 4 lane) a lane width of $12-\mathrm{ft}$. and a shoulder width of $8 \mathrm{ft}$. were used. The percentage of trucks in this and trafric stream was assumed to be $14 \%$ of the total. The highwys were assumed to be in level terrain. When one lane was closed for maintenance or resurfacing operations, the distarice trom traffic lane edge to obstruction was set at zero.

Nonlinear weighted regression analysis was used to arrive at a relationship between the average speed of traffic and the traffic flow. The general form of the model used in these analyses was:

$$
v=B_{0}+B_{1}(v)+B_{2}\left(v^{2}\right)+B_{3}\left(v^{3}\right)
$$

where

$$
\mathrm{V} \quad=\text { the average speed of traffic in miles per hour; }
$$


$v \quad=$ the traffic flow in passenger car equivalents per hour, and;

$B_{0}, B_{1}, B_{2}$, and $B_{3}=$ the parameters of the model.

Using the equation form noted above, $B_{0}$ represents the value of the average speed of traffic as the traffic flow approaches zero and $B_{1}$ can be calculated as a function of $B_{2}, B_{3}$ and $v$. The porameters $B_{2}$ and $B_{3}$ were estimated using the nonlinear weighted regression analysis.

Because the resulting equations were internal to the compriter program for forecasting road users costs, no atterapt was made to limit the reported equations to a reasonable number of significant figures. Following are the resulted equations:

2-lane highways, nomal condition:

$$
\begin{aligned}
& v=70-3.7643441339 \times 10^{-2}(v)+1.3541242 \times 10^{-5}\left(v^{2}\right) \\
& -2.86968751 \times 10^{-9}\left(v^{3}\right) \\
& R^{2} \text { value for this equation was } 0.9991
\end{aligned}
$$

2-lane highways, one lane closed:

$$
\begin{aligned}
v=45 & +7.003349954 \times 10^{-3}(v)-3.0747339 \times 10^{-5}\left(v^{2}\right) \\
& +1.28845385 \times 10^{-8}\left(v^{3}\right)
\end{aligned}
$$

$R^{2}$ value for this equation was 1.0000

4-Iane divided highways, normal conditions:

$$
\begin{aligned}
& V=-10.1617537335 \times 10^{-2}(v)+19747544 \times 10^{-6}\left(v^{2}\right) \\
&-8.42303439 \times 10\left(v^{3}\right) \\
& R^{2} \text { value for this equation was } 0.9976
\end{aligned}
$$

4-lane divided highways, one lane closed:

$$
\begin{aligned}
& V=50-1.121901513 \times 10^{-2}(v)-2.19747544 \times 10^{-6}\left(v^{2}\right) \\
& +2.32506269 \times 10^{-9}\left(v^{3}\right) \\
& R^{2} \text { value for this equation was } 1.0000
\end{aligned}
$$


where

$$
\begin{aligned}
V \quad= & \text { average speed of traffic, miles per hour, and; } \\
v \quad= & \text { traffic flow (p.c.e.) in both directions for } 2 \text { lane high- } \\
& \text { way and in one direction for } 4 \text {-lane divided highway. }
\end{aligned}
$$

Figures 10 and 11 show these relations for the types of highways considered in this study.

When traffic flow exceeded capacity it was assumed that the excess vehicles would queue up on the approech to the construction area. As the capacity (service rate) is less than the traffic flow (arrival rate), the queve will increase in length and theoretically the length of the queue will increase to infinity. In the general case, such a condition would not occur as the demand flow would drop beiow the capacity. Many drivers would not tolerate such large delays and would refuse to join the queue but would find an alternste route. The maximum average wating time in the queue therefore, would depend on the avallability of alternate routes. In the absence of specific information, it was assuned that a reasonable maximum average waiting time in the queue would be 10 and 5 minutes for 2-lane highway and 4-lane divided highway, respectively.

\section{Relationship Between the Road User Cost and the Average Speed of Traffic.}

The components of the road user cost are the operating expenditures for fuel, oll, tires, and vehicle maintenance and repair, and allowances for depreciation, time, and comfort and convenience.

The AASHO Red Book provides information which relates raad user costs for passenger cars to the average speed of traffic (1). This information is avallable for 2 -lane and divided highways, urder free, 


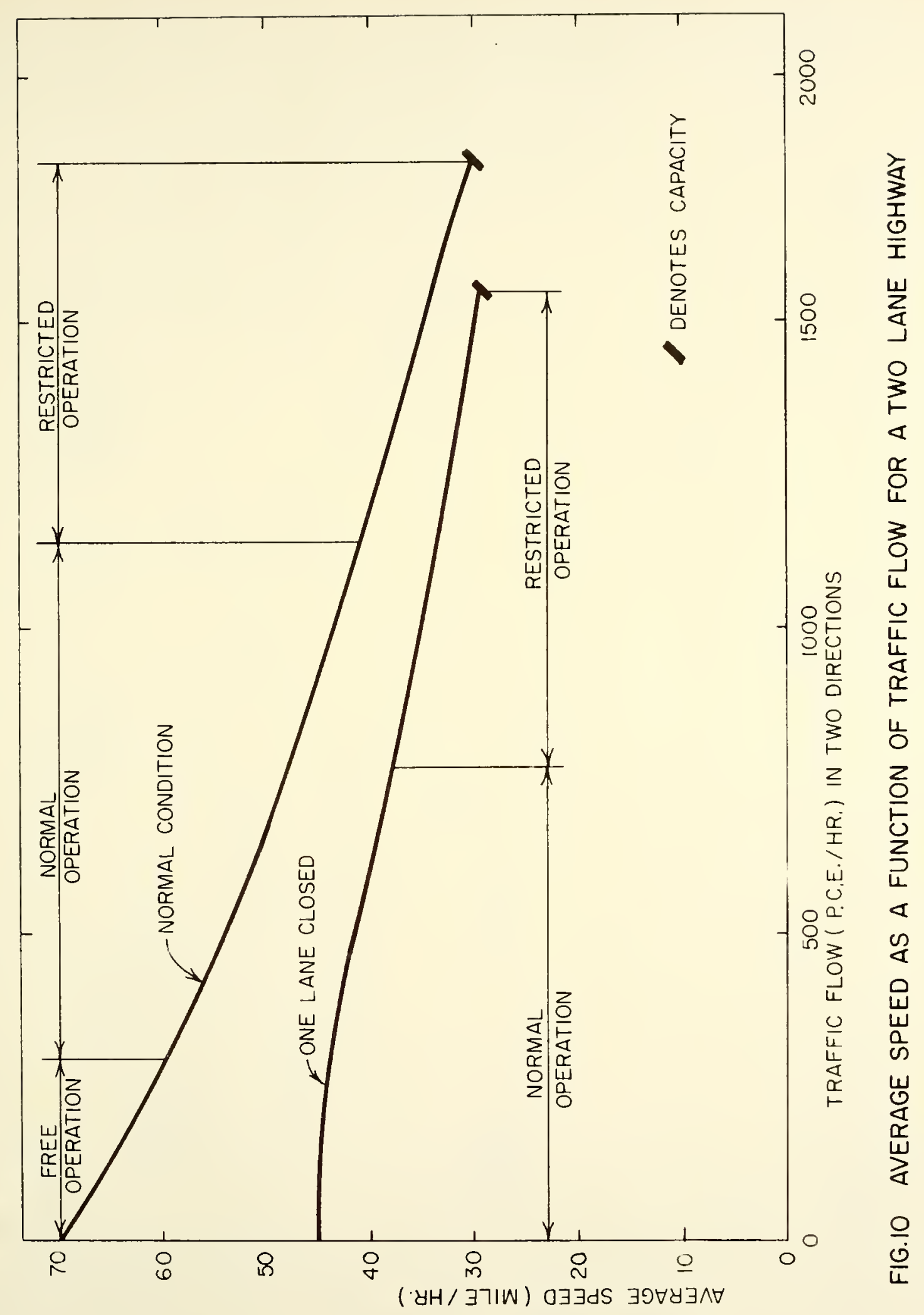




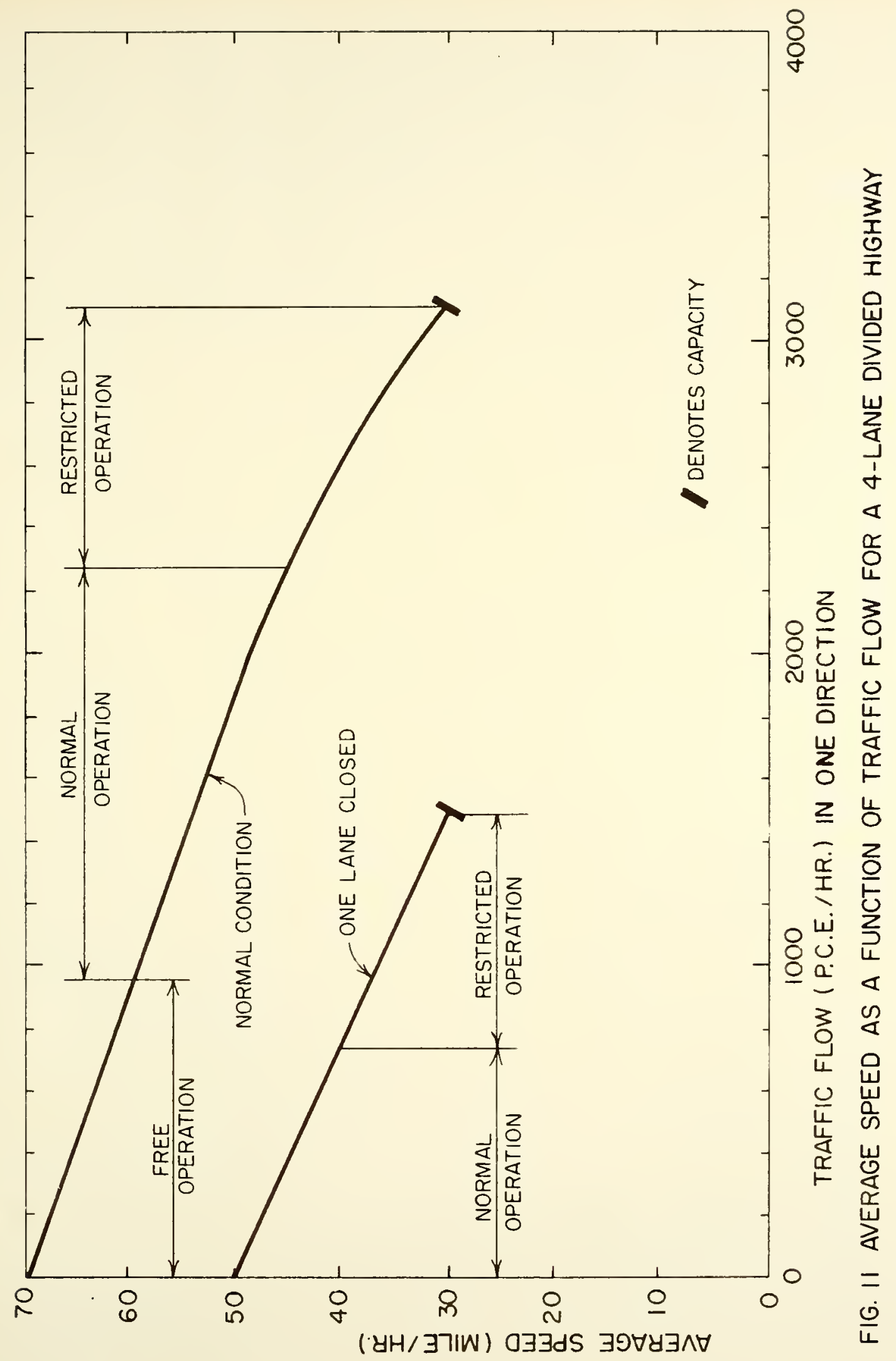


normal, and restricted operations, and four different gradient classes. Unit costs provided in this report were for the ye8r, 1959.

Data are available in Statistical Abstract of the United States (19) on the cost trends for different comodities; as well as for personal income, gross national product, and personal consumption expenditures on services. For the conversion of these data from the base year 1959 , related factors were obtained for the period from 1959 to 1969 and similarly for other base years. The followlng similarities on cost trends were assumed: fuel and oil to be the same as petroleum and products, depreciation to be the same as motor vehicle and equipments, mintenance and repair to be the same as a combingtion of 50 percent motor vehicle ard equipments and 50 percent personal consumption expenditures on services, tine cost to be the same as personal income, and comfort and convenience to be the same as gross national products. Figures $A-1, A-2, A-3, A-4$, and $A-5$, in Appendix $A$ show cost trends for petroleun and products, tires, and motor vehicles and equipmerts and the trends in personal consumption expenditures on services, and personal income and gross national products, respectively.

The factors used for converting the 2959 unit cost to 1969 's are as follows: for fuel, 1.052; 0il, 1.052; tires, 1.054; maintenance and repair, 1.365; àepreciation, 1.010; time, 1.670; and comfort and convenience, 1.7000 .

The relations between road user cost and the average speed of traffic under free, normal and restricted operations, for 2-lane highway and divided highway are shown in Figures B-I through B-6 of Appendix B. 
On Figures 10, and 11 the ranges for free, nombl, and restricted operations are specified. Using these ranges and the relitionship between the average speed of traffic and road user costs for free, normal, and restricted operations the relations between the road user cost and the average speed of traffic were obtained for 2 -lane and divided highways, for different gradient classes, and for normal condition and when one lane was closed. Figure 12 shows a Geneml example of relating rosd user cost to the average speed of traffic when the relations for free, nomnal, and restricted operations were knom. Tables 2 and 3 show the equations resulting from stepwlse refression analysis for the road user cost as a function of the average speed of traffic for different gradient classes under normal conditions and when one lane is closed for 2 -lane and divided highways. $R^{2}$ values obtained for these equations are as shown in the tables.

Figures 13, 14, 15, and 16 show the relation between road user cost and the average speed of traffle for 2-lane and divided highways, under normal condition and wher one lane was closed, for different gradient classes. A gradient class of $3-5 \%$ was adopted in this study. Road User Costs Due to Stand1 ne Delays and Reduction of Speed.

There is an extra cost associated with vehicle stops, besides that of constant speed operation. This extra cost depends on the apprach speed. There are data avaliable in the AASHO Red Book (1) that relate the extra cost per vehicle stop to the standing deluy perfod for different appraching speeds. When the traffic flow exceeds the capecity of the section, queue forms, and the approaching speed is the speed at the capaclty of the section whlch was assumed to be $30 \mathrm{mph}$ in this study. 


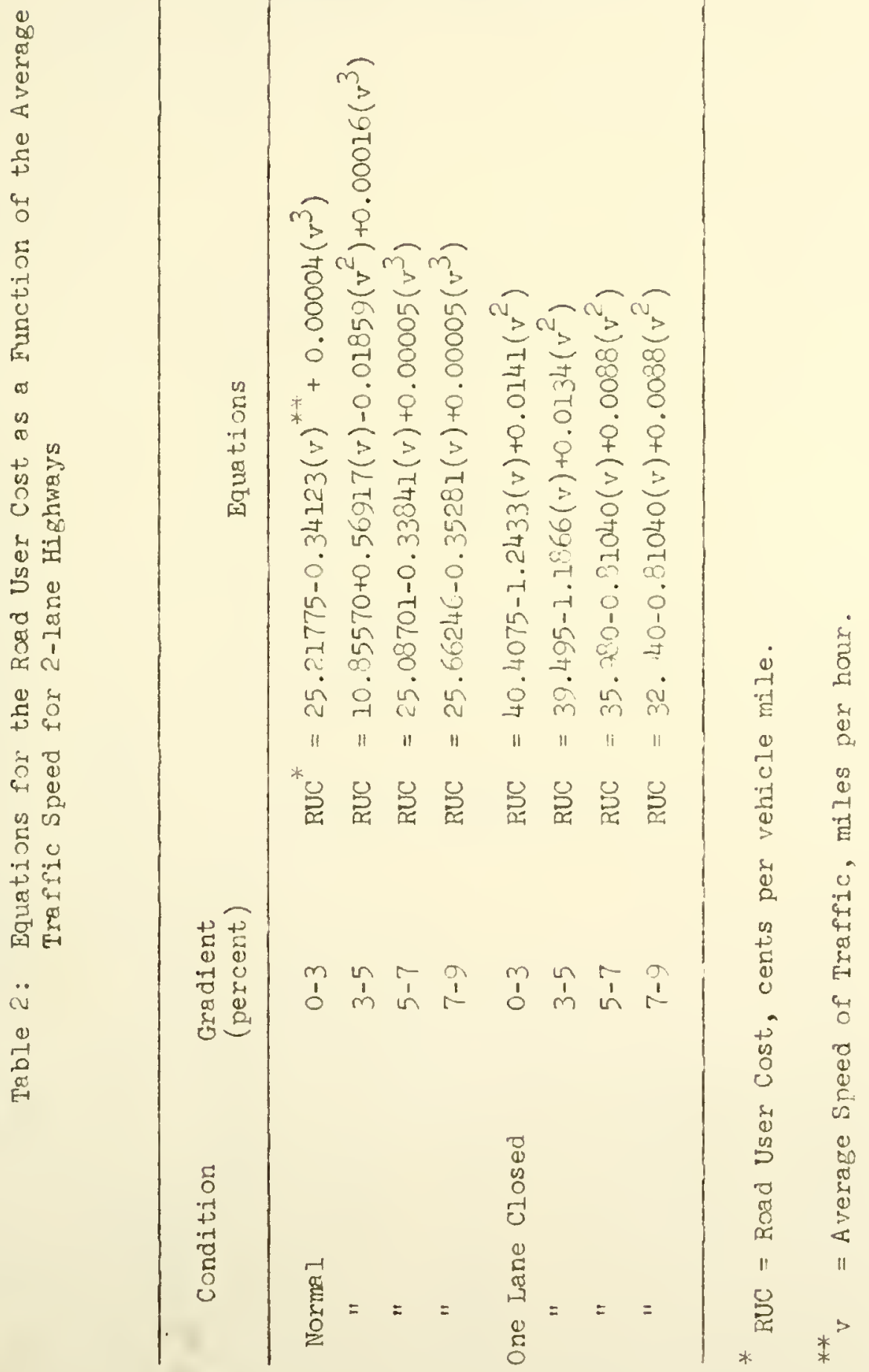




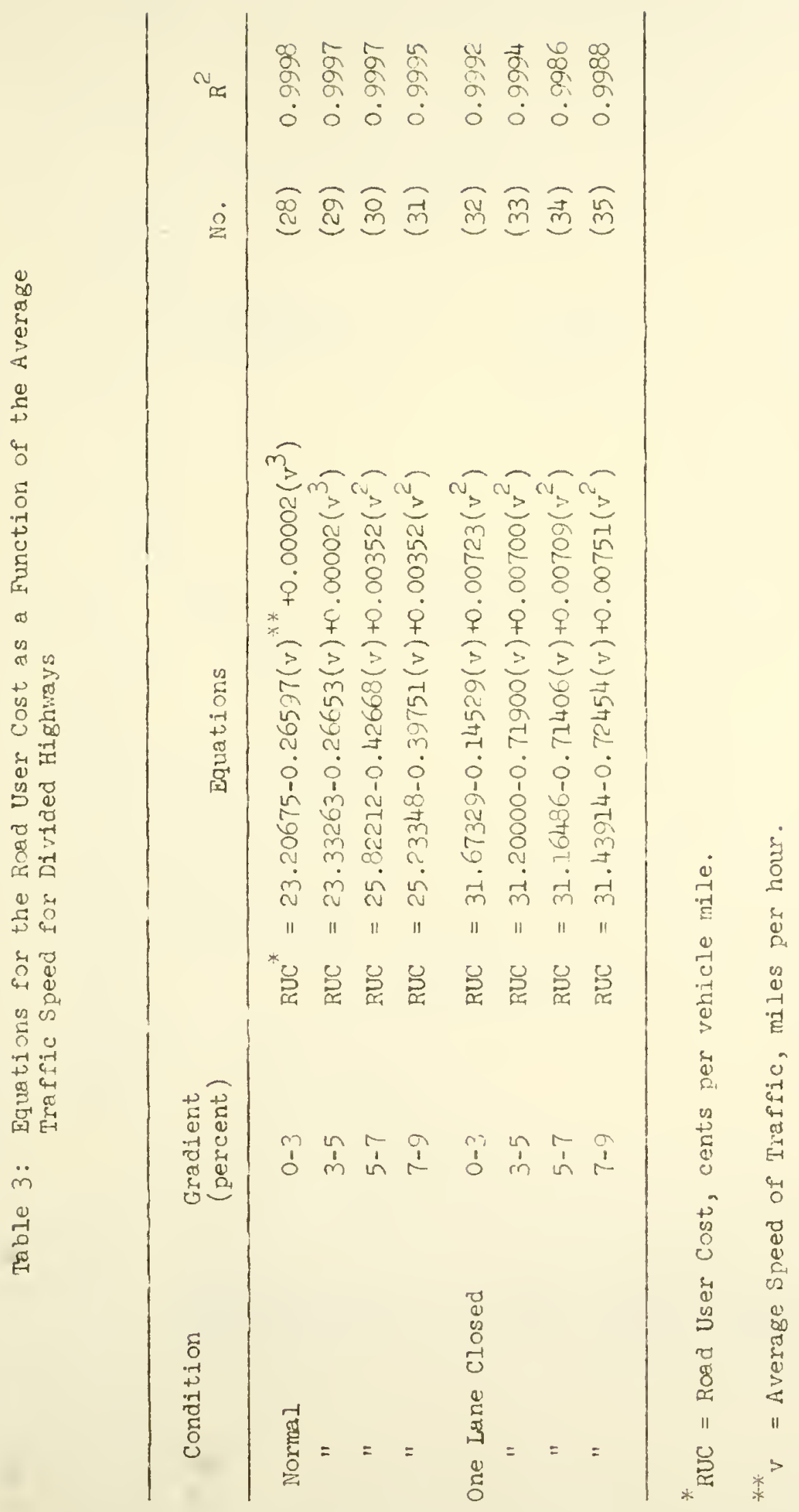




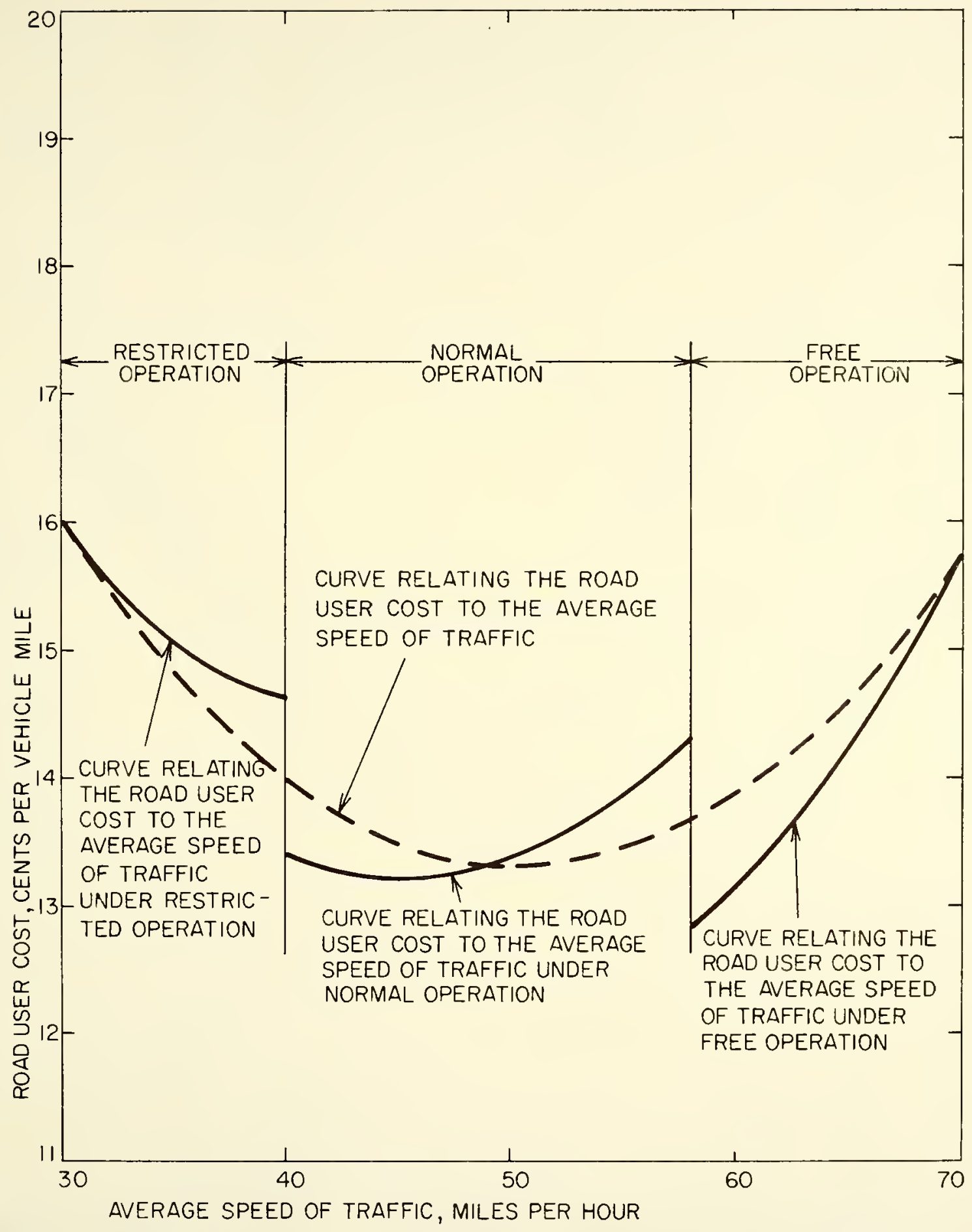

FIG 12 A GENERAL EXAMPLE OF RELATING ROAD USER COST TO THE AVERAGE SPEED OF TRAFFIC, WHEN THE RELATIONS FOR FREE, NORMAL, AND RESTRICTED OPERATIONS ARE KNOWN 


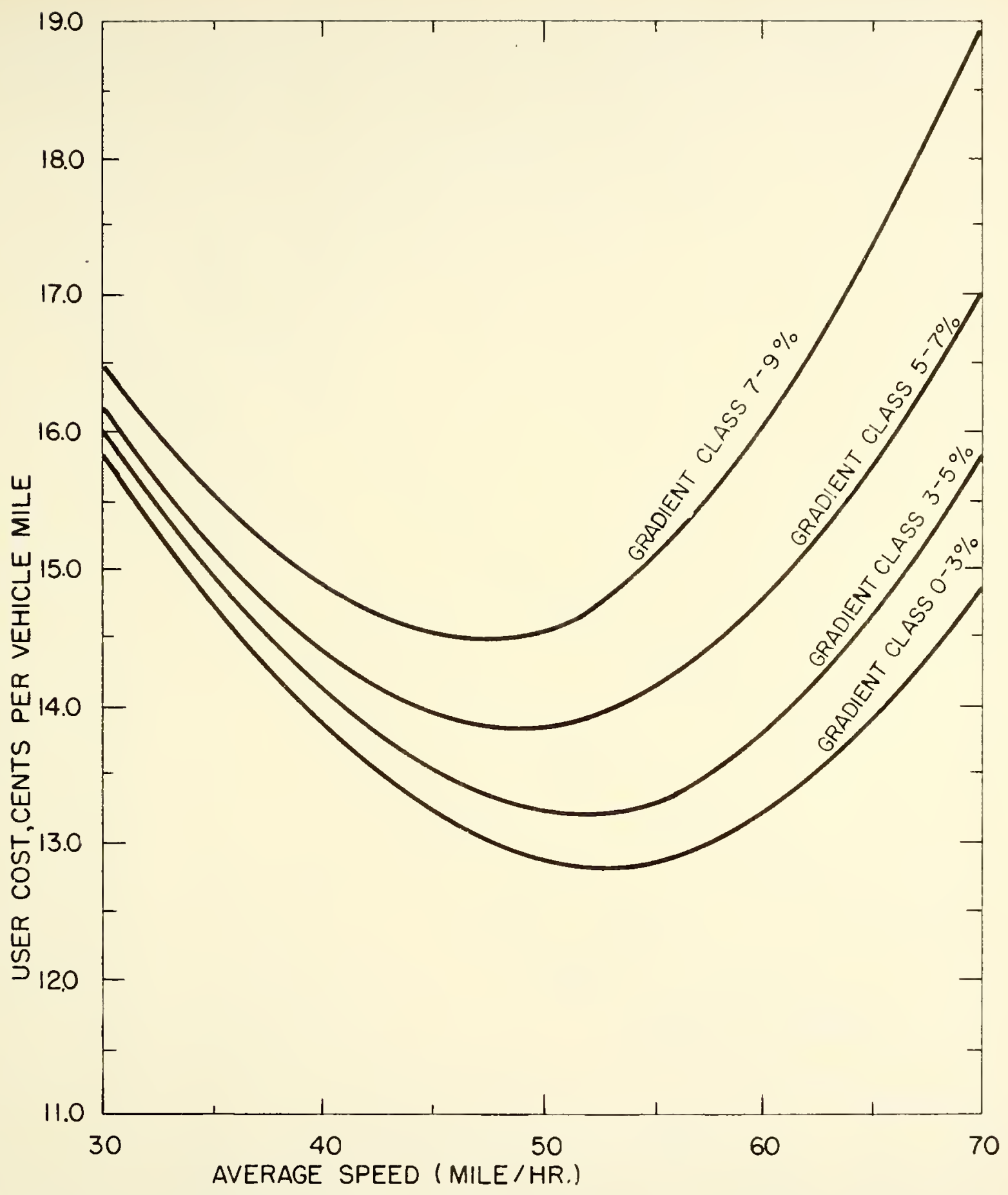

FIG.I3 ROAD USER COST FOR PASSENGER CARS ON TANGENTS OF A TWO LANE HIGHWAY AS A FUNCTION OF AVERAGE SPEED UNDER NORMAL CONDITIONS FOR SEVERAL GRADIENT CLASSES 


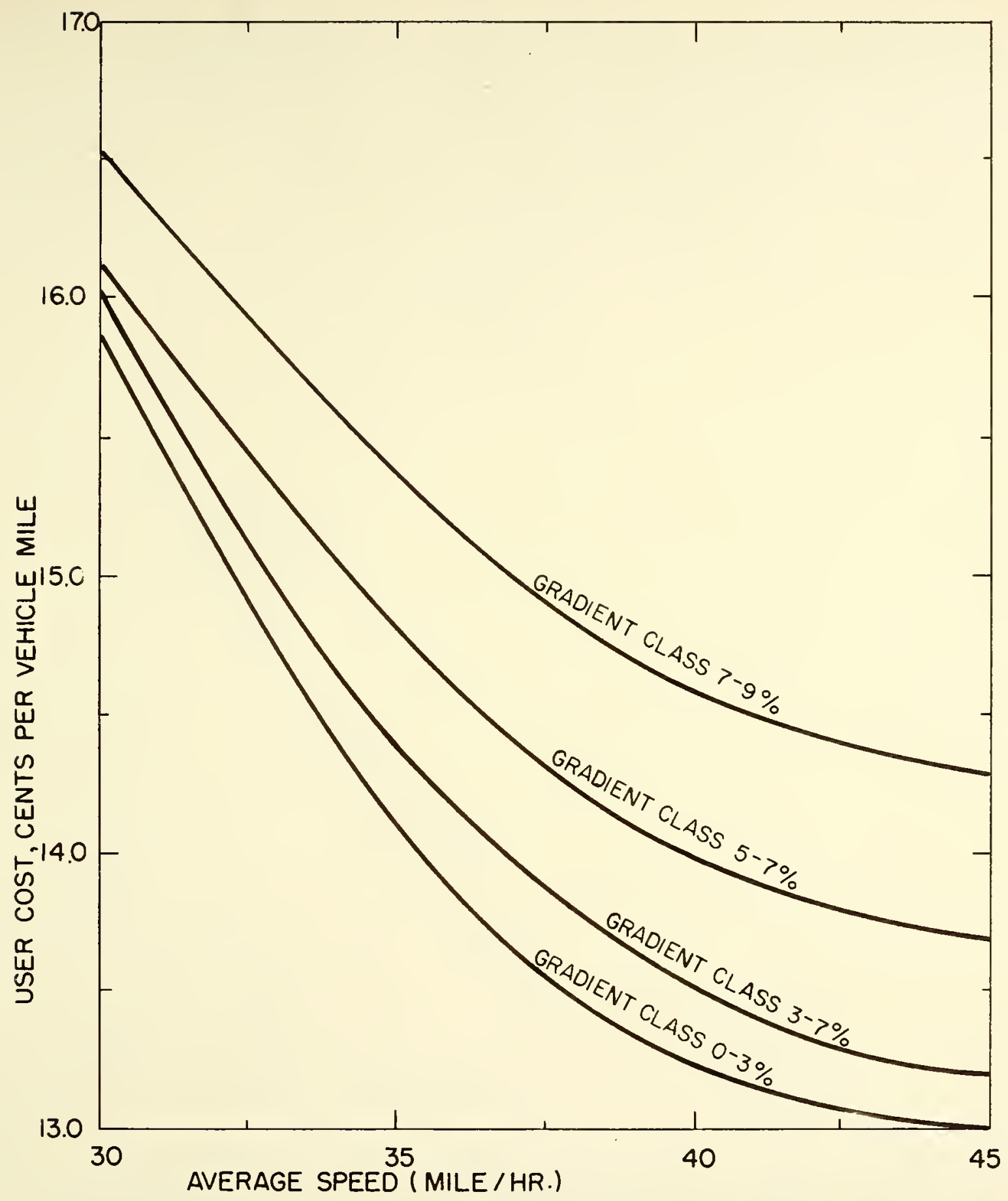

FIG. 14 ROAD USER COST FOR PASSENGER CARS ON TANGENTS OF A TWO LANE HIGHWAY AS A FUNCTION OF AVERAGE SPEED AND GRADIENT CLASS WHEN ONE LANE IS CLOSED 


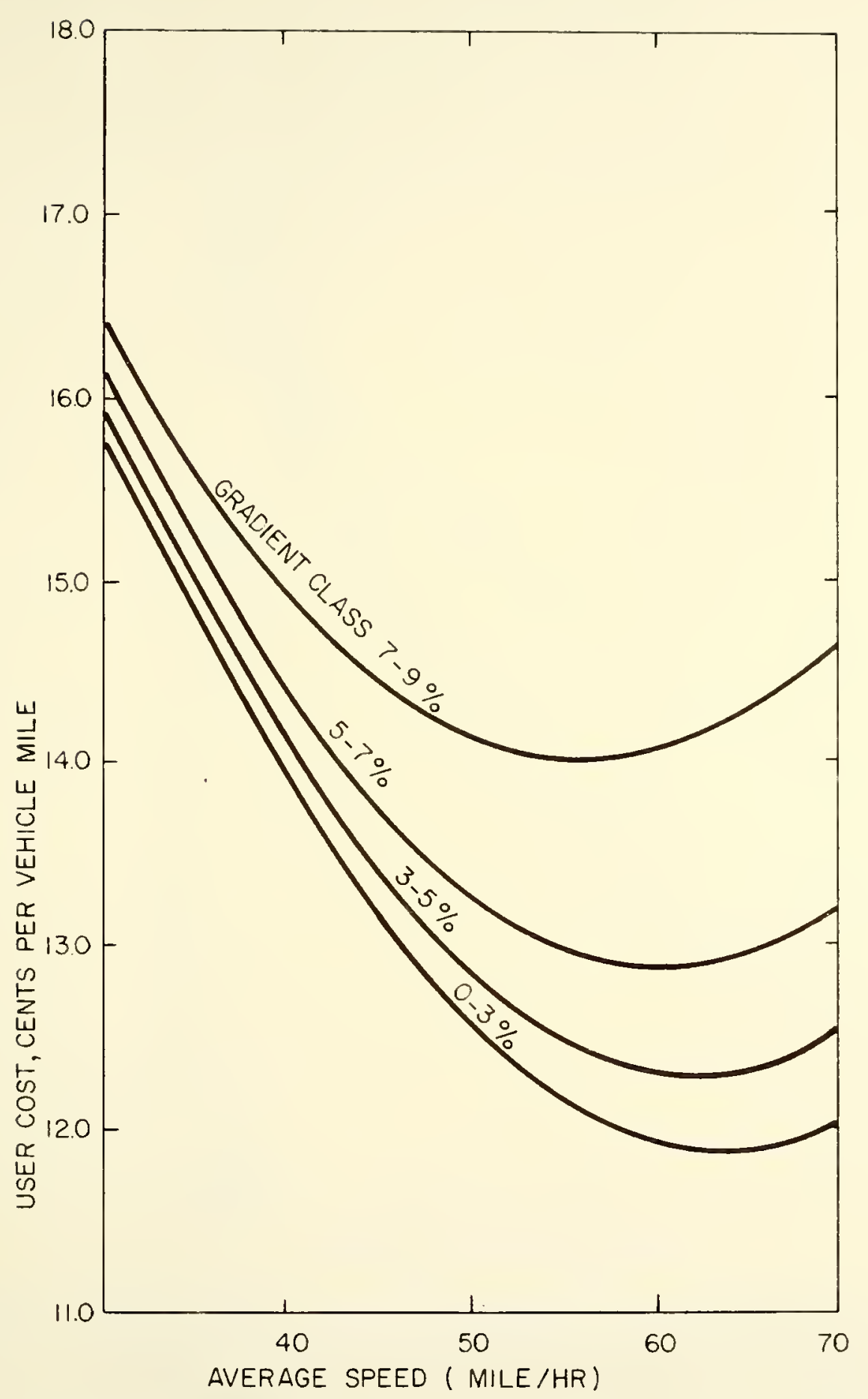

FIG.I5 ROAD USER COST FOR PASSENGER CARS ON TANGENTS FOR A 4-LANE DIVIDED HIGHWAY AS A FUNCTION OF AVERAGE SPEED UNDER NORMAL CONOITIONS FOR SEVERAL GRADIENT CLASSES 


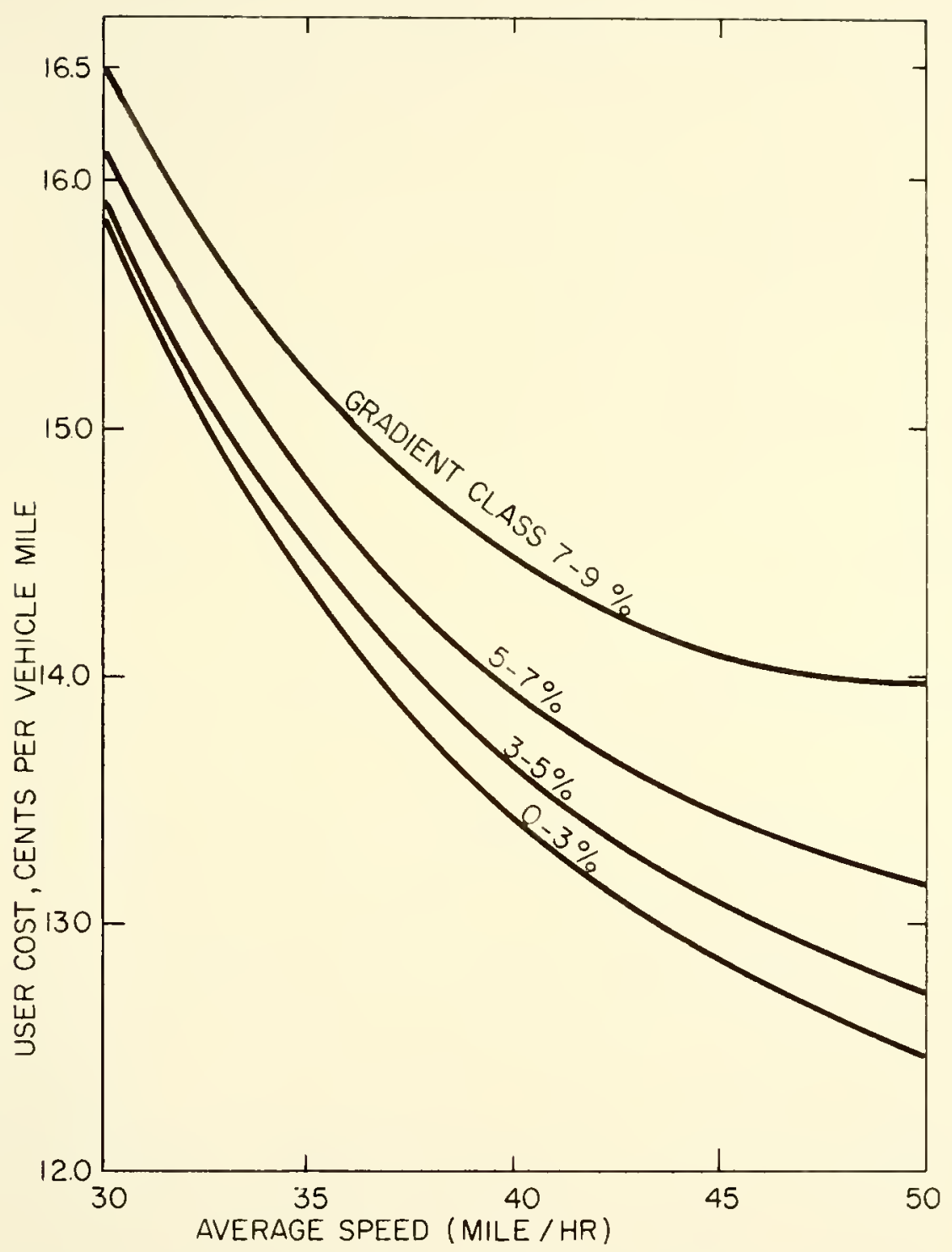

FIG. I6 ROAD USER COST FOR PASSENGER CARS ON TANGENTS OF A 4-LANE DIVIDED HIGHWAY AS A FUNCTION OF AVERAGE SPEED AND GRADIENT CLASS WHEN ONE LANE IS CLOSED 
A cost trend adjustment factor of 1.67 was applied to the data available in the AASHO Red Book to convert these costs from 1959 to 1969. This conversion factor was based only on the trends of time cost. Although the components of this cost 1tem includes other costs, the time cost would represent the in portion of it.

The relationship between extra cost per vehicle stop and the standing delay period is inear over the range of standing delay periods beyond 20 seconds. This relationship is shown in Flgure 17 . Equation 36 relates the extra cost per vehicle stop to the standing delay period over its linear range

$$
P=1.336+5.01 t
$$

where

$\mathrm{P} \quad=$ extra cost in cents per vehicle stop for an approach speed of $30 \mathrm{mph}$, and;

i = standing delay pexioà in minutes.

As traffic appraaches the construction zone, it slows dowr from the speed on the bighwy under normal condition to the speed on the construction zone, and vice versa. Claffey's (b) duta and his particular solution established a speed change unit value of 0.048 cents plus or minus 0.062 certs. A speed change unit is a plus or mirus change in speed of 1 mph. In the absence of any other information, Claffey's value of 0.048 cents was adopted in this study.

Correction Factor for the Extra Turning Maneuver Due to the Lane Closure.

The values of rowd user cast noted eyrliex were for open or high type of alinement. For conditions of curved allnement a correction is made by increasing tangert costs in accordance with a correction factor 


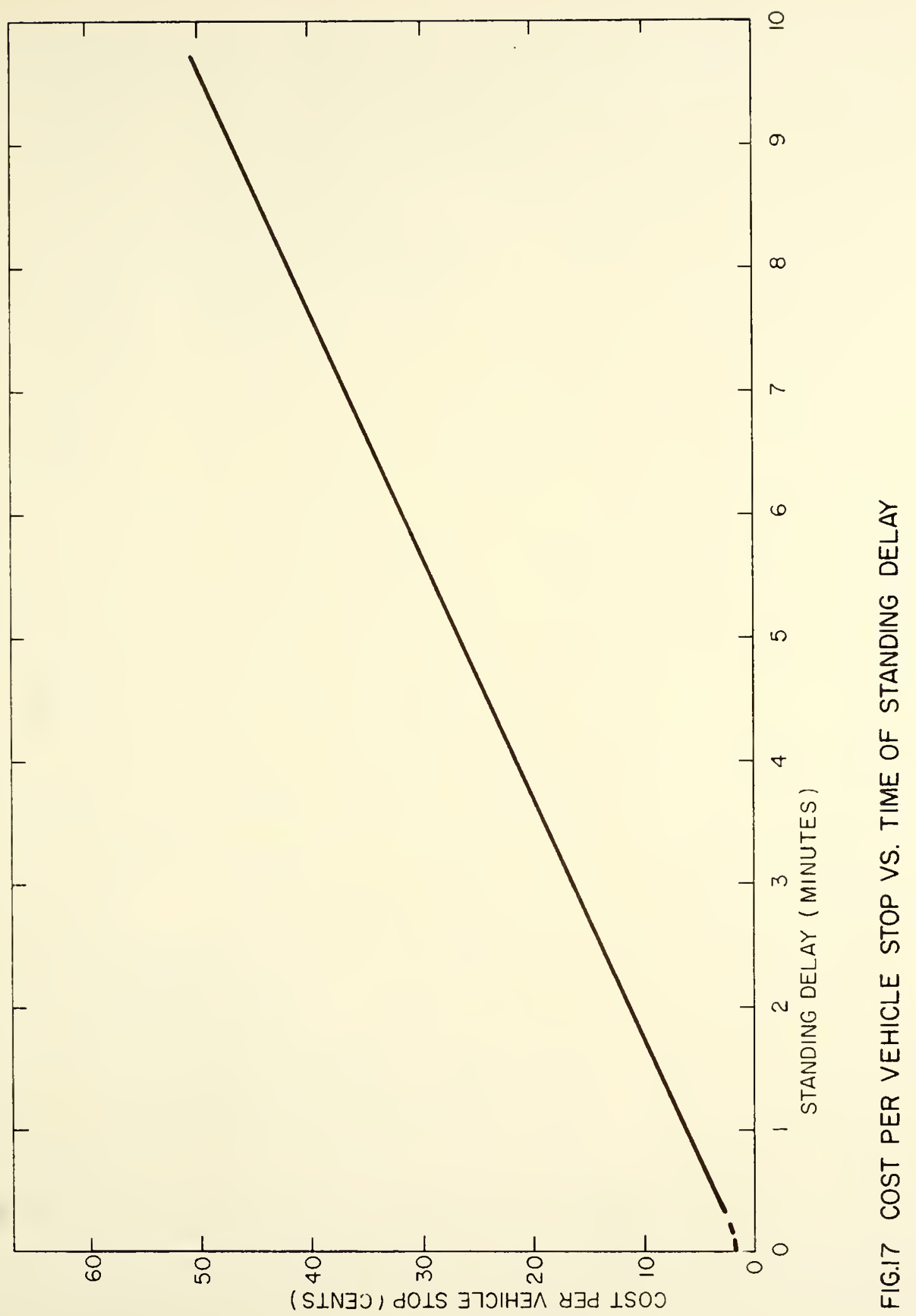


that depends on the sharpness of the curve and superelevation ( 1 ). As different alternates had the same alinement no correction was made, except for the extra turning maneuver, due to lane closure.

It was assumed that the traffic changes lane in a distance of $200 \mathrm{rr}$. Therefore, the degree of curvature for this maneuver was approximstely $4^{\circ}$. The superelevation was obviously zero. Figure 18 shows the relationship between operating costs on curves and on tangents. The dashed line on this figure shows an example of arriving at the correction factor when the average speed of traffic is known. This correction fictor should only be applied to the percent of the length of curvature. The percentage of the length of the roadwy in the construction area that will be on the curve are approximately 7 and 15, for lane ciosures lengths of 1 and $1 / 2$ mile respectively.

Considering the factors mentioned the following equations resulted Pran utilizing stepwise regression analysis:

$$
\begin{aligned}
& \text { Length of clasure of } 1 / 2 \text { mile, } \\
& \qquad F=99.12908+0.00151\left(v^{2}\right) \\
& R^{2} \text { velue for this equation was } 0.9958 \\
& \text { Length of closure of } 1 \text {. mile, } \\
& F=99.595335-0.0007\left(v^{2}\right)
\end{aligned}
$$

$R^{2}$ value for this equation was 0.9995

where

$$
\begin{aligned}
& F \quad=\text { the correction factor, percent, and; } \\
& v \quad=\text { the average speed of trafilc, miles per hour. }
\end{aligned}
$$

Figure 19 shows the correction factor for operating cost, as a function of the average speed of traffic for lane closure lengths of 1 and $1 / 2$ miles. 


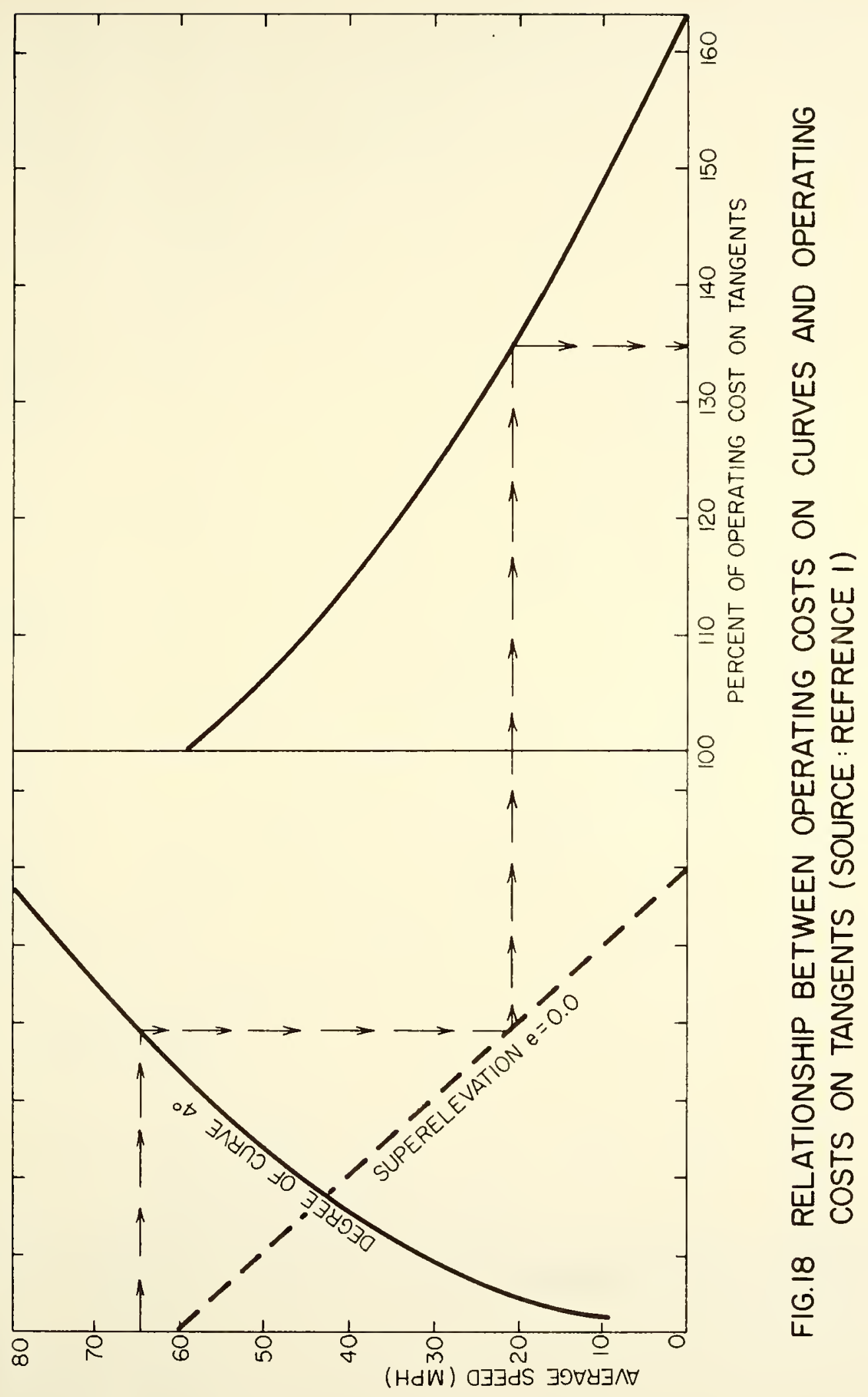




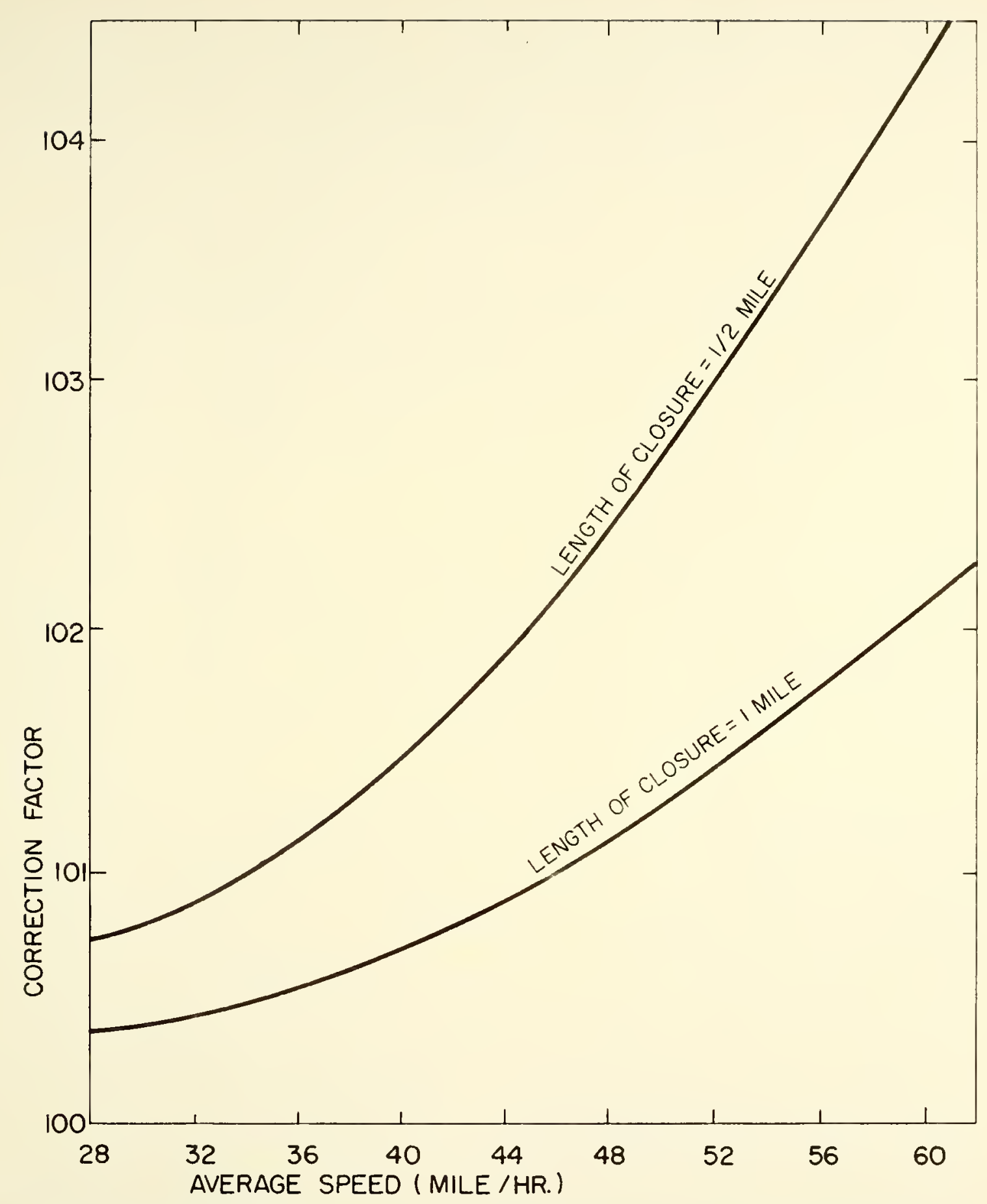

FIG. I9 CORRECTION FACTOR FOR OPERATING COST AS A FUNCTION OF AVERAGE SPEED FOR CLOSURE LENGTHS OF I AND I/2 MILES 
ANALYS IS

The models described in prevlous parts were utilized to calculate average annual costs of 2-lane highway and 4-lane divided highways. Programs were written in FORTRAN IV computer programing language. CALCOMP routines and plotter ife used to produce the necessary plots of data.

Average annual costs of highways were computed for initial design service lives of the surfaces ranging from two years up to the end of the anelysis period. The initial design service life of surface which resulted in the lowest value of the average annual cost was accepted as the best alternate.

Effects of subsoil condition, trafic, interest rate, and analysis period on the result, were studied by solving the problem for subgrade CBR values of $2,4,7,11$, and 16 percent; initial average daily traffic values of $10,50,100,1000,2000,5000$, and 10,000 ADr; annual trarfic Erowth rates of $2,6,10$, and 14 percent: interest rates of 6,13 , and 20 percent; and analysis periods of 20 and 40 years. The problem was also solved with and without the consideration of the road users costs due to lane closures.

The initial construction cost increased \&s the inftial design service life whs increased, there were also sudden rises in this cost item, when base and/or subbase was required (minimum base and subbase tinicknesses adopted in this study were 4.0 and 6.0 inches respectively). 
The routine mintenance expenditure was a decreasing function of the initial design service life of surface. This expenditure was computed on a yearly basis. Of the factors in the model used for predicting this cost 1tem, thicknesses of surface, base and subbase were subject to change as initial design life of surface was changed.

The thickness factor increased as the initial design service life of surface increased. This resulted in a decrease in routine mintenance expenditure as the initiel design service life of surface was increased. The resurfacing expenditure also decrensed as the initiul design service life increased. Therefore, the greater the initial design service life of surface, the less thickress had to be provided to maintain the pavement function throughout the remalning analysis period.

Cost of sealing was an increasing function or the initial design service life of surface in this problem. The resurfacing interval has always equrl to the initial aesign service life of the surfice. It ws assumed that if a resurface was to be placed at intervals of time greater than 10 yenrs, a seal coat layer shoula be placed on the pavenent at the and of 10 yoars. Ther fore, up to initiul design scrvice life of surface of 10 years, no seqling was required. For initial design serrlee life of surface of 10 years to $? 0$ years, one seal coat layer was needed, and for an initial design service life of surface of 20 to 20 years, two seal cant layers were required etc.

This study was corducted with and without the consideration of road user's costs due to lane closures as a component of the average anmul cost of highway. Obviously, these cost items increased as the 
number of times of lane closures increased. Poad user cost due to routine mintenance was the same for all alternates, as it was assumed that each section was closed once a year for this prupose. Road user cost due to mjor maintenance decreased as the initlal design service life of surface (which was also equal to the period of resurfacing) was increased. However, road user cost due to sealing increased as initial design service life of surface was increased since, as explained earlier, the number of times that sealings were required increased as the initial design service life was increased.

For ary given initial value of average daily traffic, rate of trafsic growth, and rate of interest, the average annual highway cost was the highest in the case of a subgrade CBR value of 2 percent and initial. design service Iffe of 2 years among the average annual highwy costs for the adopted CBR values and other initial design service Ilves of surface. Therefore, average annual highway costs were computed as a percentage of this hishest value ( $2 \% \mathrm{CBR}$ and two year interval) for different $C B R$ values and other initial design service lives average annual cost. The computer plotter was so utilized to produce plots of this percentage of cost of surface, as a function of the initial design service Iife of surface, and for the subgrade CBR values adopted for this study.

Plots of cost were produced in the same manner for the two and four lane highways, with and without the consideration of road user cost due to lane closures and for analysis periods of 20 and 40 years; the adopted values of average daily traffic; annual traffic rates of growth; and rates of interest. 
Figure 20 shows a typical plot produced by the CAICOMP plotter, showing the percentage of the average annual cost of highway to be the appropriate average annual cost of the highway for a subgrade CBR value of 2 percent, and intial design service life of surface of 2 years. The example in Figure 20 is for a 4 -lane divided highway with an average daily traffic value of 1000 ADr; annual rate of traffic growth of 2 percent; rate of interest of 6 percent; analysis period of 40 years; and with the consideration of the road users costs due to lane closures. The function relating the average annusl cost of highwy to the intial design service life of surface is a one of sequerce, since the average annual cost of higlway is defined only for the exact thme of the intin design service lif̂e of surface. There were sudden rises and ralls in the avcrage annual cost of highay as the iritial design service life of surtace was incrcased. This occurred because cf

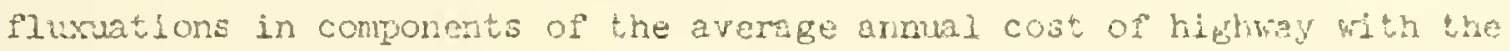
Increas of the initial design service lite of surfuce as descrived in the provious peregraph. Therefore the producs plots ropresert the average arnual cost of higliny as a price-wise linear function of the intital desien sarvice lifte of surfuce.

Bounuse of the cormpluxity of analyzing the factors that caused the rises and falls, it was assured that the snooth curves passing abcut the lower parts of the produced plots represented the relationship between the percentage of the onmal cost of the highway to its appropriate average annul cost of higkway for a subgrade CBh vaiue of 2 percent and initial design service life of suriace of 2 years. The dashed smooth curves on Figure 20 illustrate this assumption through 


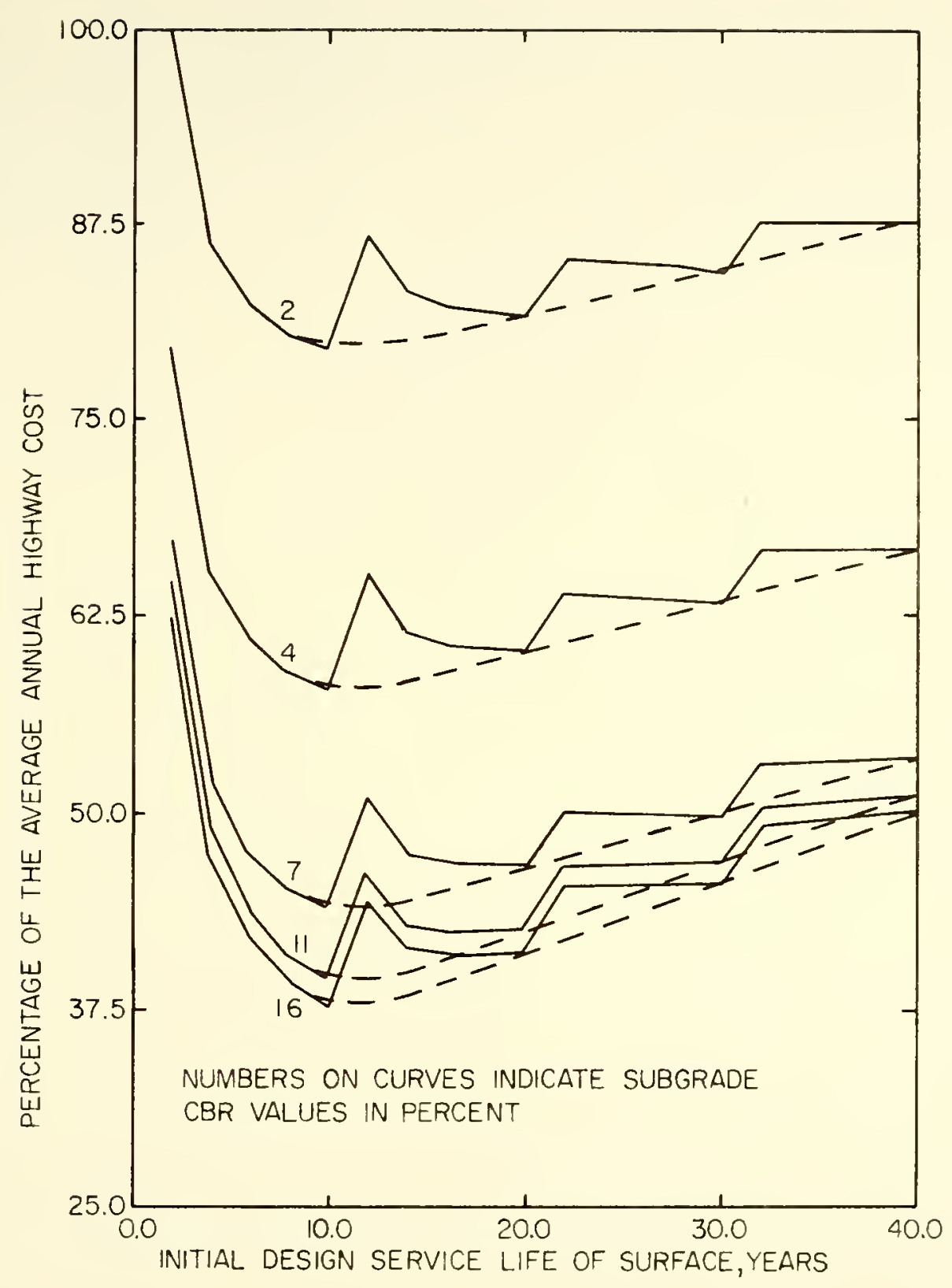

FIG 20 A TYPICAL PLOT PRODUCED BY THE CALCOMP PLOTTER 
visual inspection. That is, inftial design service life of surface results in minimum values of average anmal cost of a 2 -lane highway and 4-lane divided highway. The effects of the length of anazsis period, consideration of road user costs due to Iane closures, subgrade CBR, inltial yearly equivalent 18-kip, sirgle-axle load applications, anmal rate of traffic growth, and interest rate were studied. 
RESULIS AND FINDINGS

The inftial design service life factor which resulted in the minimum average anmal cost of 2-lane highway and 4-lane divided highway where determined through visual inspection of the modifled plots. Figur es 21 through 36 show the optimu infial design service ife of pavement surface as a function of the initial yearly EAL. These facts were detemined with and without considerat1 on of rod users costs rasulting from lane closures, different interest rates, subgrade CBR values, traffic rate of growth, araljsis periods of 20 and 40 years, and for 2-lane and 4-lane divided highways. The following sumarizes the results noted fram the inspection of Fipures 21 through 36 :

1) Up to a certain value, the optimum initial design service life remained constant as the initial yearly EAI increased. However, beyond this value the service life increased as a constant rate. The vilue of the initial yearly EAL at whlch the initial design service life changes trom a constant value to an increasing function of the initial yearly EAL was deined as the critical value of the initial yearly $\mathrm{EAL}$. The value of the critical initial yearly EAL depended upon the consideration of road user costs due to lane ciosures, interest rate, traffic rate of growth, subgrade CBR value, and the analysis period. Tris value decreased as the traffic rate of growth increased, but interest rate decreased. As the analysis 
period or:subgrade CBR increased the critical value of the initial yearly EAL decreased.

The rate of increase in the initial design service life beyond the critical value of the initial yearly EAL depended on the rate of interest, subgrade $C B R$ value, analysis period, and on the traffic rate of growth. The rate of increase in the initial design service life lessered as subgrade CBR value and/or rate of interest increased.

For a 4-lane divided highway critical values of the initial EAL are higher than those of a 2 -lane highway; and the rate of increase in the optimu initial design service life of a 4-lane highwy is lower than that of a 2-lane highway. This is particularly true for high CBR values.

2) The optimum initial design service life decreased as the interest rate increased. For low subgrade CBR values this was the case for the entire range of the initial yearly EAL. However, for higher subgrade CBR values (only beyond the critical value of the initial yearly EAL) the optimum initial design service life was lower for higher interest rates.

3) Analysis with consideration of the road user costs due to lane closures resulted in a decrease of the optimm initial design service life over the total range of the initial yearly EAi for low subgrade CBR values and over the range beyond the critical value of the initial yearly EAL for higher subgrade CBR values. The difference between the optimum initial design service life when road user costs due to lane closures here 
considered and when road users costs due to lane closures were not considered was as $11 \mathrm{gh}$ as 2 years over the range before the critical initial design service life. Beyond this range the difference was as high as 10 years for an analysis period of 20 years and even higher for the analysis period of 40 years. Beyond the initial design service life this gap decreased. The difference between the initial design service life with the consideration of the rond user costs due to lane closures was greator for a 4 -lane highwy than for \& 2 -lane highway beyond the critical value of the initial yearly Fat.

4) At low subgrade CBR values, before the critical value of the ycarly EAL, the optimum initial desion service life decreased when the interest rate increased. When rad users costs due to iane closures were considered at higher subgrade CBR values, the optimur design service life was approxinately the same (about 10 years). In the range bejond the critical value of the initial yearly EAL, the initial design service lite lecrcased as subgrade CBR value increased.

5) In the range beyond the critical value of the initial yearly EAl, when road user costs due to lane closures were considered and when they were not considered, the difference between the optimum initlal design service life decreased when rate of interest increased.

6) The optimum initial design service life in the range before the critical value of the initial yearly EAL was constant and approachei 10 years for both 2-lane highwys and 4-lane divided 
highways and aiso for the analysis periods of 20 and 40 years. The critical value of the initial yearly EAL is lower for 2lane highways in the range beyond this value. The optimum Initial design service life is lower for 4-lene divided highways and for analysis period of 20 years. 


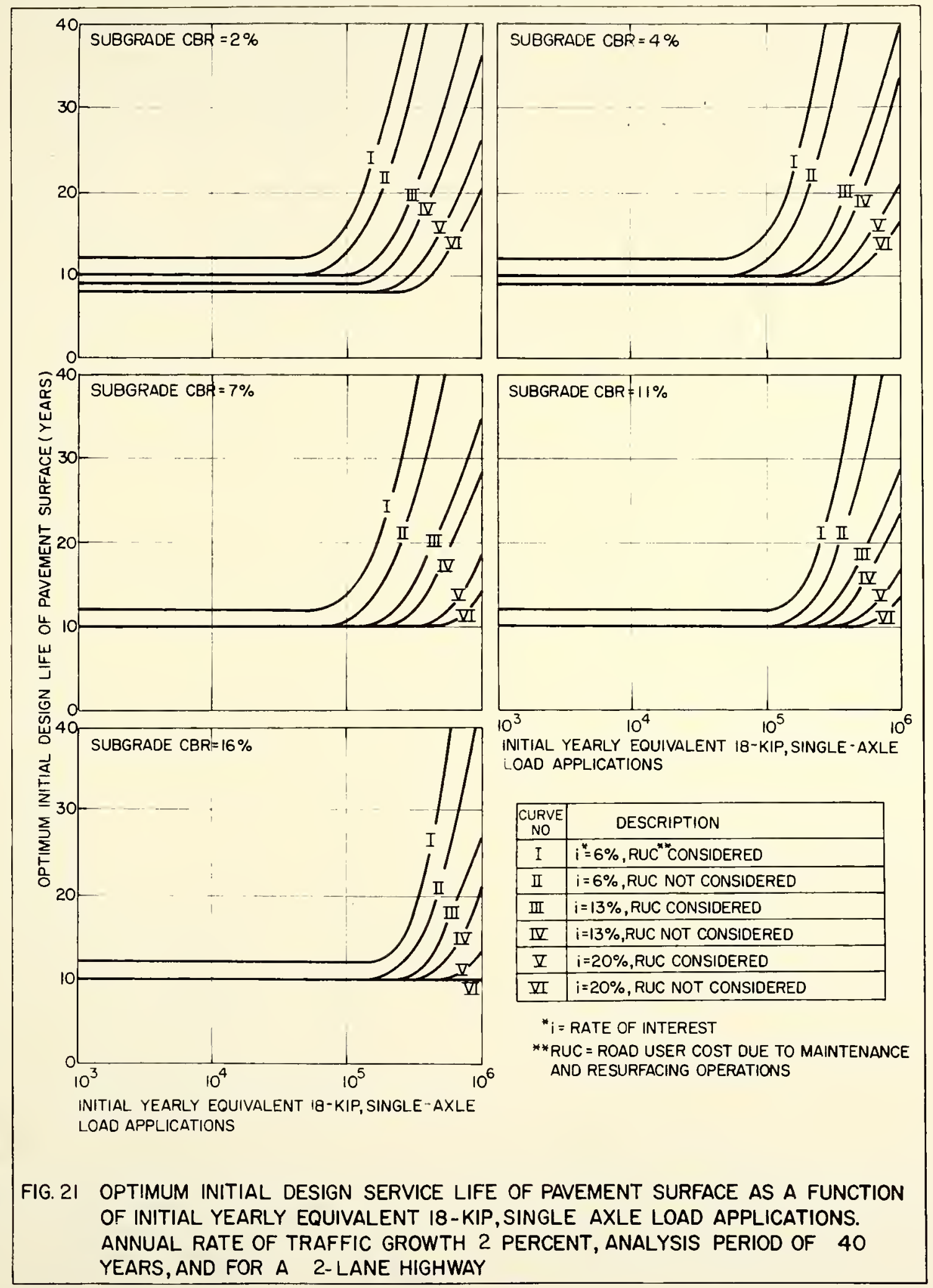




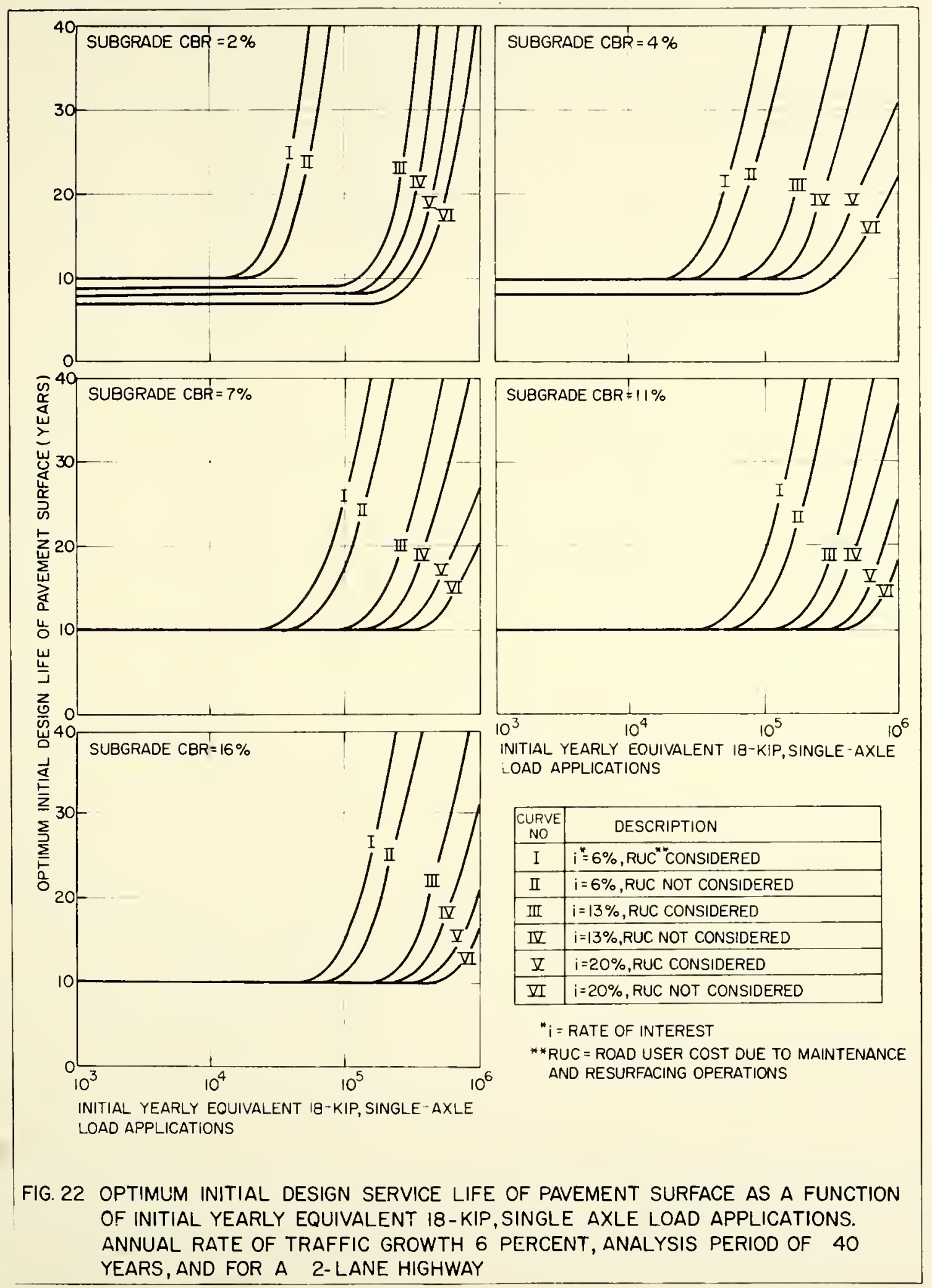




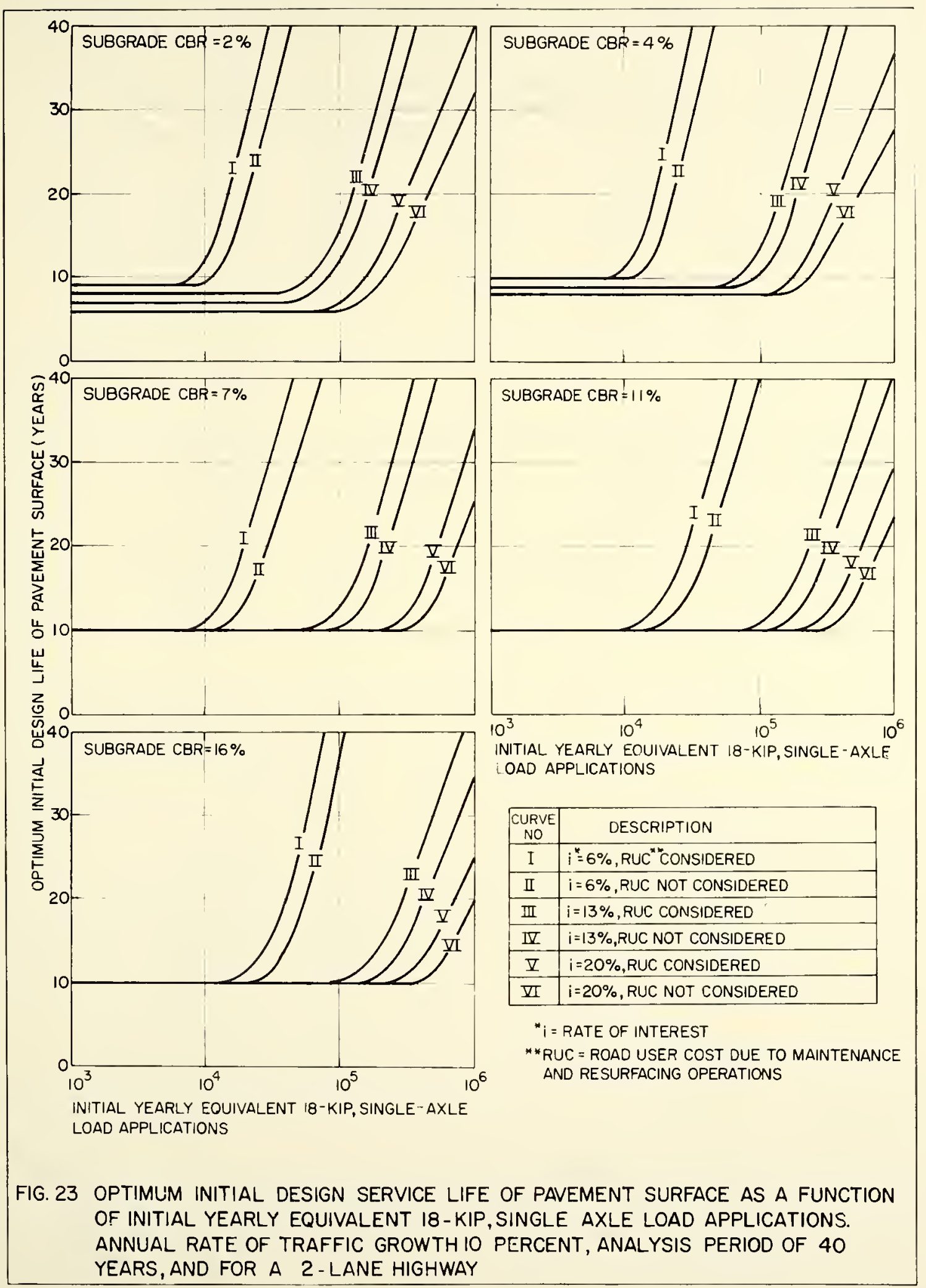




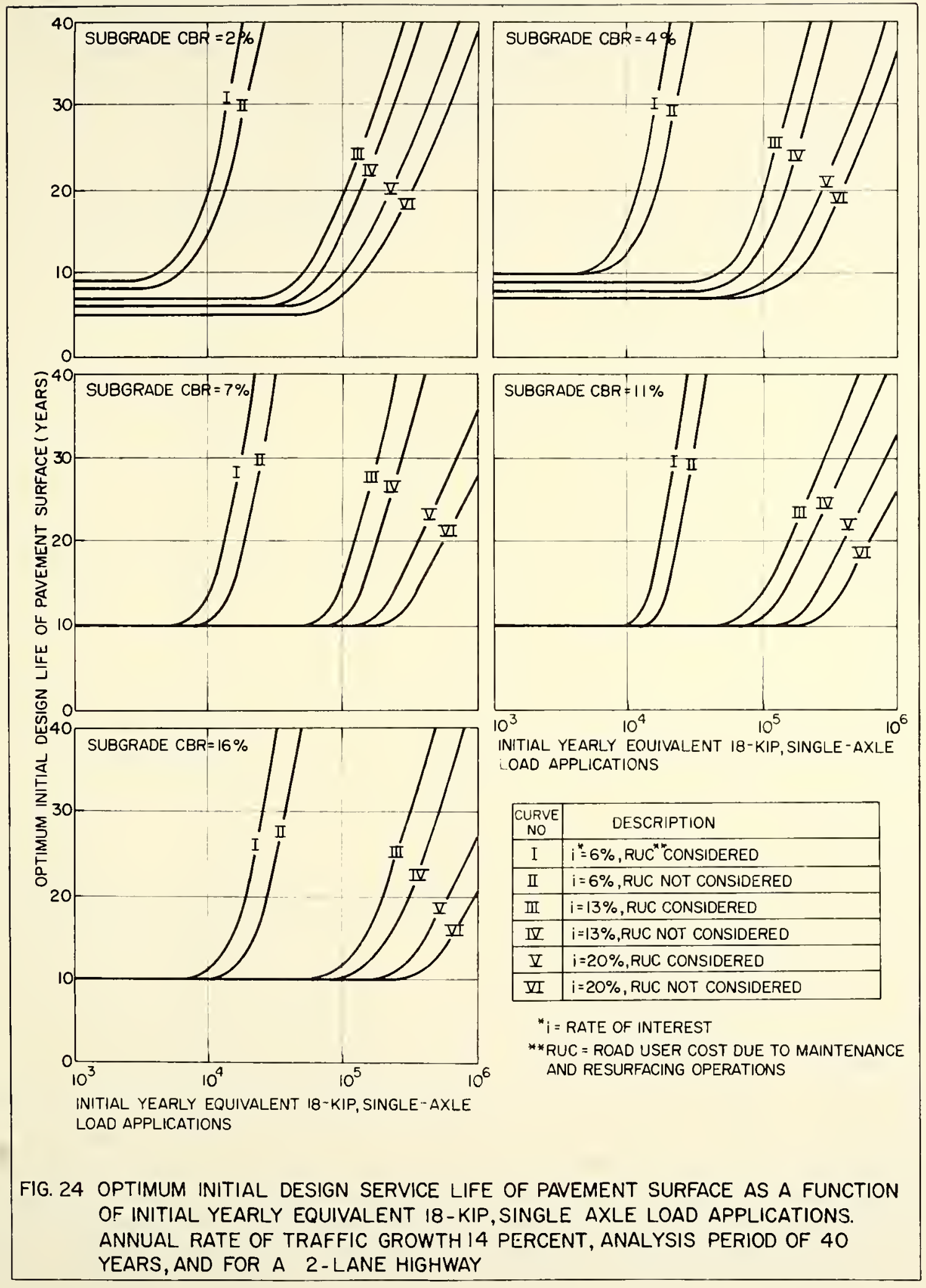




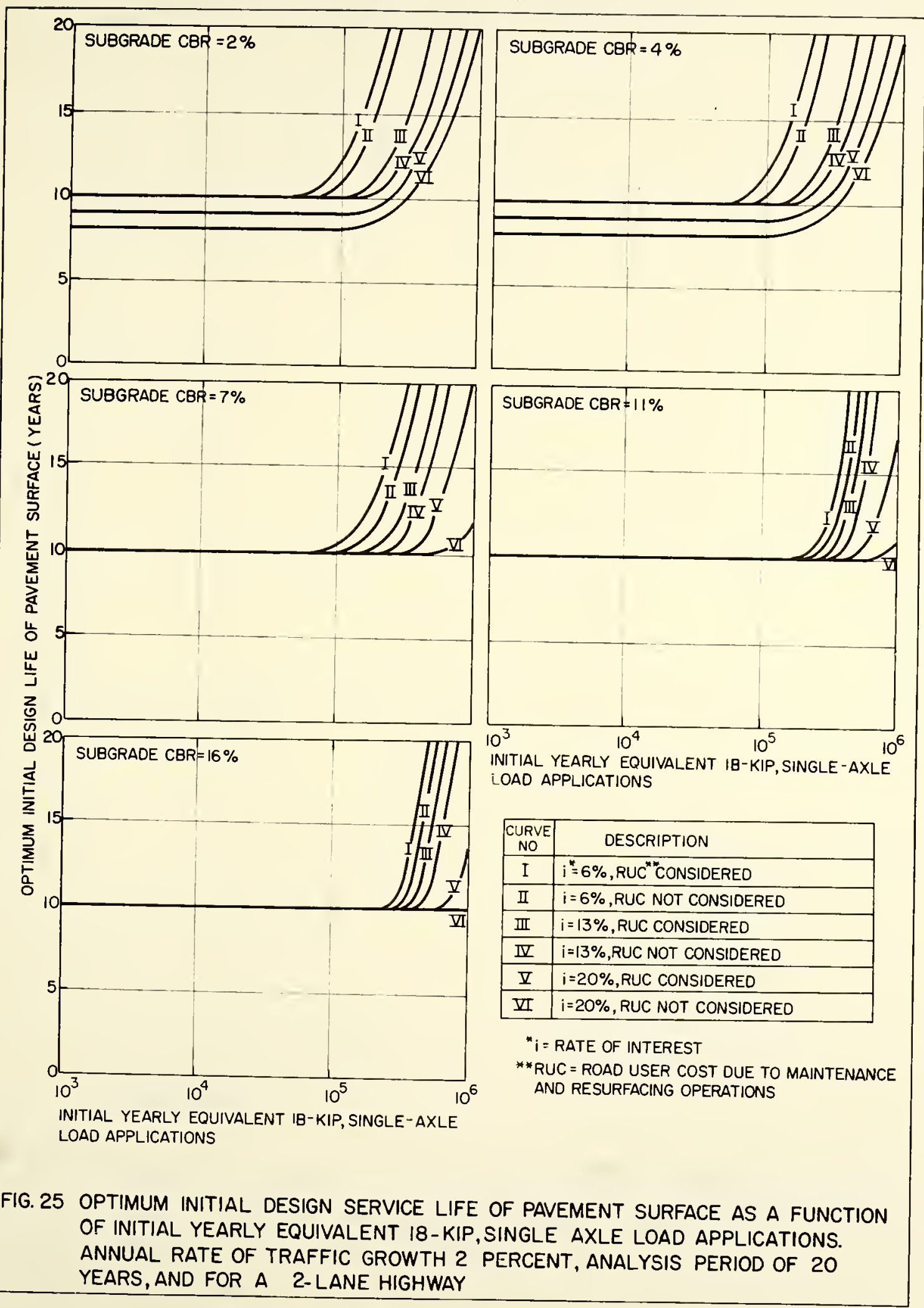




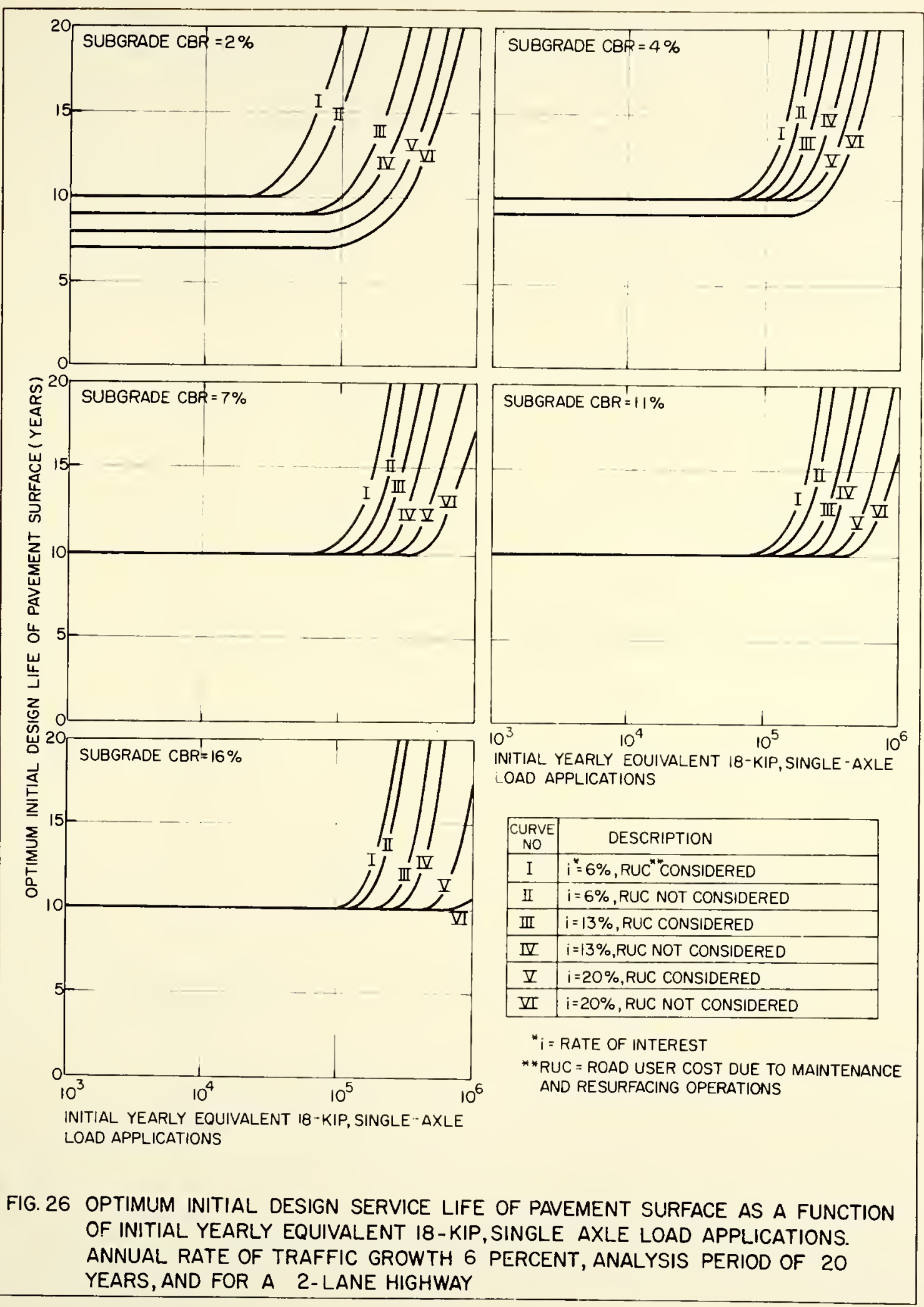




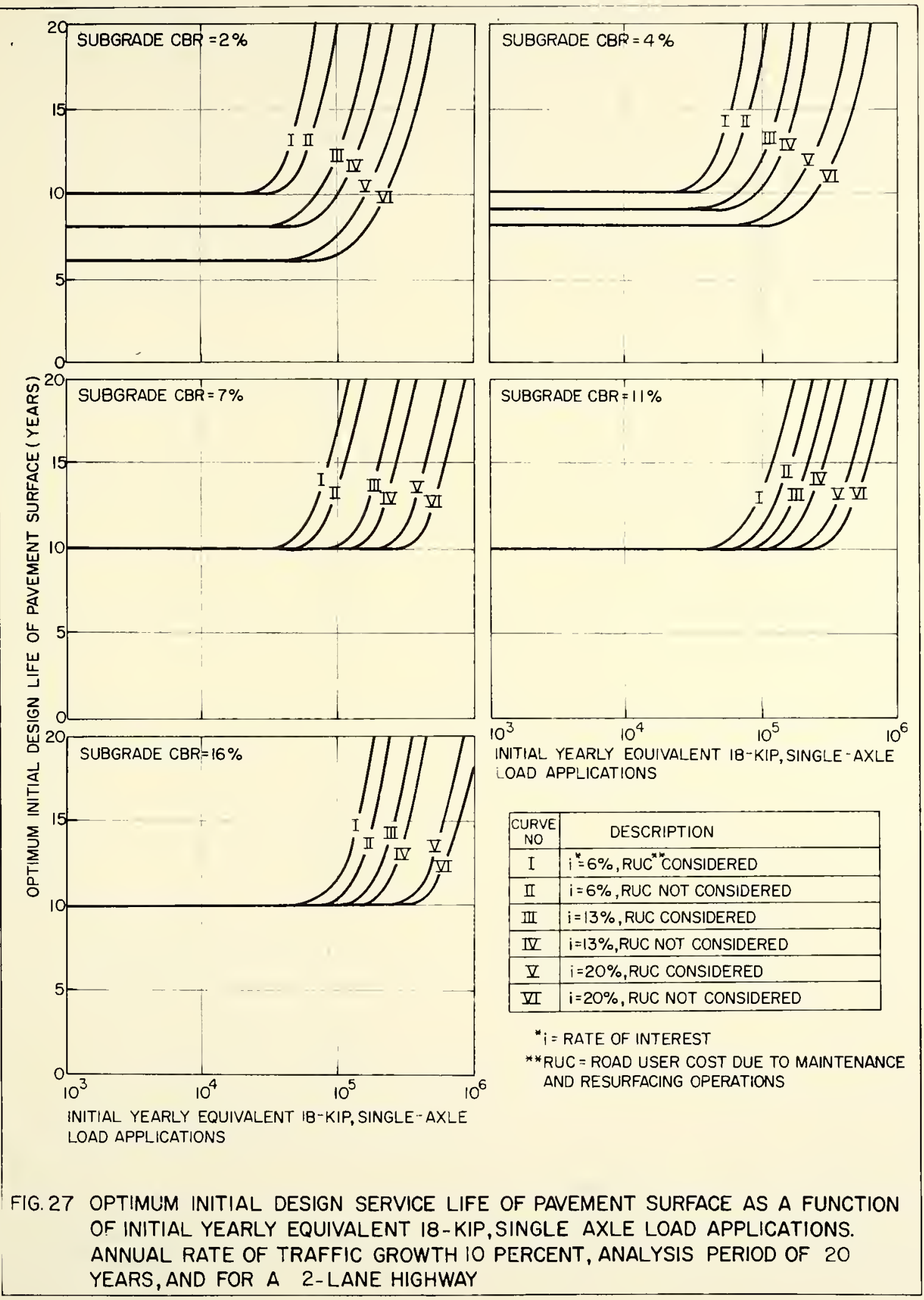




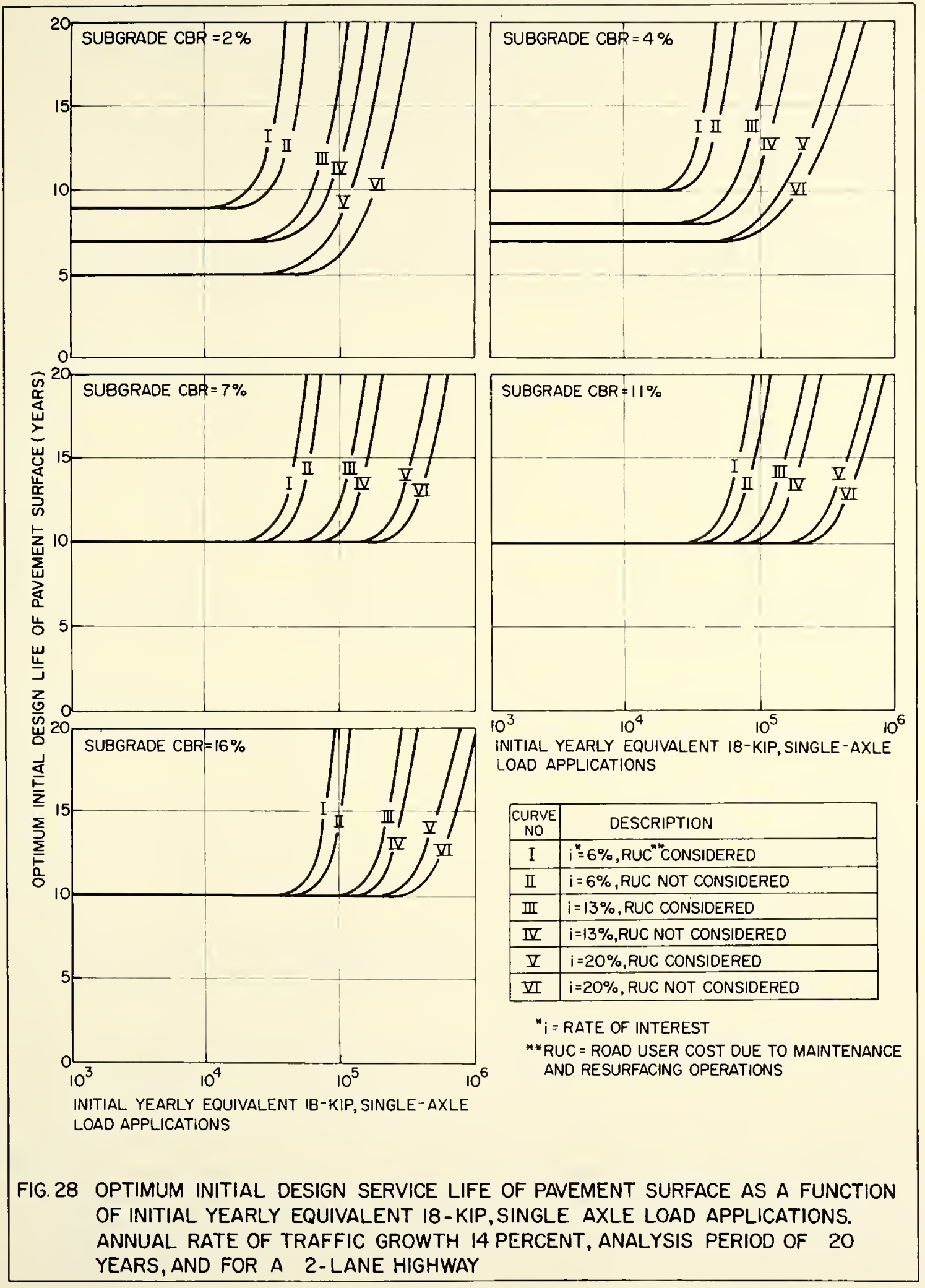




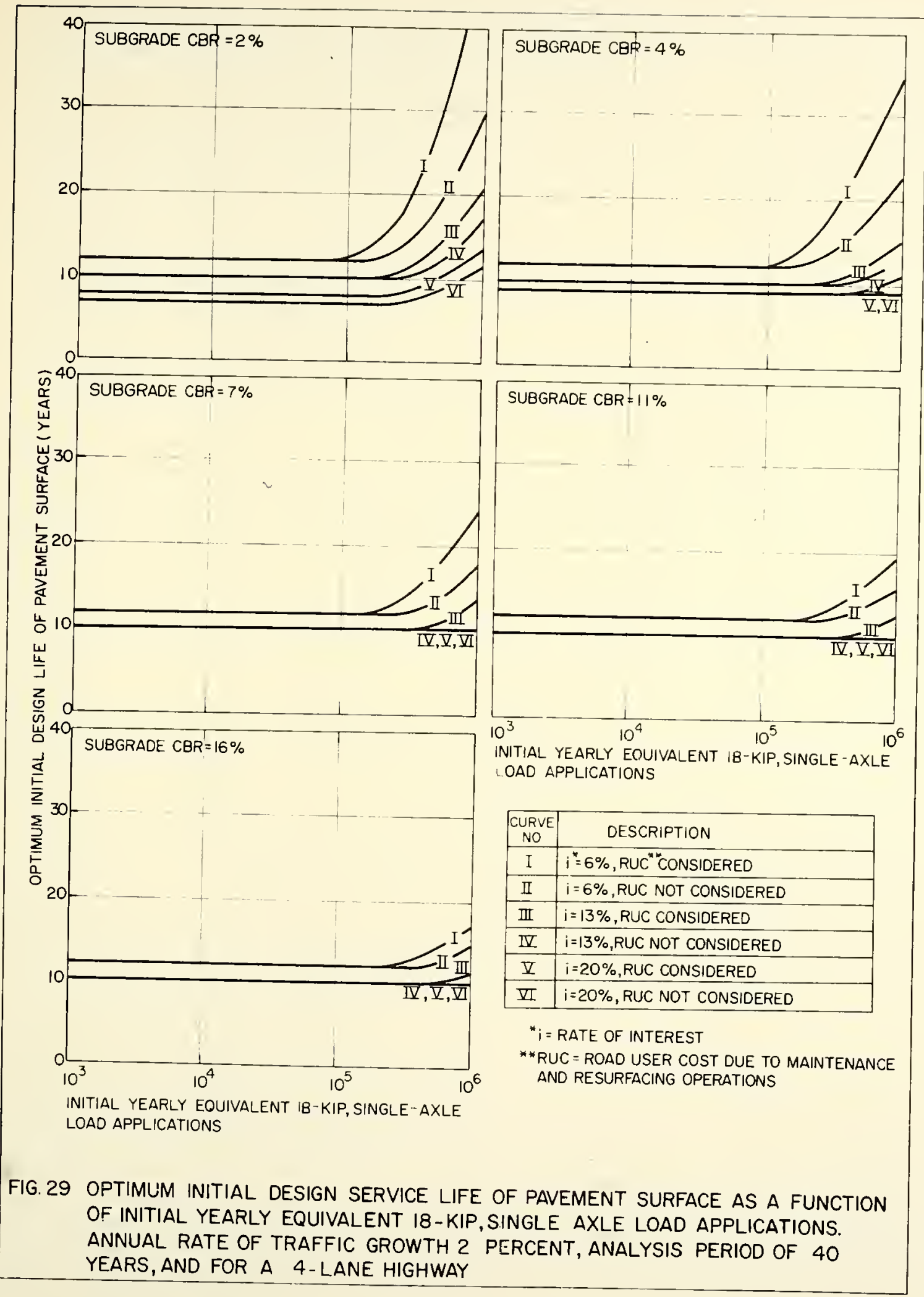




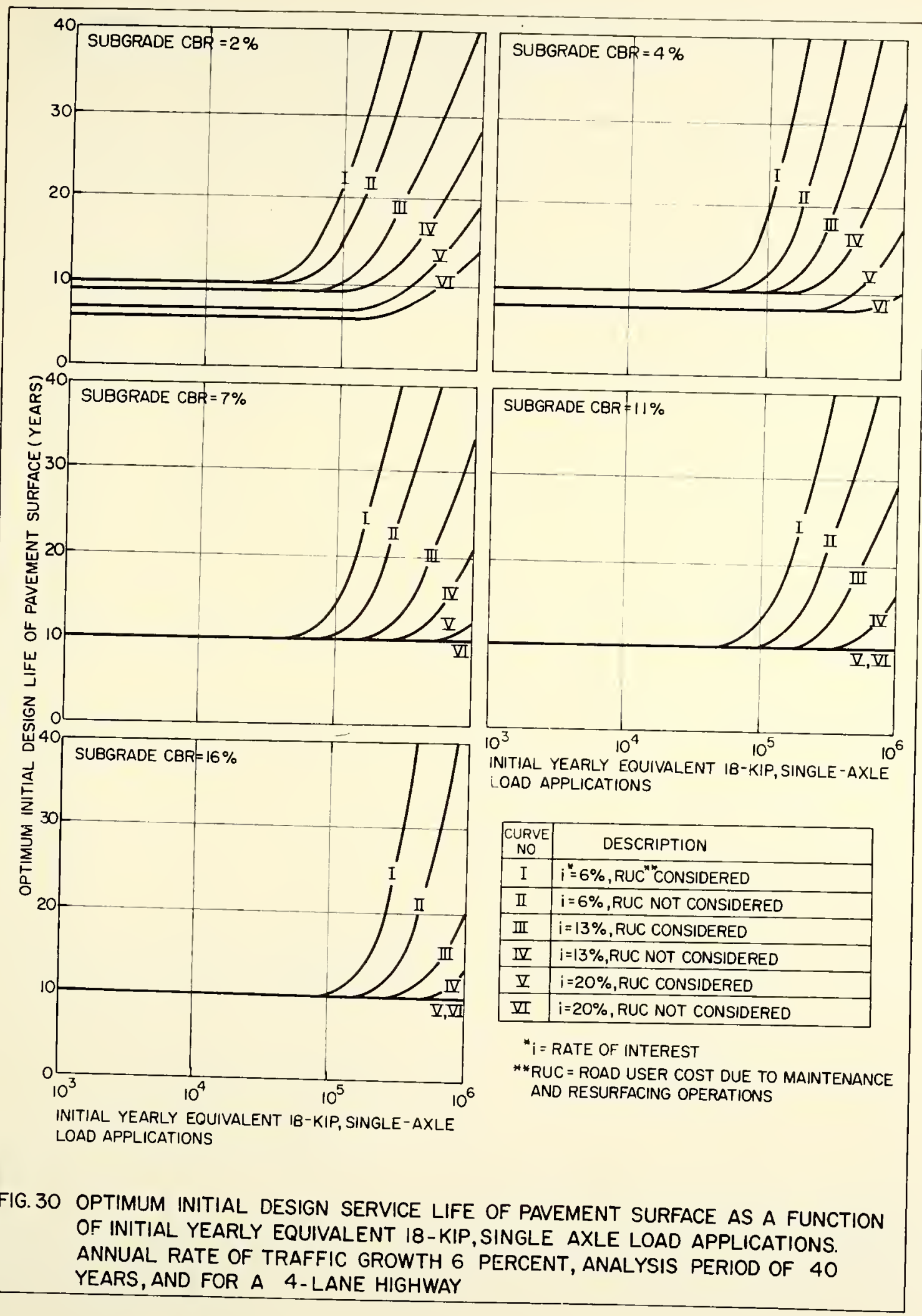




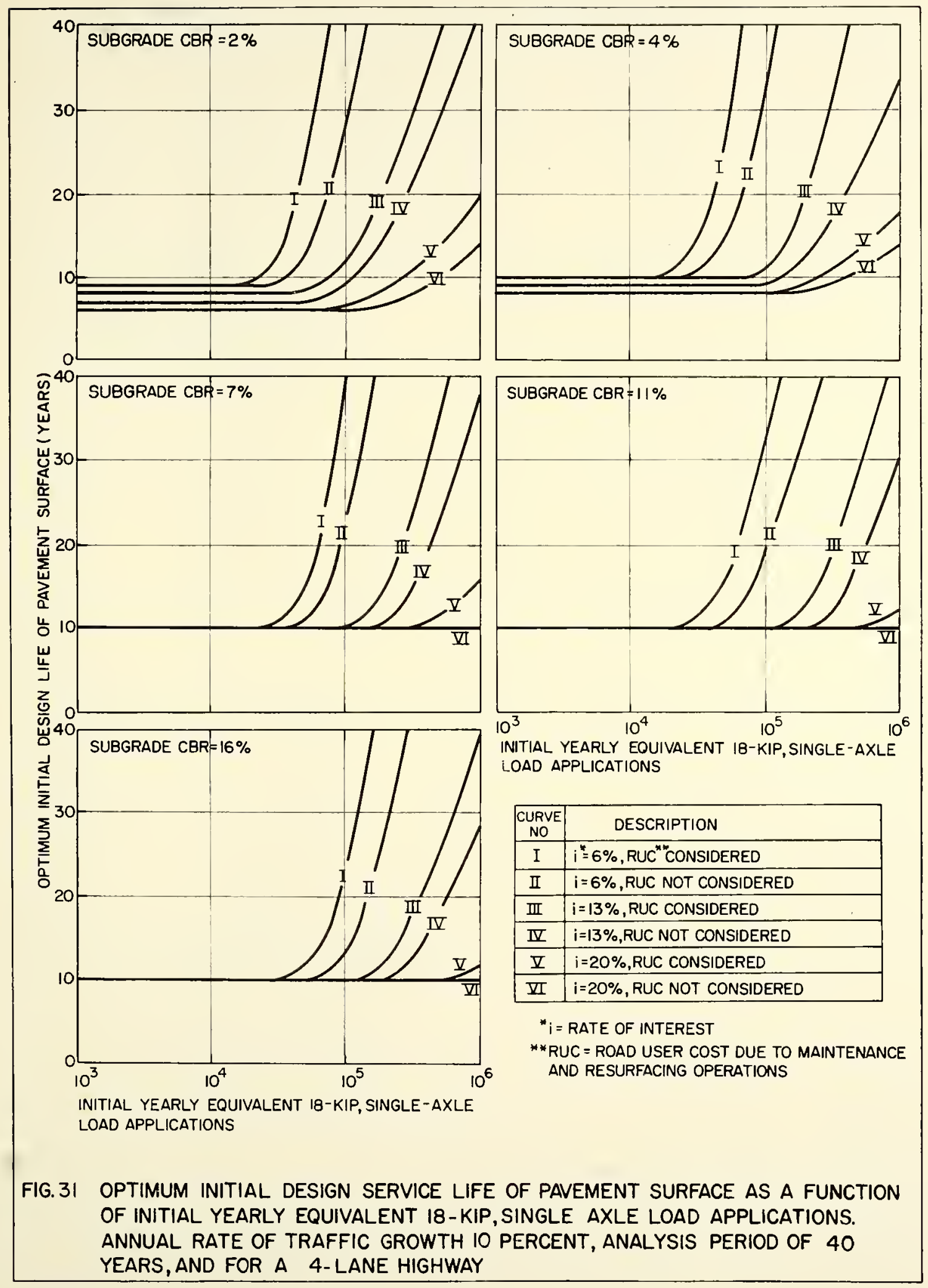




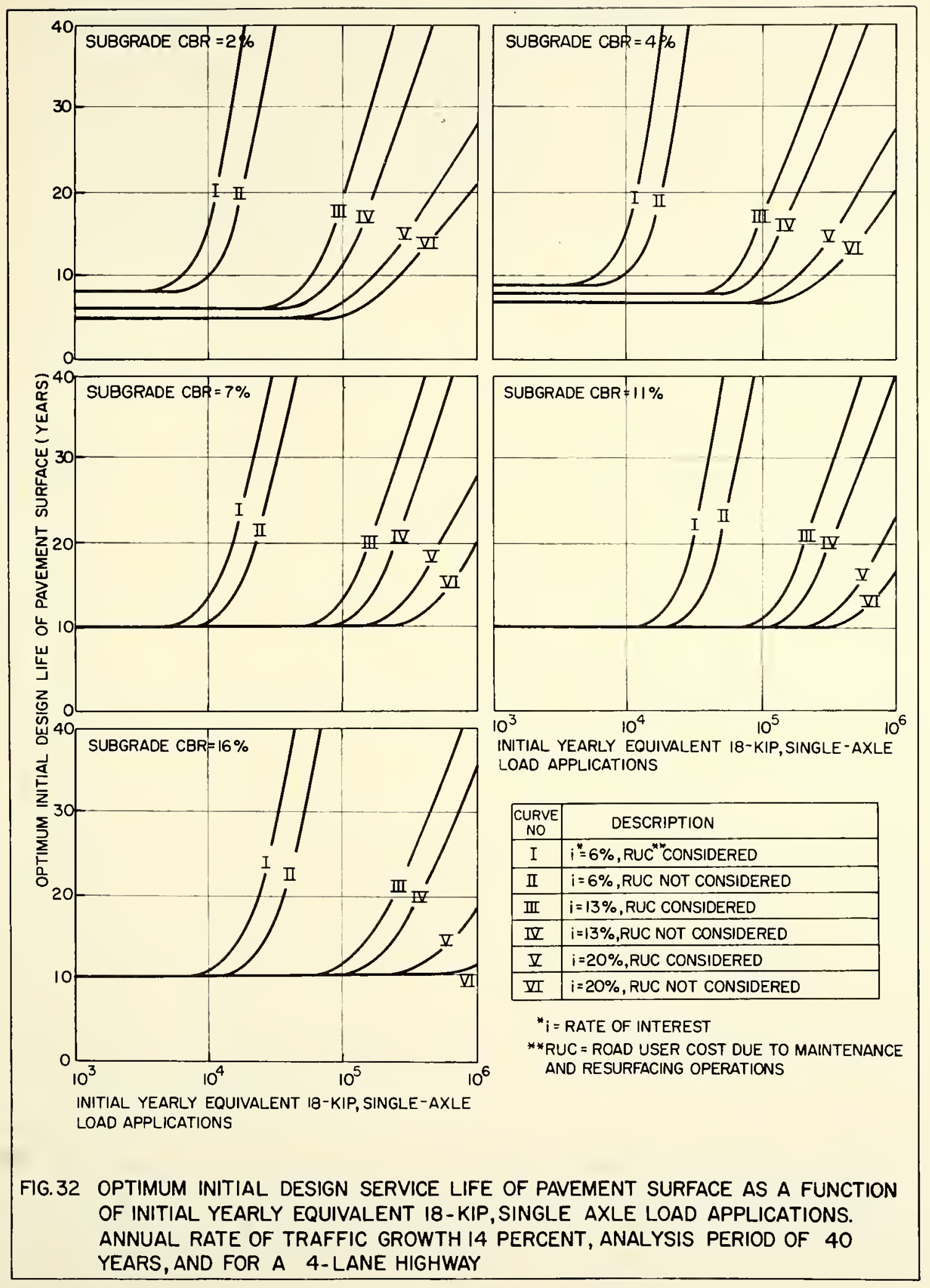




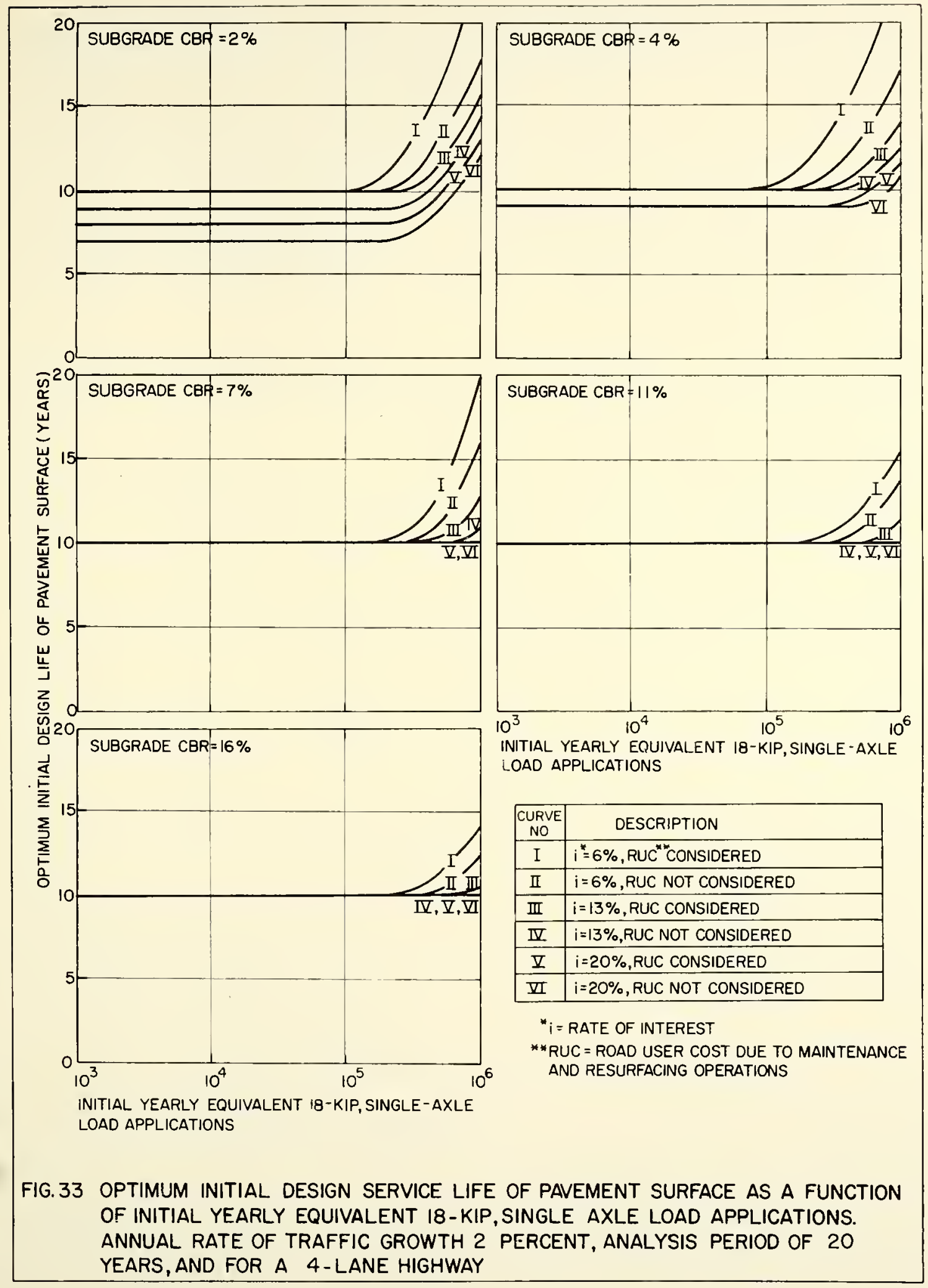




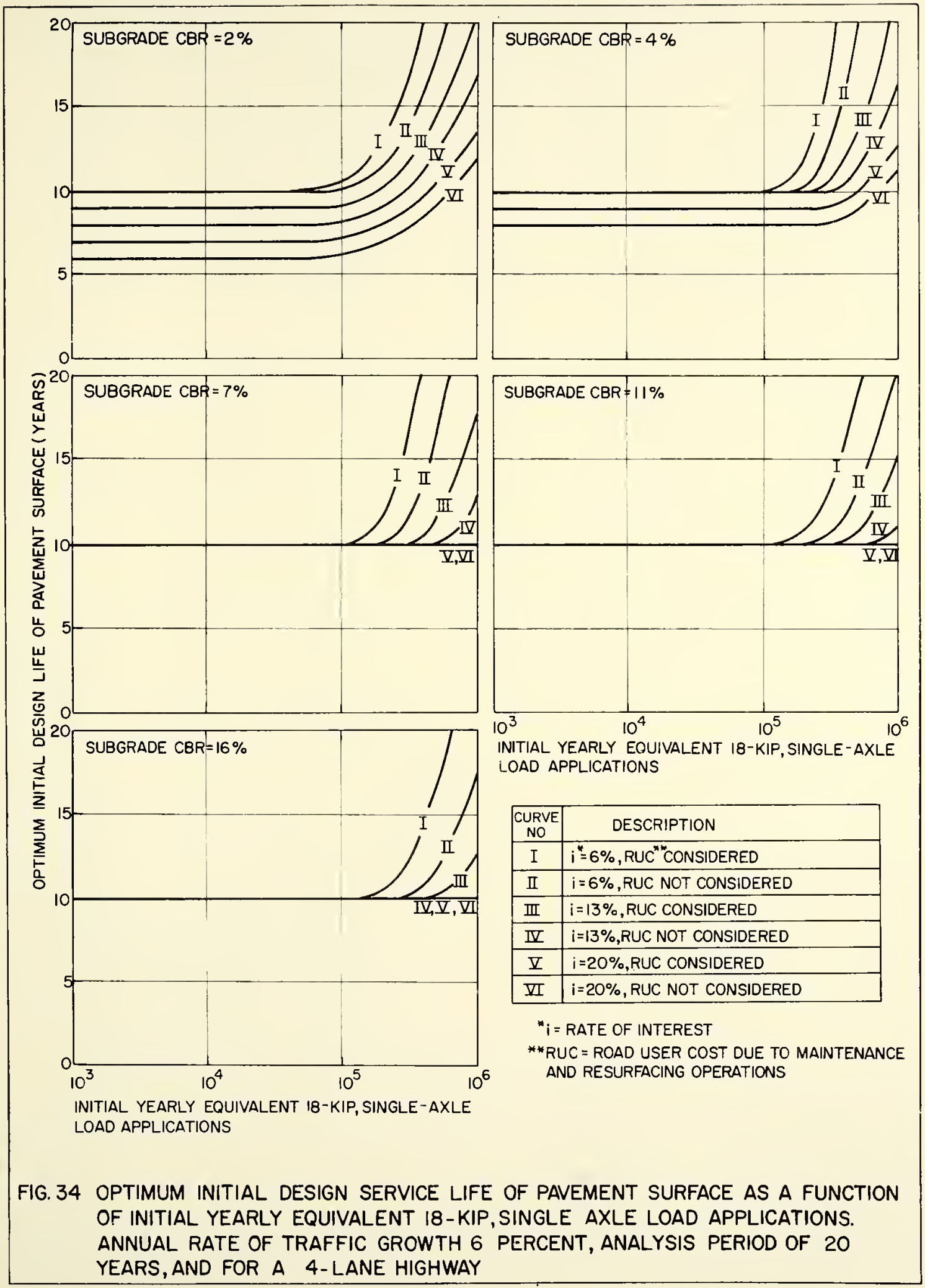




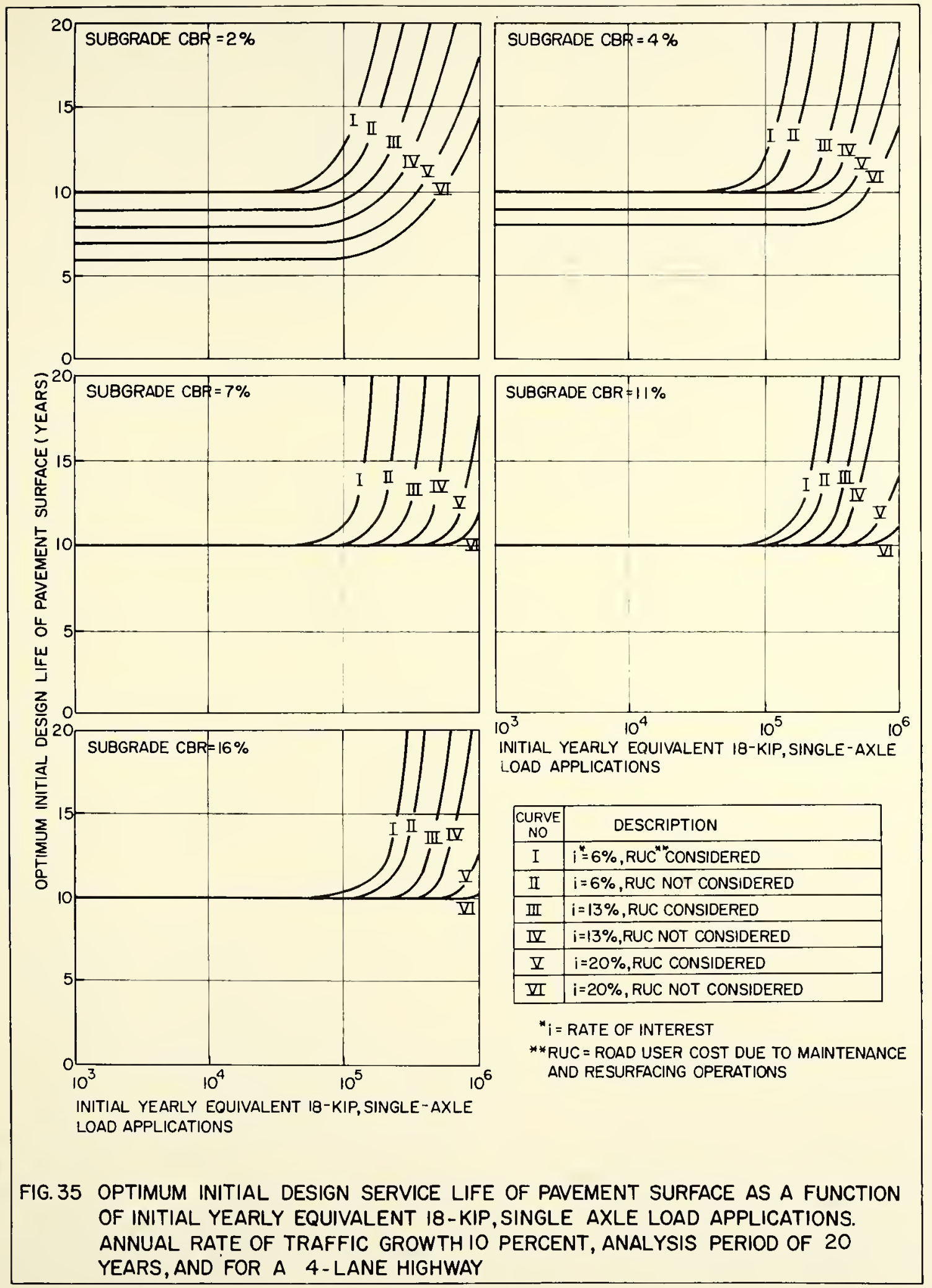



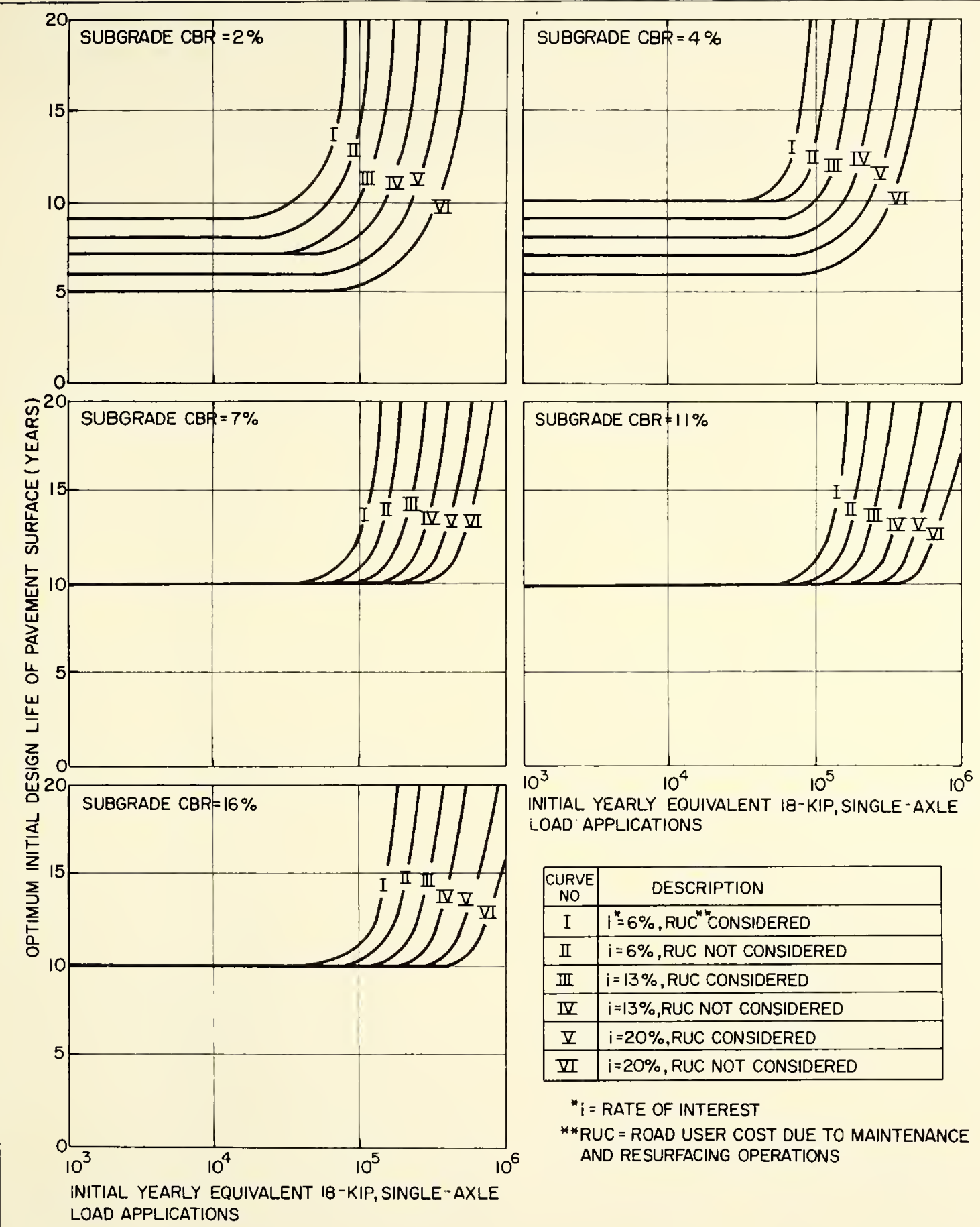

INITIAL YEARLY EOUIVALENT IO-KIP, SINGLE-AXLE LOAD APPLICATIONS

\begin{tabular}{|c|l|}
\hline $\begin{array}{c}\text { CURVE } \\
\text { NO }\end{array}$ & \multicolumn{1}{|c|}{ DESCRIPTION } \\
\hline I & $i=6 \%$, RUC" CONSIDERED \\
\hline II & $i=6 \%$, RUC NOT CONSIDERED \\
\hline III & $i=13 \%$, RUC CONSIDERED \\
\hline II & $i=13 \%$, RUC NOT CONSIDERED \\
\hline Z & $i=20 \%$, RUC CONSIDERED \\
\hline III & $i=20 \%$, RUC NOT CONSIDERED \\
\hline
\end{tabular}

${ }^{*} i=$ RATE OF INTEREST

**RUC = ROAD USER COST DUE TO MAINTENANCE AND RESURFACING OPERATIONS

LOAD APPLICATIONS

FIG. 36 OPTIMUM INITIAL DESIGN SERVICE LIFE OF PAVEMENT SURFACE AS A FUNCTION OF INITIAL YEARLY EQUIVALENT 18-KIP, SINGLE AXLE LOAD APPLICATIONS. ANNUAL RATE OF TRAFFIC GROWTH 14 PERCENT, ANALYSIS PERIOD OF 20 YEARS, AND FOR A 4-LANE HIGHWAY 
RECOMMENDATIONS FOR ADDITIOIAL RESEARCH

During the conduct of this study the need for research on the following subjects was noted.

1. There is a need to develop a model for predicting highway pavement routine malntenance costs which are directly applicable to the State of Indiara. Data regaroing surface condition just prior to mintenance intervals at which routine manteruance is done, could be used to refine the model developed in this study.

2. Additional research is needed in the development of a model for estimating road user costs due to lane closure. Itta should be gathered regarding the length and duration of lane closure typical of various types of mintenance operations on the highry. The average length of time drivers will tolerate waiting in a queue when the re is a lane closure, should be determined. Average speed of traffic ahead of, and on the maintenance zone should also de evaluated. 


\section{BIBLIOGRAFHI}

1. American Association of State Highwy Officials, "Rosd User Benefit Analyses for Highway Improvements," 1960.

2. Argentina Ministry of Fublic Works, "A Long Range Flan for Argentina," 1962.

3. Baldock, R. H., "Determination of the Arnukl Cost of Highwajs," Highway Research Board, Highway Kesearch Record No. 12, 1363.

4. Betz, J. M., "Hikhway liri nt unince Cost.s, A vonsideration for Devaloping Aruas," Highway Reseuruh Bonr, Highway hostarch Record No. $94,1965$.

5. Clat"ey, P. J., "Whareteristics of lassenger Car Travel on Toit Rcads and Comparable Free Rrais, "Highray Ruscarch Julletin N10. $306,1261$.

6. Draper, H. R., and Snith, k., "Applied Regression Aralyzis," Jokn Wiley and sunc, Inc., life.

7. Engineering lews-Record, "Enginemrity hews-Record Conztruction Cost Index," Wouran-Hill Co., Mrch 1760 , larch 2965 , and Warch 1369.

8. Gronberg, C. D., and Blussor, N. B., "Livfs of Highings Surfaces. Hali Century Trends," Proceedings, Highwy Research Bomid, 1356.

9. Highway Reserroh Bourl, "Highway Capacity lenual, " hibhway kescarch Evard Special Report ivo. E7, 1 Jí.5.

10. Moyer, -R. A., and Limpe, J. E., "A Study of Amual Costs of Flexible and Rifid Pavements for State Hikhwdys in Califurma, "Highway Research Board, Highway Research Record IJo. 77, 1965.

11. Oglesby, C. H., "Highway Engineering," (second edition), John Wiley and Sons, Inc., 1303.

12. Oklahoma Department of Highways," Research Study of Mintenance of Highways in Oklahoma," Hureau of" Public Roads, 1968.

13. Ostle, Bernard, "Statistics in Research," Iowa University Press, 1969. 
14. Radzikowski, H. A., "Report of the Conmittee on Mintenance Costs," Highway Reseerch Board Bulletin $110.155,1956$.

15. Road Rescarch Laboratory, Ministry of Transport, "The Cost of Constructing and Mantaining Flexible and Concrete Pavements over 50 -years," 1969.

16. Texas Highray Department, "Test Method Tex-117-E," 1964.

17. Turnbull, W. J., Foster, C.R., and Ahlvin, R. G., "Design of Flexible Pavenents Considering Mixed Loads and Traffic Volume," Froceedings, Ist International Conference on Structural Design of AsphaIt Eavements, University of Michigan, 1962.

18. Ulbricht, E. P., "A Method for Comparine Alternate Favement Designs," MSCE Thesis, Furdue University, $196 ?$.

19. U. 9. Department, of Comerce, Eureau of Cersus, "Statstical Abstract of the United States," 1958, 3959, 1960 and 1961.

20. Woods, K. B., (editor) "Highway Engineering Hanåbook, "Sections 3, I8, and 27, HcGraw-H11, 1960.

21. Work. J. K., "An Economic Replacement Model for Surface Determination," Highway Research Board, 2963.

22. Yoder, E. J., "Selection of Soil Strength Values for Design of Flexible Iavements," Highway Research Board Record No. 276, 1969. 
A PPENDIX A

FIGURES RELATIIG TO COST TRENDE 


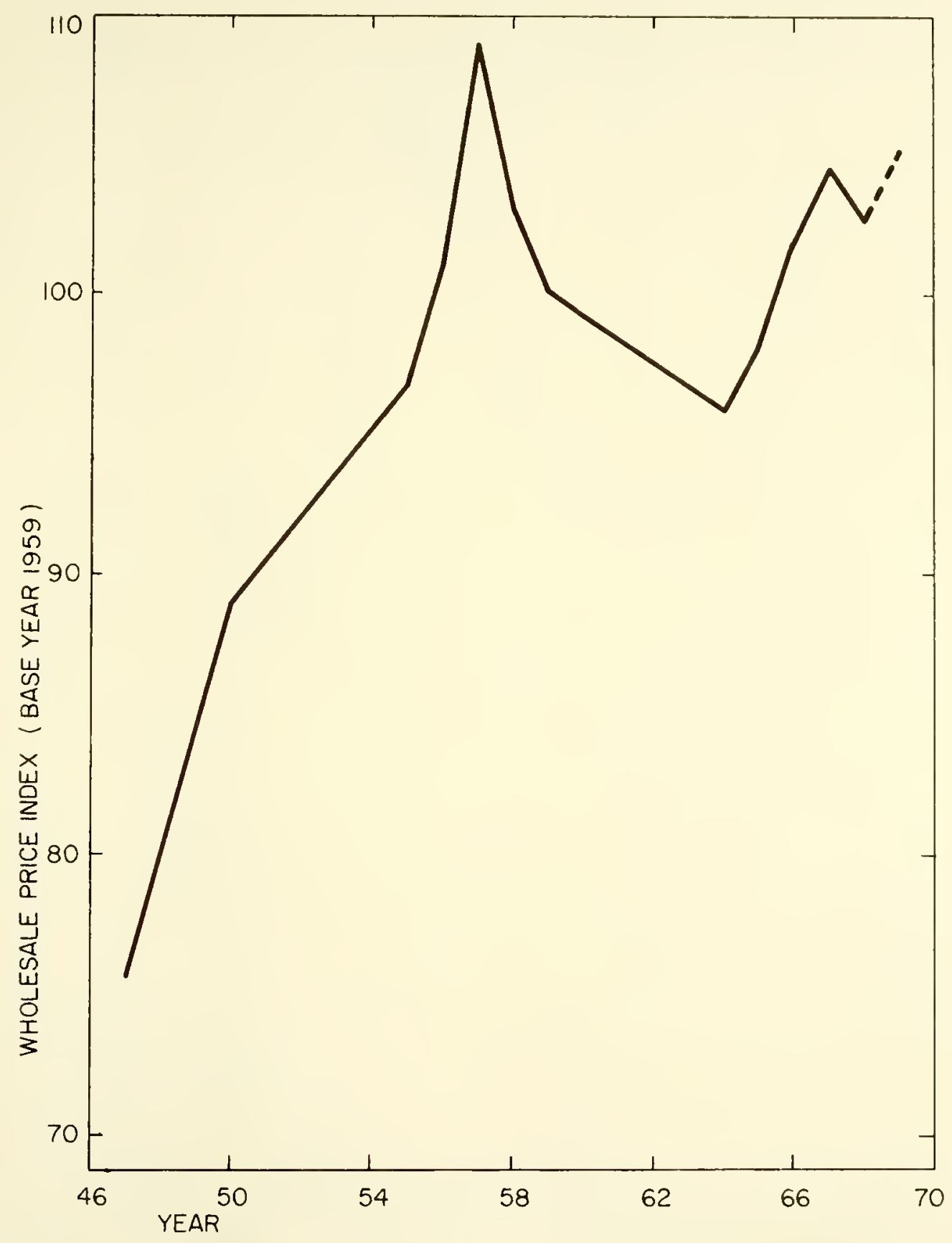

FIG.A-I COST TRENDS - PETROLEUM AND PRODUCTS ( FROM STATISTICAL ABSTRACT OF THE UNITED STATES ) 


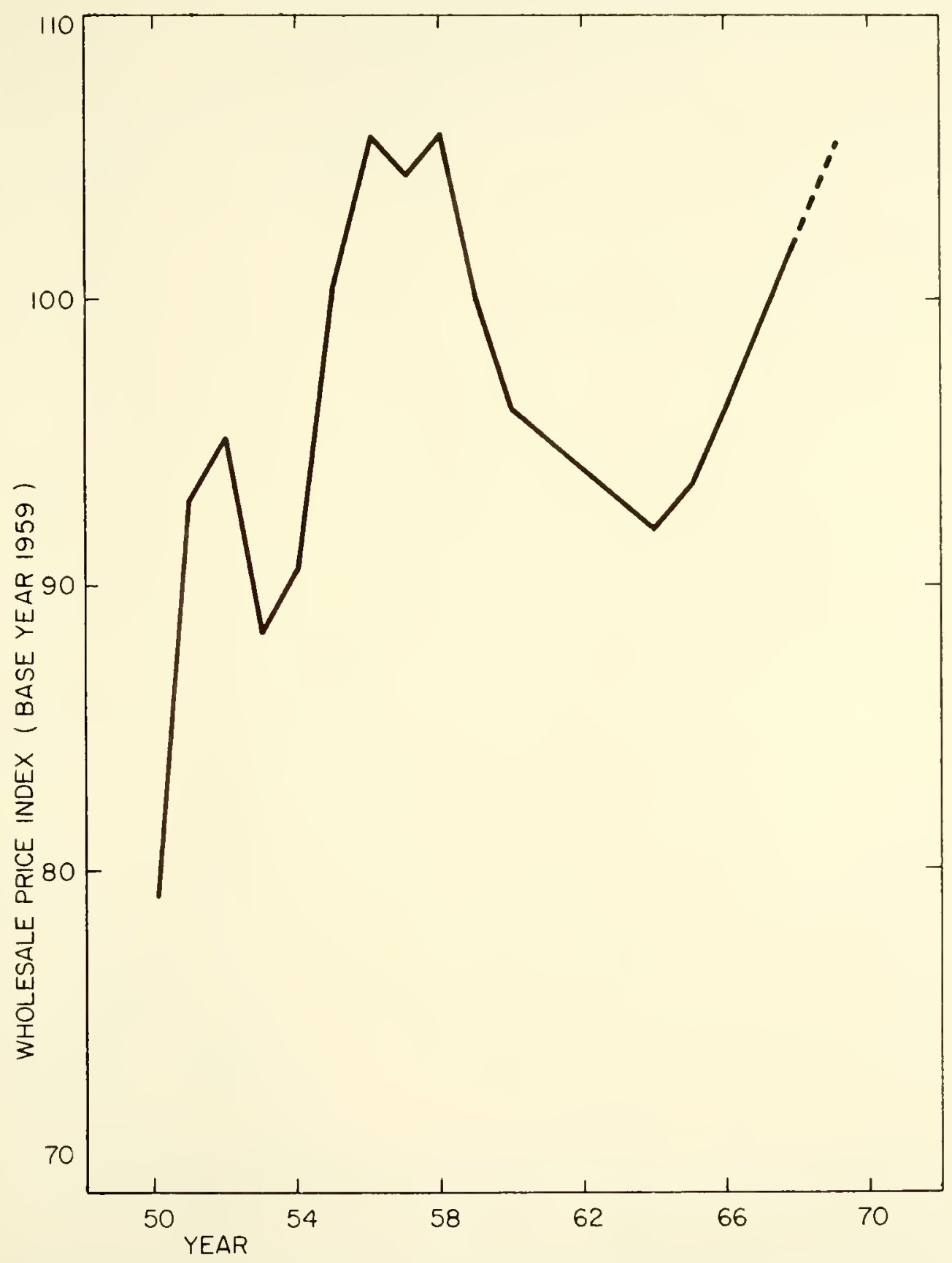

FIG.A.2 COST TRENDS - TIRE (FROM STATISTICAL ABSTRACT OF THE UNITED STATES ) 


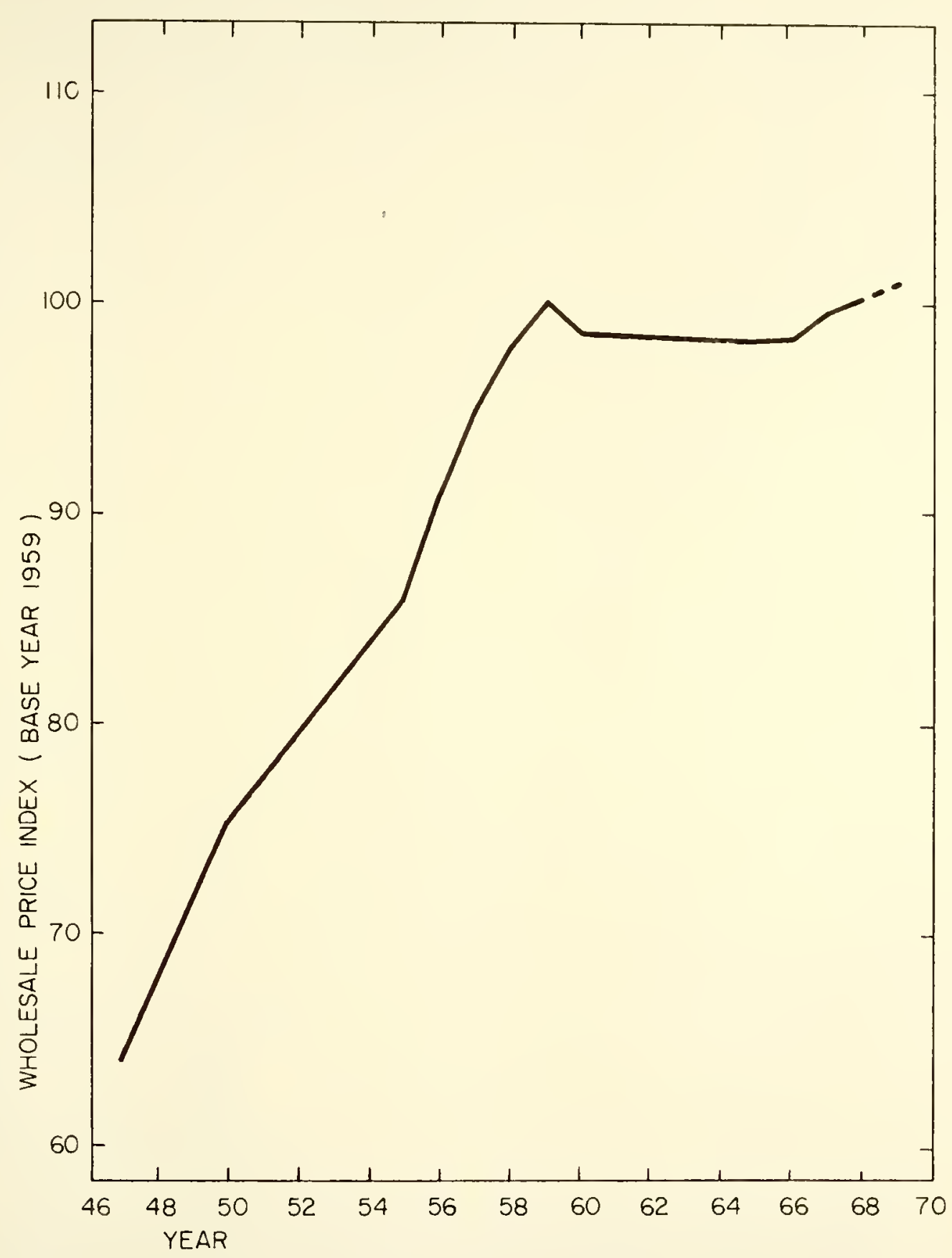

FIG.A.3 COST TRENDS-MOTOR VEHICLE AND EQUIPMENT (FROM STATISTICAL ABSTRACT OF THE UNITED STATES ) 


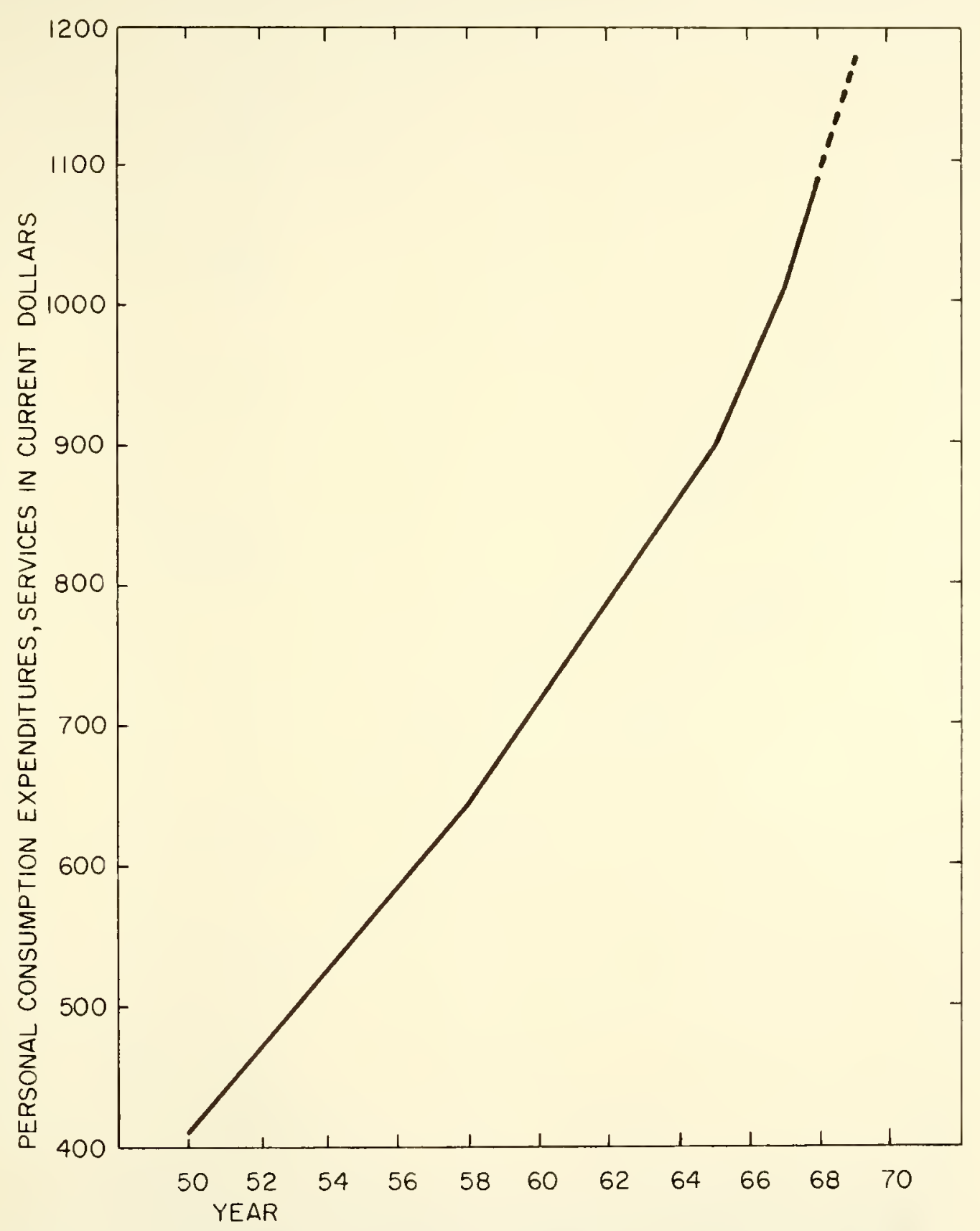

FIG.A.4 TRENDS IN PERSONAL CONSUMPTION EXPENDITURES SERVICES (FROM STATISTICAL ABSTRACT OF THE UNITED STATES ) 


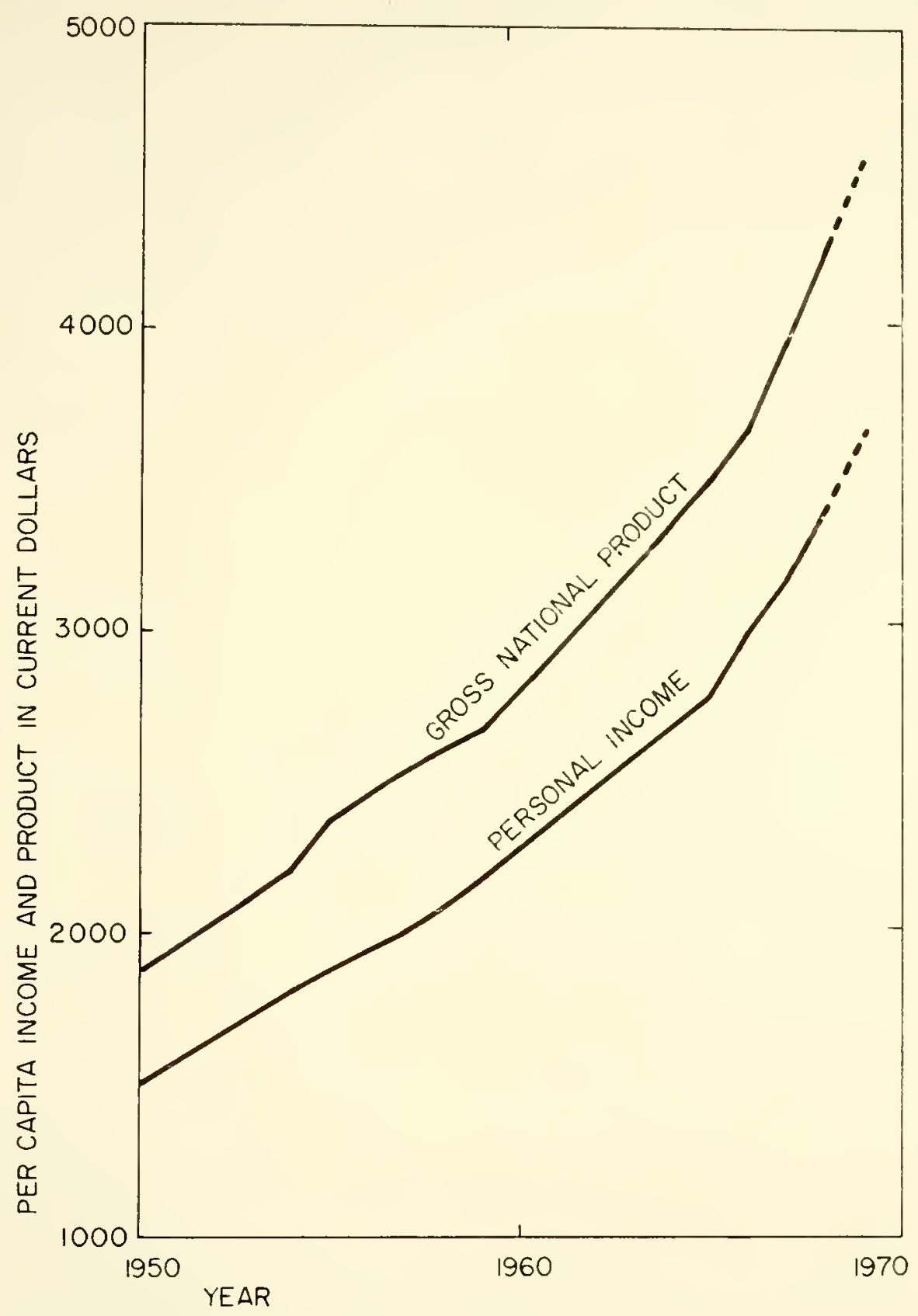

FIGA.5TRENDS IN PERSONAL INCOME AND GROSS NATIONAL PRODUCT ( FROM STATISTICAL ABSTRACT OF THE UNITED STATES ) 


\section{APPENIDIX B}

FIGURES FOR DETERMIVING ROAD USER COSTS 


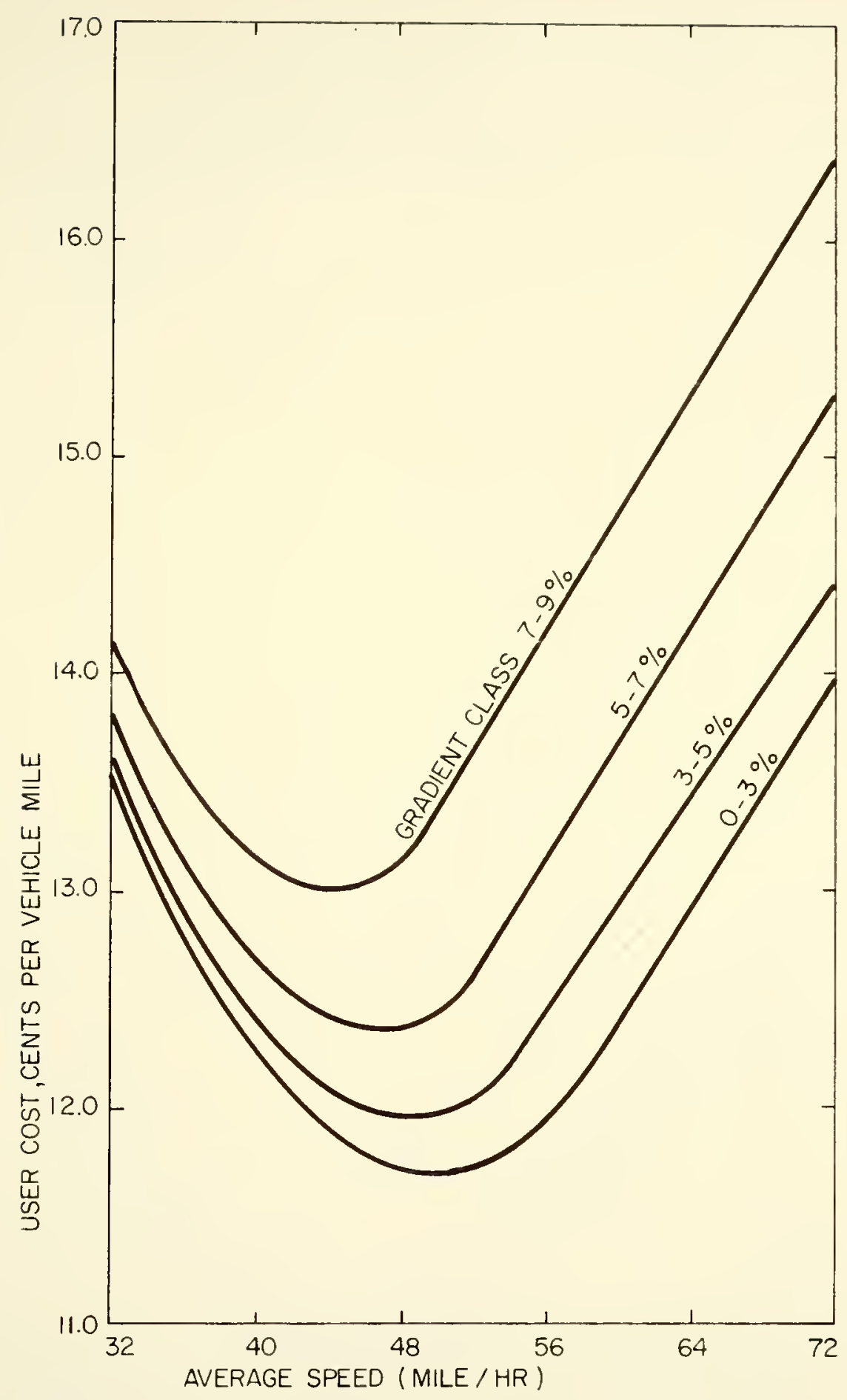

FIG.B-I ROAD USER COST FOR PASSENGER CARS ON TANGENTS OF A 2-LANE HIGHWAY AS A FUNCTION OF AVERAGE SPEED UNDER FREE OPERATION 


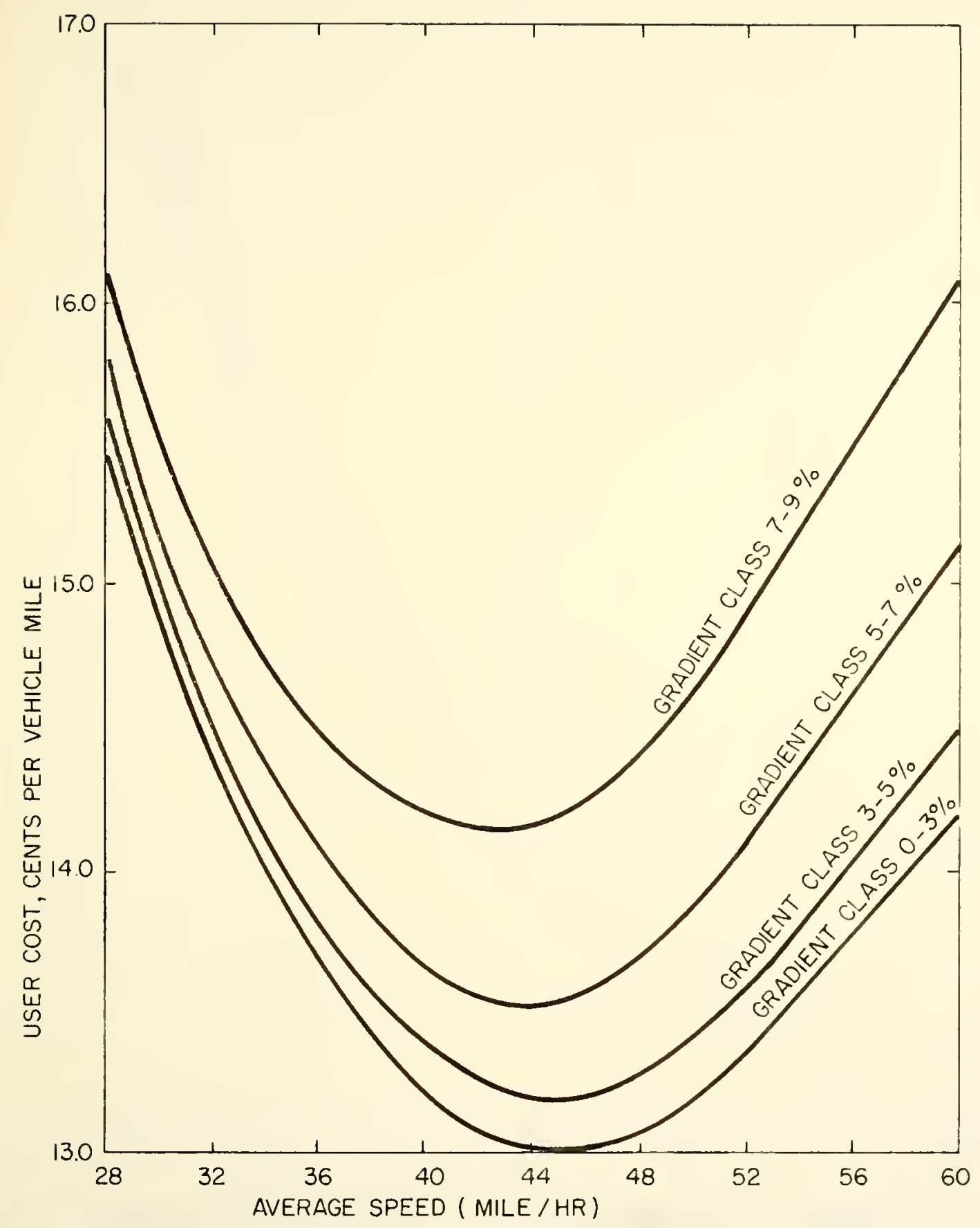

FIG.B.2 ROAD USER COST FOR PASSENGER CARS ON TANGENTS OF A 2-LANE HIGHWAY AS A FUNCTION OF AVERAGE SPEED UNDER NORMAL OPERATION 


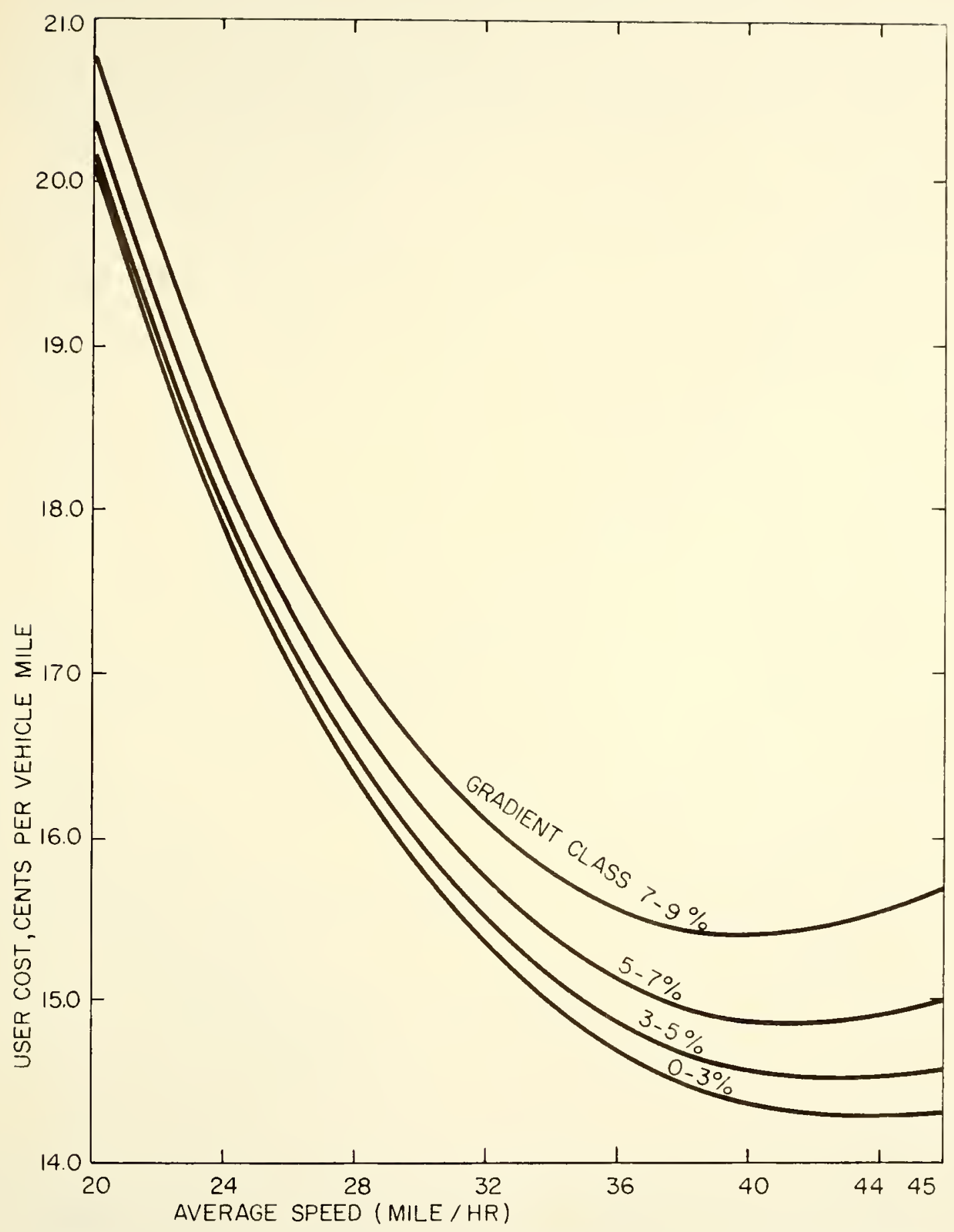

FIG.B-3 ROAD USER COST FOR PASSENGER CARS ON TANGENTS OF A 2-LANE HIGHWAY AS A FUNCTION OF AVERAGE SPEED UNDER RESTRICTED OPERATION 


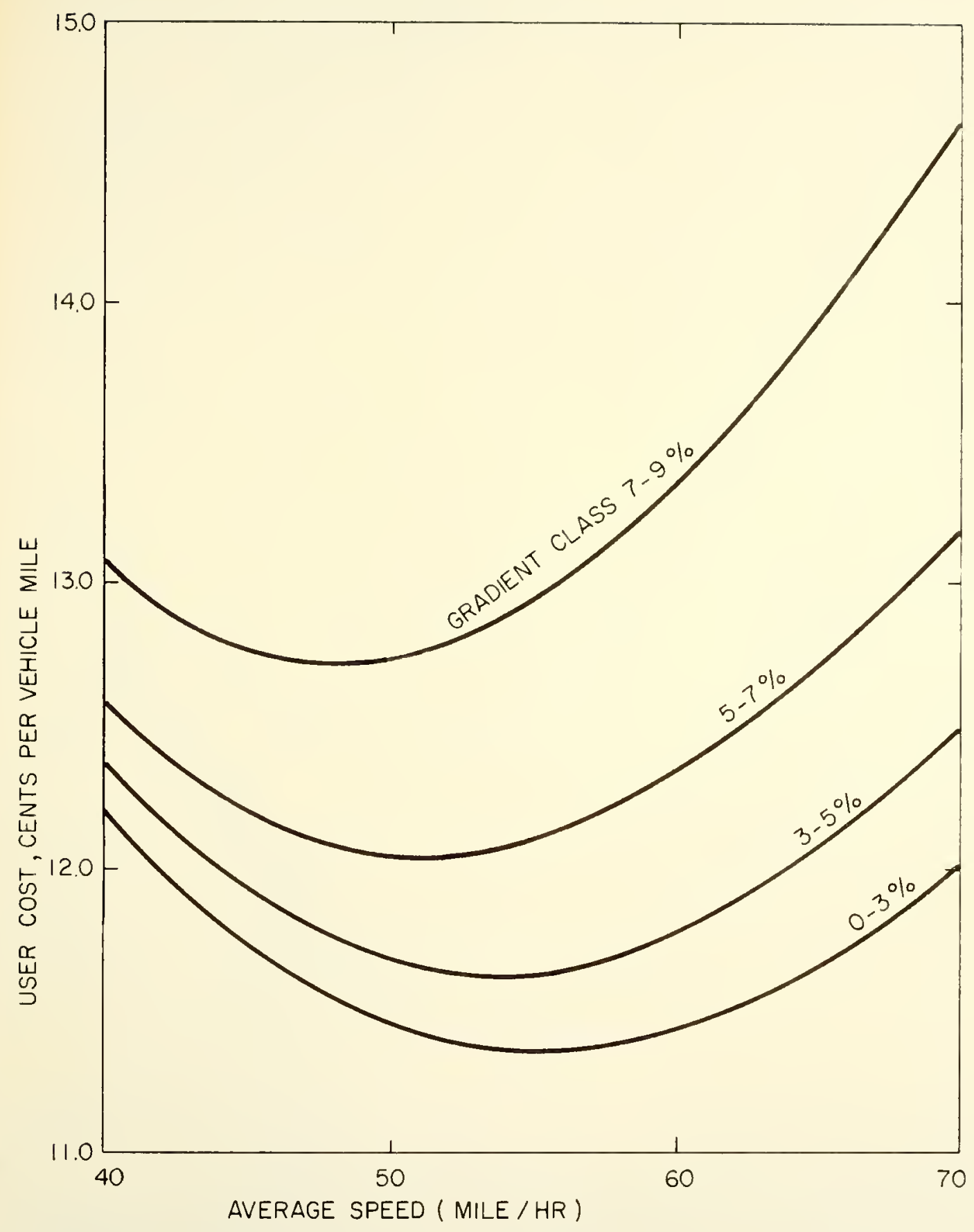

FIG.B.4 ROAD USER COST FOR PASSENGER CARS ON TANGENTS OF A DIVIDED HIGHWAY AS A FUNCTION OF AVERAGE SPEED UNDER FREE OPERATION 


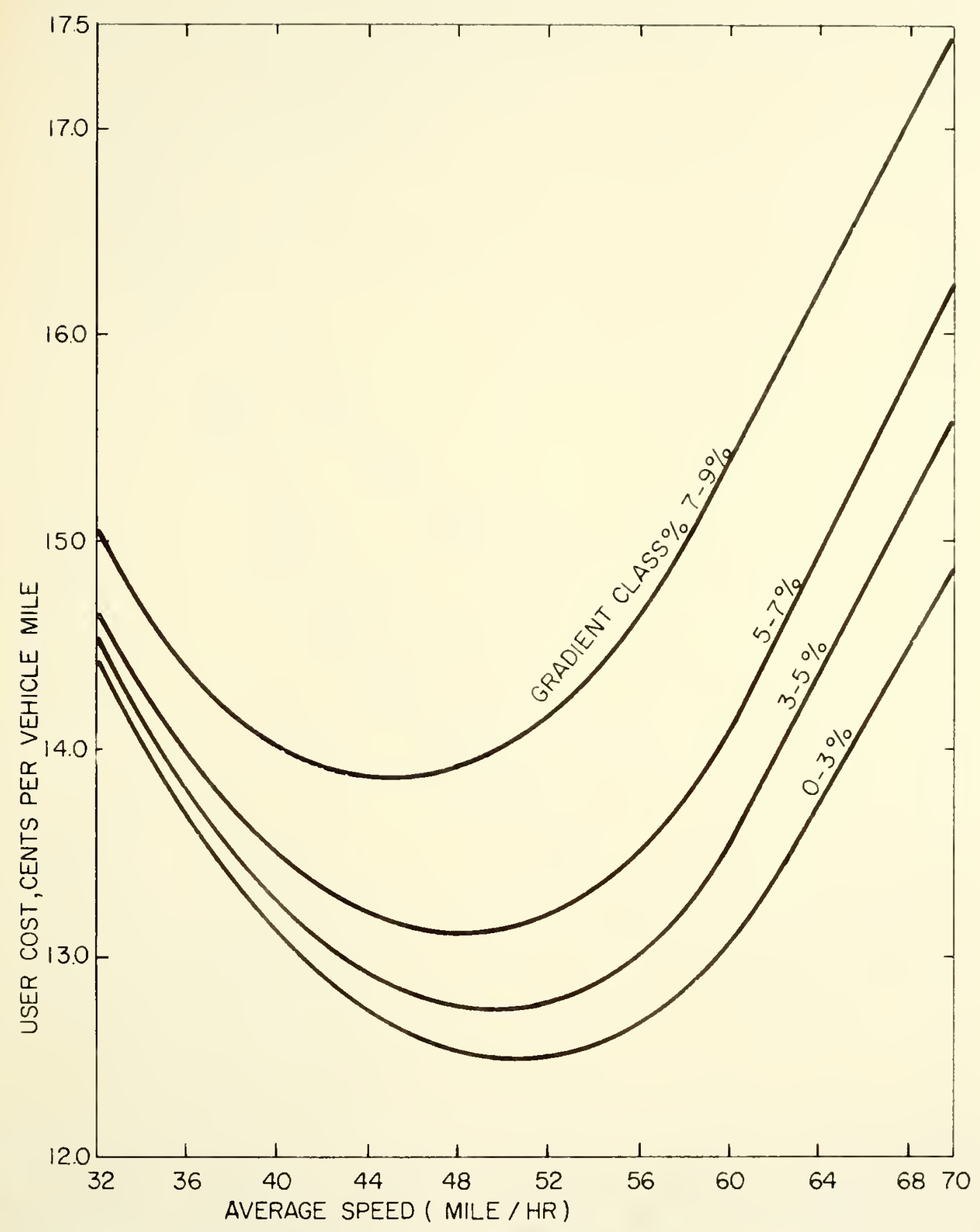

FIG.B.5ROAD USER COST FOR PASSENGER CARS ON TANGENTS OF A DIVIDED HIGHWAY AS A FUNCTION OF AVERAGE SPEED UNDER NORMAL OPERATION 


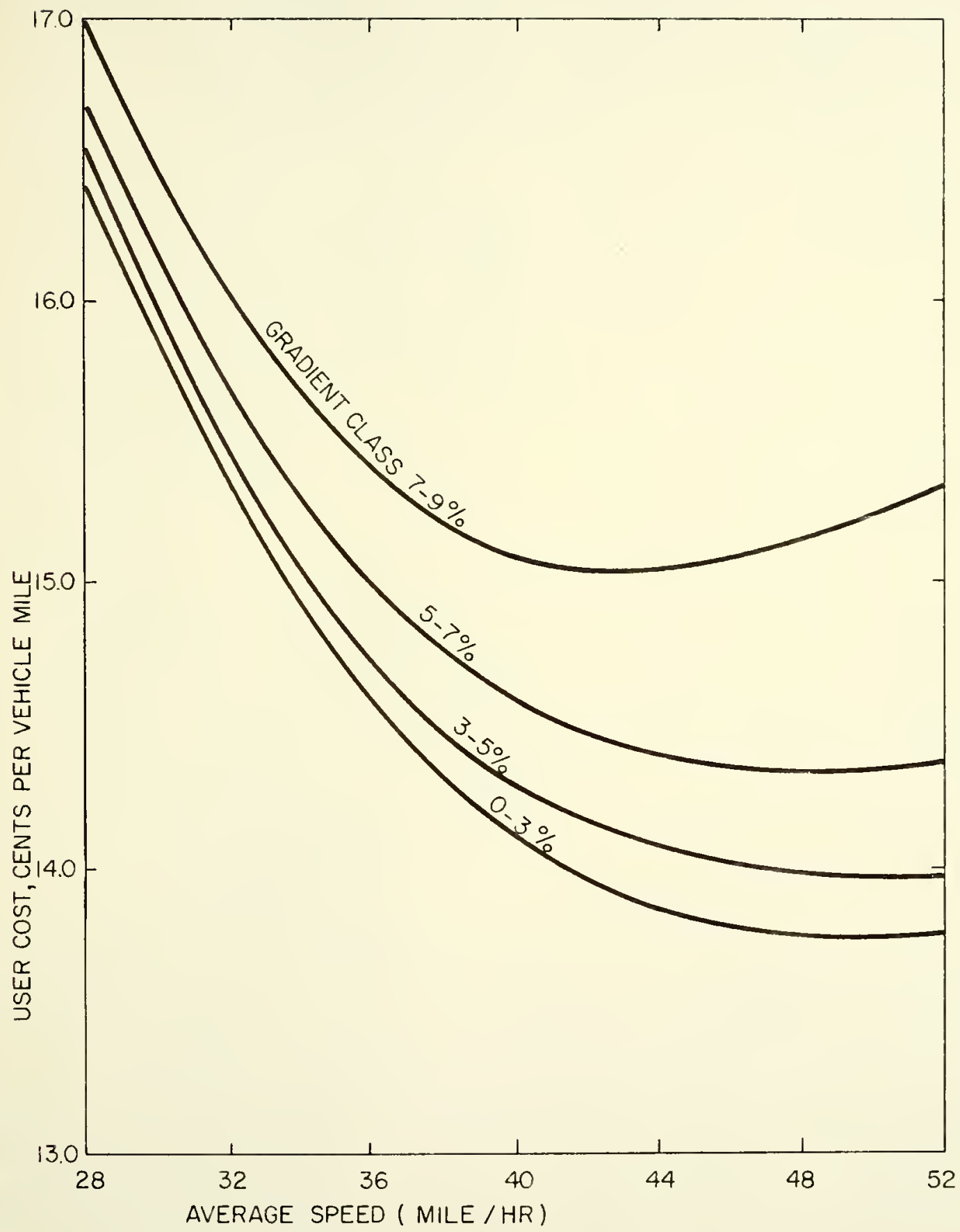

FIG.B.6ROAD USER COST FOR PASSENGER CARS ON TANGENTS OF A DIVIDED HIGHWAY AS A FUNCTION OF AVERAGE SPEED UNDER RESTRICTED OPERATION 


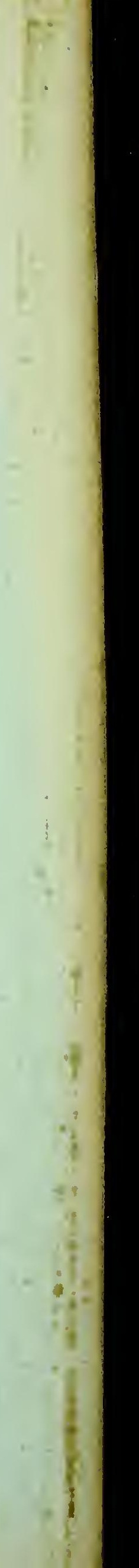

